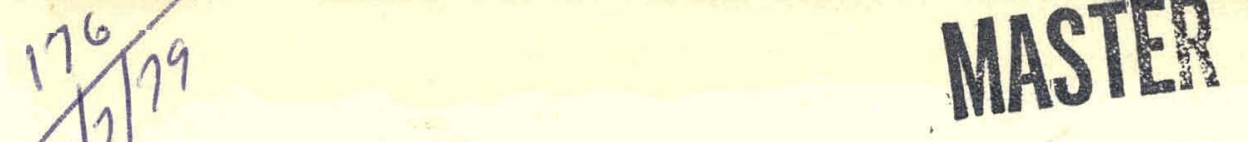

GA-A15455

UC-77

\title{
GCFR UPFLOW/DOWNFLOW STUDY SUMMARY REPORT
}

\author{
by \\ PLANT AND FUELS ENGINEERING STAFF
}

Edited by

H. F. MENZEL

Work supported by

Contract DE-AT03-76SF71023

for the San Francisco Operations Office

Department of Energy

DATE PUBLISHED: AUGUST 1979 


\section{DISCLAIMER}

This report was prepared as an account of work sponsored by an agency of the United States Government. Neither the United States Government nor any agency Thereof, nor any of their employees, makes any warranty, express or implied, or assumes any legal liability or responsibility for the accuracy, completeness, or usefulness of any information, apparatus, product, or process disclosed, or represents that its use would not infringe privately owned rights. Reference herein to any specific commercial product, process, or service by trade name, trademark, manufacturer, or otherwise does not necessarily constitute or imply its endorsement, recommendation, or favoring by the United States Government or any agency thereof. The views and opinions of authors expressed herein do not necessarily state or reflect those of the United States Government or any agency thereof. 


\section{DISCLAIMER}

Portions of this document may be illegible in electronic image products. Images are produced from the best available original document. 


\title{
NOTICE
}

This report was prepared as an account of work sponsored by the United States Government. Neither the United States nor the Department of Energy, nor any of their employees, nor any of their contractors, subcontractors, or their employees, makes any warranty, express or implied, or assumes any legal liability or responsibility for the accuracy, completeness or usefulness of any information, apparatus, product or process disclosed, or represents that it.s use would not infringe privately owned rights.s.

\author{
Printed in the United States of America \\ Available from \\ National Technical Information Service \\ U.S. Department of Commerce \\ 5285 Port Royal Road \\ Springfield, Virginia 22161 \\ Price: Printed Copy $\$ 8.00$; Microfiche $\$ 3.00$
}


GA-A15455

UC-77

\section{GCFR UPFLOW/DOWNFLOW STUDY SUMMARY REPORT}

by

PLANT AND FUELS ENGINEERING STAFF

Edited by

H. F. MENZEL

This report was prepared as an account of work
sponsored by the United States Covernment. Neither the
United States nor the United States Department of
Energy, nor any of their employees, nor any of their
contractors, subcontractors, or their employees, makes
any warranty, express or implied, or assumes any legal
liability or responsibility for the accuracy, completeness
or usefulness of any information, apparatus, product or
process disclosed, or represents that its use would not
infringe privately owned rights.

Work supported by

Contract DE-AT03-76SF71023

for the San Francisco Operations Office

Department of Energy

GENERAL ATOMIC PROJECT 6114

DATE PUBLISHED: AUGUST 1979

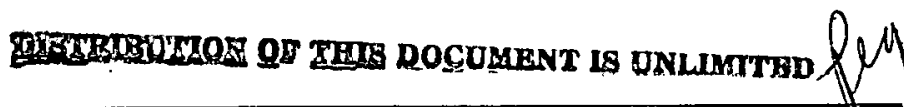




\section{THIS PAGE \\ WAS INTENTIONALLY \\ LEFT BLANK}




\section{ABSTRACT}

General Atomic Company, with the participation of Kraftwerk Union, Erlangen, West Germany, conducted a study to investigate possible advantages of an upflow core for the gas-cooled fast breeder reactor (GCFR). During the one-year study a conceptual upflow core plant design was developed and the downflow core plant reference design updated. A comparison was made between the two plant designs in critical areas of plant performance, safety, and licensing.

The results of that comparison led to the recommendation to adopt an upflow core for the GCFR plant reference design. Although additional development and design efforts are required, the potential of residual heat removal by natural circulation alone offers a decisive safety and licensing advantage. 
THIS PAGE

\section{WAS INTENTIONALLY \\ LEFT BLANK}


CONTENTS

1. SUMMARY . . . . . . . . . . . . . . . . . . . . . . 1-1

1.1. Summary of Upflow Design Study . . . . . . . . . . . 1-1

1.2. Summary of Downflow Design Study............ . 1-3

1.3. Summary of Studies Common to both Upflow and Downflow Design . . . . . . . . . . . . . . . 1-4

2. INTRODUCTION . . . . . . . . . . . . . . . . . . . 2-1

3. PLANT DESIGN DESCRIPTION . . . . . . . . . . . . . . . . . 3-1

3.1. PCRV Design and Arrangements . . . . . . . . . . . 3-7

3.2. Cavity Liner, Penetrations, and Cavity Closures . . . . 3-12.

3.3. Core Support Structure . . . . . . . . . . . . 3-17

3.4. Shielding ................... 3-20

3.5. Thermal Barriers .. . . . . . . . . . . . 3-24

3.6. Control Rod Drive . . . . . . . . . . . . . 3-24

3.7. Instrument Tree with Associated Components . . . . . 3-28

3.8. Fuel Assembly . . . . . . . . . . . . . . . . 3-30

3.9. Control and Shutdown Assembly . . . . . . . . . . . 3-37

3. 10. Blanket Assembly . . . . . . . . . . . . . 3-38

3.11. Radial Reflector/Shield Assembly .. . . . . . . . 3-38

3.12. Refueling System . . . . . . . . . . . . . 3-38

3.13. Steam Generator . . . . . . . . . . . . . . 3-43

3.14. Core Auxiliary Heat Exchanger (CAHE) . . . . . . . . . 3-44

3.15. Main Helium Circulator. . . . . . . . . . . 3-52

3.16. Auxiliary Circulator . . . . . . . . . . . . 3-52

3.17. Containment/Confinement Building . . . . . . . . . 3-54

3.18. Reactor Service Building . . . . . . . . . . . 3-54

4. RESIDUAL HEAT REMOVAL BY NATURAL CIRCULATION . . . . . . . . . 4-1

4.1. Natural Circulation Analysis . . . . . . . . . . . . 4-1

4.1.1. Case 1: Primary Coolant Natural Circulation... 4-3

4.1.2. Case 2: Natural Circulation RHR . . . . . . 4-11 
CONTENTS (Continued)

4.2. Reliability Analysis ... . . . . . . . . . . 4-14

4.3. Licensing Position on RHR and Natural Circulation

Cooling ................. 4-23

5. SAFETY ASSESSMENT . . . . . . . . . . . . . . . . . 5 5-1

5.1. Core Disruptive Accidents . . . . . . . . . . . 5-1

5.2. Post-Accident Fuel Containment . . . . . . . . . . 5-5

5.3. Licensing Position on $\mathrm{CDA}$ and PAFC . . . . . . . . . . 5-7

6. SYSTEM AND COMPONENT COMPARISON . . . . . . . . . . . . . . 6-1

6.1. Evaluation Criteria ............. 6-1

6.2. Upflow versus Downflow Comparison . . . . . . . . 6-1

7. COST AND SCHEDULE COMPARISON ................ . . 7-1

7.1. Capital Cost . . . . . . . . . . . . . . . 7-1

7.2. Development Cost and Schedule . . . . . . . . . . 7-1

8. CONCLUSIONS AND RECOMMENDATIONS . . . . . . . . . . . . . 8-1

8.1. Conclusions . . . . . . . . . . . . . . . 8-1

8.2. Configuration Recommendations . . . . . . . . . 8-2

8.3. Recommendations for Future Activities . . . . . . . . 8-3

APPENDIX A: CORE SEISMIC ANALYSIS . . . . . . . . . . . . . . . . . . A-1

APPENDIX B: CORE DISTORTION ANALYSIS. . . . . . . . . . . . . . B-1

APPENDIX C: KEY DESIGN CHARACTERISTICS ASSUMED IN AUXILIARY

LOOP NATURAL CIRCULATION ANALYSES . . . . . . . . . . C-1

APPENDIX D: ALTERNATIVE DESIGN STUDIES . . . . . . . . . . . D-1

REFERENCES ............................. . . E-1 
FIGURES

3-1. Main cooling system flow diagram . . . . . . . . . . 3-2

3-2. Core auxiliary cooling system flow diagram . . . . . . . . . . 3-4

3-3. Shutdown cooling system flow diagram . . . . . . . . . 3-6

3-4. Upflow PCRV arrangement . . . . . . . . . . . . . . . 3-9

3-5. Downflow PCRV arrangement . . . . . . . . . . . . . 3-10

3-6. Double rotating plug for upflow . . . . . . . . . . . 3-14

3-7. Downflow fixed core cavity plug . . . . . . . . . . . 3-15

3-8. Core support structure for upflow . . . . . . . . . . 3-18

3-9. Core support structure for downflow . . . . . . . . . 3-19

3-10. Shielding arrangement for upflow . . . . . . . . . . 3-21

3-11. Shielding arrangement for downflow . . . . . . . . . . . 3-22.

3-12. Thermal barrier general arrangement for upflow . . . . . . 3-25

3-13. Thermal barrier arrangement for downflow . . . . . . . . . 3-26

3-14. Control rod drive and instrument tree arrangement

3-15. Control rod drive and instrument tree/core lock actuator
arrangement for downflow . . . . . . . . . . . . . . . 31

3-16. Plan view of upflow and downflow cores . . . . . . . . . 3-33

3-17. Elevation view of upflow and downflow cores......... . 3-34

3-18. Fuel assembly for upflow and downflow cores . . . . . . . 3-35.

3-19. Fuel handling machine for upflow . . . . . . . . . . . . 3-40

3-20. Fuel handling machine and operational sequence for 3-42

3-21. General arrangement of downflow refueling system . . . . . 3-45

3-22. General arrangement of upfluw refueling systeli . . . . . . 3-47

3-23. Steam generator for upflow . . . . . . . . . . . . 3-48

3-24. Steam generator for downflow . . . . . . . . . . . 3-49

3-25. Core, auxiliary heat exchanger for upflow . . . . . . . . 3-50

$3-26$. Corc auxiliary heat cxchanger for downflow . . . . . . . 3-51 
FIGURES. (Continued)

3-27. Main helium circulator . . . . . . . . . . . . . . . 3-53

3-28. Containment/confinement building for upflow and downflow . . 3-55

4-1. Core auxiliary cooling loop model . . . . . . . . . . . 4-2

4-2. Temperature history of maximum-powered fuel and blanket assembly (case 1)................ 4-5

4-3. Core outlet temperature history . . . . . . . . . . . . 4-6

4-4. Maximum cladding temperature as a function of loop

transfer time (case 1) .................. 4-9

4-5. Effect of loop isolation valve malfunction on maximum cladding temperature (case 1) .. . . . . . . . . 4-10

4-6. Required elevation differences for natural circulation to ultimate heat sink.................. 4-12

4-7. Temperature history of maximum-powered fuel and blanket assembly (case 2)................. 4-13

4-8. Reliability allocation tree.............. . 4-16

6-1. GCFR upflow/downflow evaluation form ............ . 6-4

A-1. Grid plate horizontal envelope response spectrum scaled to $1.0 \mathrm{~g} O \mathrm{OBE}$. . . . . . . . . . . . . . . . $\mathrm{A}-2$

D-1. Bowing reactivity insertion during normal startup from
hot standby (GCFR and CRBR) . . . . . . . . . . . . . . . B-4

D-1. Upflow fixed core cavity plug . . . . . . . . . . . . D-2

D-2. Upflow core - fixed plug concept. Control rod drive
and instrument tree arrangement . . . . . . . . . . . D-3

D-3. General arrangement of seven-assembly concept . . . . . . . D-6

D-4. PCRV bottom head arrangement with horizontal main helium... D-8

D-5. Horizontal main helium circulator installation . . . . . . D-9 
2-1. Major milestone summary . . . . . . . . . . . . . . 2-4

3-1. Design basis core data for upflow/downflow comparison . . . . 3-32

4-1. Maximum cladding temperatures for natural circulation cooling in the CACS (maximum powered and with hot spot factors) .................. . . . 4-8

4-2. Independent failure probability for dominating events . . . . 4-19

4-3. Common cause failure probability for dominating events . . . 4-20

4-4. Dominating events... . . . . . . . . . . . . . . 4-21

5-1. Comparison of postulated PCRV failure modes . . . . . . . . 5-8

6-1. Evaluation criteria . . . . . . . . . . . . . . . 6-2

6-2. Comparison between upflow and downflow plants . . . . . . . 6-6

7-1. GCFR upflow/downflow evaluation summary of capital cost differentials upflow versus downflow trend cost (effective January 1979) . . . . . . . . . . . . . . . . 7-2

7-2. GCFR upflow/downflow evaluation assessment of engineering program cost impact by changing to, upflow core plant design (total program).................... 7-3

A-1. Upflow/downflow core design:: core assembly seismic response response . . . . . . . . . . . . . . . . . A-3

B-1. Upflow/downflow core design: core distortion analysis . . . B-2 


\section{SUMMARY}

In early 1978, Helium Breeder Associates (HBA) requested General Atomic (GA) to conduct a study to identify and evaluate possible advantages an upflow core may offer in comparison with the downflow core of the present gas-cooled fast reactor (GCFR) reference design. HBA indicated that it was highly desirable for the GCFR group of Kraftwerk Union (KWU) to participate in the study, and thus contribute to a convergence between international program partners with regard to core flow direction and plant design.

Between April 1978 and April 1979, an engineering study program was planned and conducted at GA by resource and project personnel under the direction of a Technical Management Committee (TMC). In Germany, a smaller activity was conducted by KWU, who in October 1978 sent a team to GA for a 6-week joint design effort to converge on a suitable upflow plant configuration for the final phase of the upflow versus downflow comparison study.

The results of the study were jointly reviewed and evaluated by the TMC and the cognizant engineers of selected design areas. Although it is recognized that additional development and design efforts are required, the plant design and licensing advantages of an upflow core were considered sufficient by GA and KWU to recommend its adoption for the GCFR reference design.

\subsection{SUMMARY OF UPFLOW DESIGN STUDY}

Major conceptual design and analysis accomplishments were in the following areas:

- Core and core elements

- Core lateral restraint system and associated replaceable reflector/ shield assemblies 
- Core seismic and distortion analysis

- Dual-rotating plug with toggle type holddown

- Straight-1ine fuel handling machine and system

- Fully removable control rod guide tubes and instrument tree

- Rotating plug penetration service connections layout problems

- Internal shielding and duct shadow shielding

- Grid plate and grid plate support structure

- In-vessel post-accident fuel containment evaluated

- Steam generator with top superheat steam exit

- Dynamic analysis of natural circulation to establish primary coolant loop proportions

- Dynamic analysis of fuel and blanket assembly temperatures for average and hot channels

- Dynamic and static natural circulation analysis of core auxiliary heat exchanger cooling system established reasonable elevations of components all the way to atmospheric heat sink

- PCRV layout and structural sizing to accommodate all primary system components and requirements

- Containment and part of Nuclear Island layout

- Evaluation of lower axial blanket "drains" as a means for mitigating the consequences of postulated core disruptive accidents 


\subsection{SUMMARY OF DOWNFLOW DESIGN STUDY}

The existing downflow reference design 300 MW(e) GCFR demonstration plant was substantially revised and updated. Notable conceptual design and analysis accomplishments were in the following areas:

- Core lateral restraint structure added to provide restraint above top of the active core to solve seismic and distortion problems while retaining potential for individual element fallaway as means to mitigate core disruptive accidents

- Core layout revised to accommodate replaceable reflector/shield assemblies to limit doses to core lateral restraint structure

- Radial shield assembly incorporating replaceable shield segments in lower core cavity plenum (avoids additional exit end shielding on core elements, which would aggravate seismic and restraint problems)

- Primary coolant loop layout revised to accommodate top-mounted, electric-motor-driven, main helium circulator

- Core auxiliary cooling system revised to accommodate bayonet tube heat exchanger

- Core cavity closure revised to accommodate toggle type holddown as required for commercial plant size

- In-vessel post-accident fuel containment resized

- PCRV layout revised as required by component change

- Containment and part of Nuclear Island layout revised

- Refueling system evaluated for handling of replaceable reflector/ shield assemblies and shield segments, and for scalability; 
excessive downtime for refueling and shield segment replacement is a major concern for large plants.

\subsection{SUMMARY OF STUDIES COMMON TO BOTH UPFLOW AND DOWNFLOW DESIGNS}

Studies in the following areas were conducted in support of the upflow and downflow plants. The results are not factors in the upflow versus downflow recommendation, but are important in defining the concepts.

- Evaluation of shielding requirements for postulated major maintenance (such as replacement of grid.plate) indicated impracticability to the point of infeasibility with gas in the primary system.

- Water flooding of defueled core cavity for major maintenance was investigated in selected cirtical areas. Credible concepts were developed for handling major components. Thermal barrier floodability was evaluated as potentially but not definitely feasible. Design and materials problems and implications of flooding were identified but not resolved. Much further work is required to establish designs suitable for flooding.

- System design of forced circulation residual heat removal systems. 


\section{INTRODUCTION}

This report summarizes the results of a one-year study in support of. the GCFR upflow versus downflow plant design evaluation. Following a request by HBA, the study commenced in April 1978. Recognizing the importance of achieving an international design convergence on a GCFR demonstration plant configuration, GA and KWU personnel jointly performed this study. In Germany, the GCFR design group of KWU participated by investigating selected design areas, and in October 1978 by sending a KWU team to GA for a 6-week joint design effort on an upflow plant configuration for the final phase of the study. A KWU representative was also present during the final review and evaluation of the competing upflow and downflow designs and during the deliberations leading to the recommendation to HBA management.

Major incentives for considering an upflow core design included:

1. Potential for core cooling by natural circulation and thus increasing residual heat removal (RHR) reliability and diversity.

2. Opportunity for plant design improvements, especially in the areas. of refueling and main helium circulator location.

An upflow core for the GCFR presents a major departure from the present downflow core reference design. It was, therefore, considered mandatory for the study to: (1) determine whether an upflow core CGFR design is feasible, and (2) to provide sufticient plant design and safety-related information to support a recommendation for. changing core flow direction in the GCFR.

In the past, there have been several gas-cooled fast breeder reactor studies based on an upflow core. The European Association for Gas Breeder Reactors (GBRA) undertook several, and their latest study culminated in the 
GBR-4 design concept, which provided considerable information about general plant design and its safety aspects (Ref. 1). In the GBR-4 design, the possibility of using natural circulation cooling in the pressurized case for residual heat removal was studied in some detail; their results indicated good RHR potential. KWU, in their study of alternatives to the GA reference design, has been investigating several design options with upflow cores. They have developed a preference for upflow cores based on application of existing light water reactor (LWR) and liquid metal fast breeder reactor (LMFBR) technology, coupled with some advances in vessel technology arising from gas-cooled reactor (GCR) and LWR programs. GA performed a significant conceptual study of alternative designs (Ref. 2). The main thrust of this work paralleled KWU's efforts in looking at design alternatives. The results of this latest GA study as they relate to upflow core design and natural circulation provided some input to this upflow/downflow study.

The following main objectives of the upflow/downflow study were identified:

1. Development of a set of evaluation criteria, and outlining the general decision process for use in this study.

2. Development of an overall upflow plant design concept in sufficient detail to permit evaluation of the technical feasibility of the nuclear steam supp1y system (NSSS) design features, and also to serve as a model for analysis and safety assessment.

3. Revision and update of the GCFR demonstration plant reference design to conform to a set of criteria and basic design data common to both upflow and downflow.

4. Development of a computer program simulating the upflow plant configuration to analyze initiation and continuity of pressurized natural circulation cooling. Also, establishment of a natural circulation RHK scenario using either main or auxiliary loops. 
5. Development of methods to describe analytically the history and consequences of hypothetical core disruptive accidents (CDAs). Determination of the potential of an upflow and downflow core design to prevent or mitigate consequences of such accidents.

6. Submittal to GA management of a final TMC recommendation with regard to core flow direction by March 30, 1979.

A conceptual design of the prestressed concrete reactor vessel (PCRV) and associated NSSS components was developed for the upflow plant (Ref. 3), as were portions of the balance of plant (BOP) that interface with refueling and naturalcirculation requirements. The downflow plant was updated to incorporate the latest design changes since the issuance of Ref. 4.

The major systems and components of the upflow and downflow plant designs are described in Section 3. Section 4 deals specifically with residual heat removal by natural circulation. Natural circulation analysis with natural circulation on the primary coolant side only, and also to the ultimate heat sink, are described together with a reliability assessment of this additional upflow plant feature. Possible licensing impact is also discussed. In Section 5, the possible impact of core flow direction on hypothetical core disruptive accident scenarios and consequences is determined. The design and performance features of some 40 selected design elements of the competing concepts, i.e., upflow versus downflow, are compared and evaluated in Section 6 . The possible cost and schedule impact by changing core flow direction is briefly addressed in Section 7. And, finally, in Section 8 are summarized the conclusions and recommendations to adopt the upflow configuration as the new reference design. Also included in the last section are some recommendations for additional work to confirm several design configuration choices. Some core-design-related. topics are briefly discussed in the appendixes.

The overall schedule for the study is given by the major milestone summary in Table $2-1$. 
TABLE 2-1

MAJOR MILESTONE SUMMARY

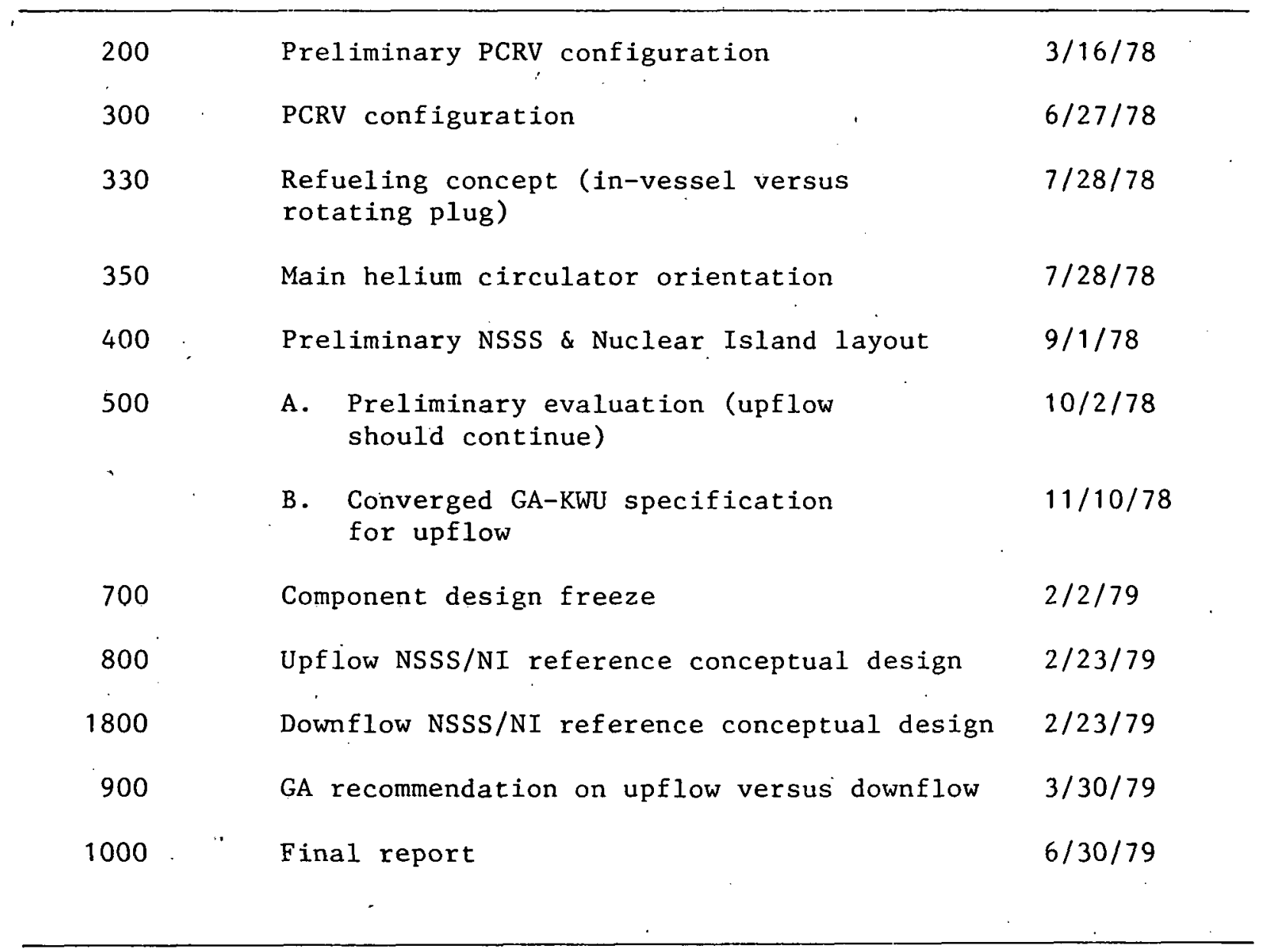




\section{PLANT DESIGN DESCRIPTION}

The 300 MW(e) GCFR demonstration plant design defined in Ref. 4 formed the basis for the downflow plant; it was updated to include the latest changes in plant performance and/or configuration. The upflow concept was originally developed by adopting applicable portions of the downflow design and adding specific upflow design features. After a preliminary assessment (Ref. 3) and a successful conclusion of the GA/KWU. design. convergence effort, the upflow conceptual design was modified.

The conceptual designs of the upflow and downflow as presented here are the latest versions, and they were used in the upflow/downflow evaluation. It is important to remember that the upflow plant presents only a conceptual design developed to assess the advantages and disadvantages of an upflow plant when compared with the current downflow reference plant design. As the study progressed, it became apparent that some of the design features adopted for the upflow core would not favorably contribute to the overall upflow concept evaluation. Some alternatives were investigated. This work is described in subsequent sections where possible design changes and configuration selection are discussed.

For either design, the NSSS of the 300 MW(e) GCFR demonstration plant comprises one main cooling system and two independent safety-class residual heat removal (RHR) systems, i.e., the shutdown cooling system and the core auxiliary cooling system. All of these are contained within the prestressed concrete reactor vessel (PCRV).

The main cooling system (MCS) consists of three indpendent and separate helium loops and two independent water/steam loops (Fig. 3-1).

Each helium loop has a steam generator, a main helium circulator, and a loop isolation valve. Helium transfers heat from the core to the 


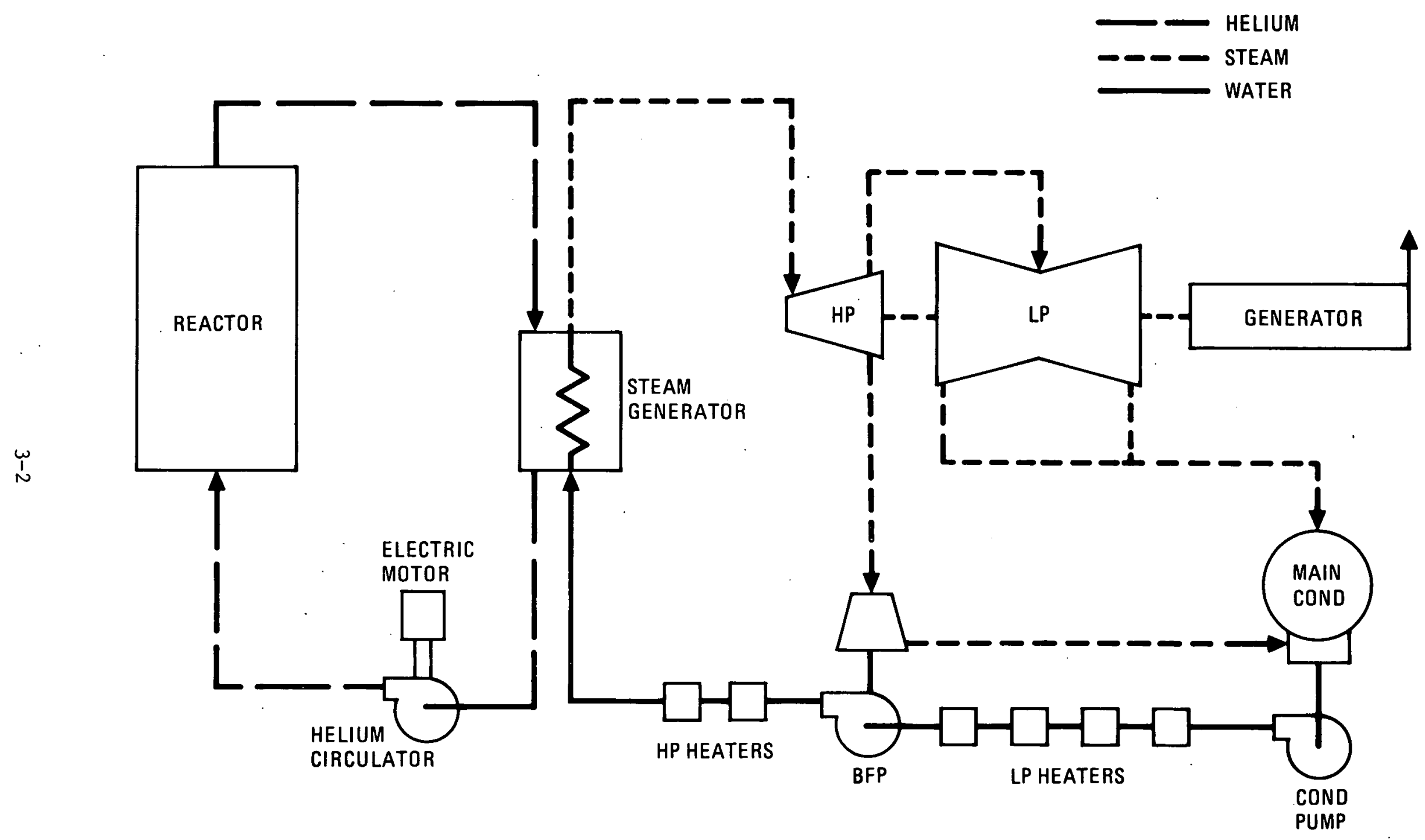

Fig. 3-1. Main cooling system flow diagram 
water/steam in the steam generators; it is then compressed by the main helium circulators and returns to the core. The loop isolation valves are mounted in the main circulator inlet ducts:

The water/steam loops and associated equipment are part of the BOP. The main water/steam loops receive superheated steam from the steam generators and transfer it to the main steam turbine. After expansion in the turbine, the wet steam flows into the main condenser. Condensate pumps then deliver the water through the low-pressure feedwater heaters to a deaerator. From there, steam-turbine-driven main boiler feedwater pumps return the water through a high-pressure feedwater heater to the steam generator. The two loops are entirely separate, except for the main turbine generator, which is a single unit. The main condenser is cooled by the circulating water system. The latter has two circulating water pumps and lines, but a single main cooling tower with two water basins.

During startup and shutdown operation, two bypass steam systems are used. Each has a desuperheater, a flash tank, atmospheric steam release, and steam bypass lines to the main condenser. Steam from this system can be provided for driving the boiler feedwater pump steam turbine, and to heat steam lines and feedwater heaters.

The core auxiliary cooling system (CACS) consists of three independent and separate cooling loops. Each cooling loop comprises three heat transfer circuits: primary coolant helium (but in the event of a depressurization accident, a helium/air mixture), water, and air (Fig. 3-2).

Each primary coolant circuit contains a core auxiliary heat exchanger (CAHE), an auxiliary circulator, and a loop isolation valve. The primary coolant removes heat from the core and transfers it to the CAHE. Heat is then transferred by the water from the CAHE to the air-cooled auxiliary loop cooler (ALC), from which it is discharged to the atmosphere.

Each water circuit has piping, pump, valves, and a pressurizer. Each air circuit contains an ALC, louvers, and air fans. All piping, structures, 


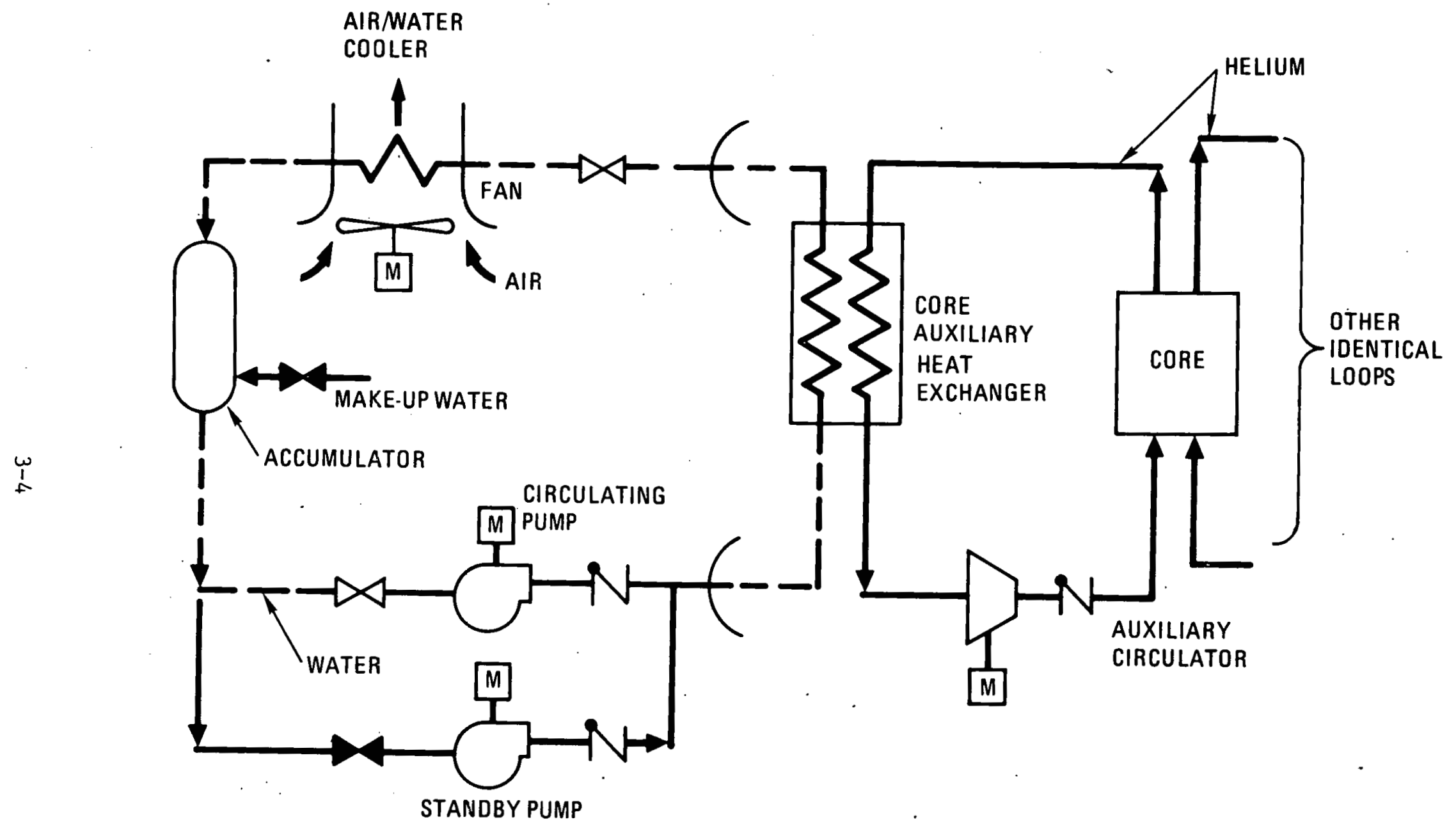

Fig. 3-2. Core auxiliary cooling system flow diagram 
and individual components are designed to be safety class, seismic category 1. Power for all of the system is safety class (IE) electric power. However, the upflow core offers the additional means of pressurized natural circulation cooling should all electric power be lost.

The shutdown cooling system (SCS) consists of three independent and separate cooling loops. Each cooling loop has three heat transfer circuits: helium, water and air (Fig. 3-3).

Helium, circulated by the pony-motor-driven main helium circulators, removes heat from the core and transfers it to the steam generators after they have been flooded with water, using the main boiler feedpumps. The heat is then transferred by the water from the steam generators to aircooled heat exchanges, from which it is discharged to the atmosphere.

Each water circuit consists of an SCS pump, valves, piping, and a pressurizer. Each air circuit includes a water/air heat exchanger, louvers, and air fans. The water and air circuits are conceptually similar to the core auxiliary cooling water system (CACWS), but because of different functional requirements and for diversity, the equipment will not be identical. Power for all of the system is safety class (IE) electric power. All piping, structures, and individual components are designed to be safety class, seismic category 1 .

Both upflow and downflow concepts have many system and component design features in common. However, for some areas core flow direction was judged to have a major design and/or configuration impact. The following items were identified to fall into this category:

1. PCRV

2. PCRV closures

3. Shielding 


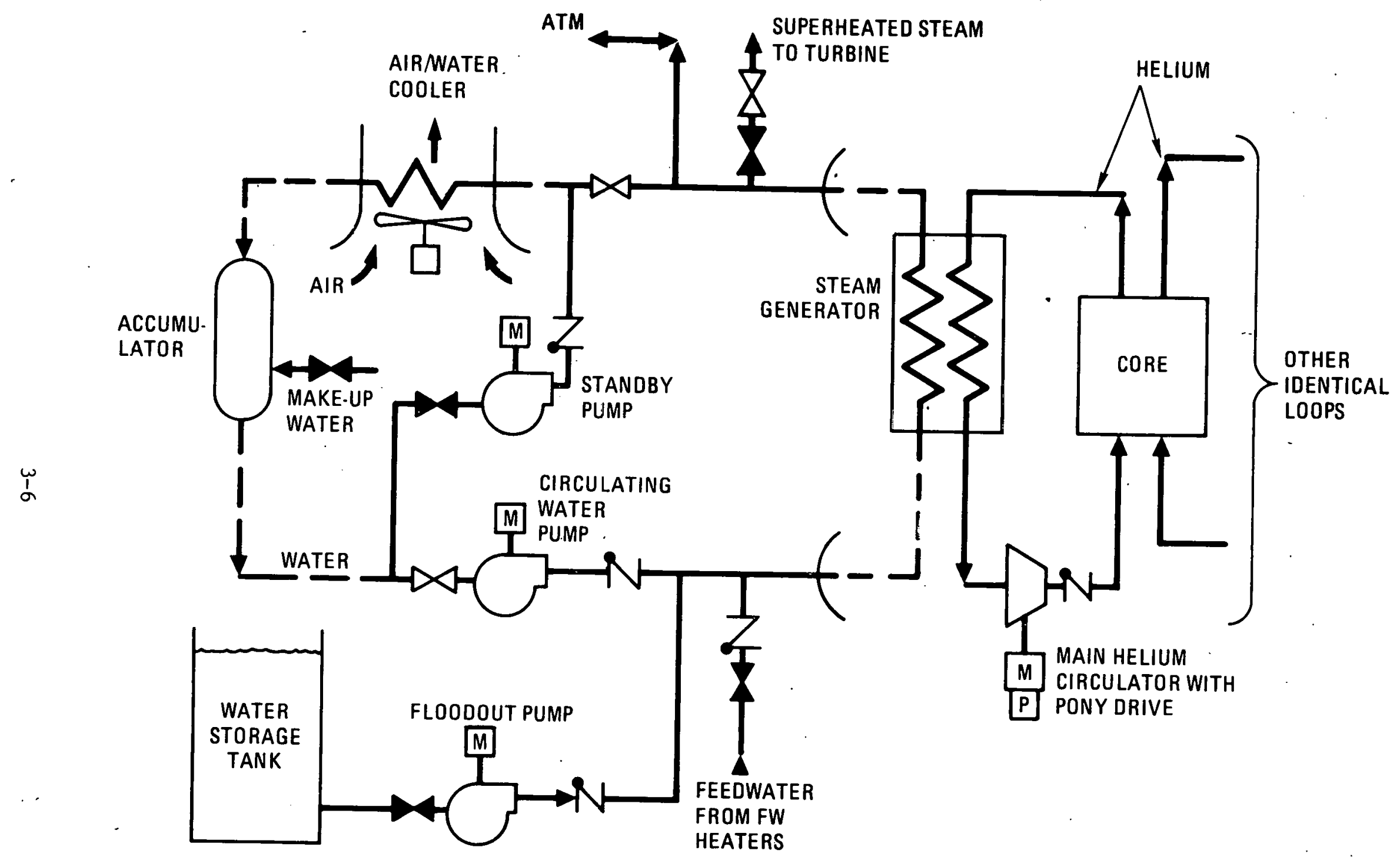

Fig. 3-3. Shutdown cooling system flow diagram 
4. Core support structure

5. Reactor core

6. Control rod drive line guide/instrument tree

7. Refueling

8. Steam generator/core auxiliary heat exchanger

To avoid repetition, the upflow and downflow plant design descriptions have been arranged side by side. Where appropriate, i.e., where the concepts are identical or very similar, a common description has been given. However, there are separate descriptions for upflow and downflow if design features are sufficiently different to warrant it.

\subsection{PCRV DESIGN AND ARRANGEMENTS}

The PCRV designs for the upflow and downflow plants are similar. They are constructed of high-strength concrete reinforced by bonded reinforcing steel. The concrete vessel is prestressed vertically by linear steel tendons and radially by circumferential wire winding. The linear tendon system consists of metal conduits embedded in concrete to accommodate the multiple prestressing slidils Llal provide the precompression needed to balance the axial forces due to the cavity pressure. Circumferential prestressing is provided by wire strands placed in circumferential channels of steel plate around the vertical outer surface of the PCRV. The PCRV is a multicavity vessel with the core cavity being surrounded by six cylindrical cavities. of these, three loops contain the main cooling system components with each having one steam generator and one main helium circulator with loop isolation valve. The other three are the core auxiliary cooling system loops, each containing one CAHE and one auxiliary circulator with loop isolation valve. 


\section{Upflow Plant}

The PCRV arrangement and helium flow path are shown in Fig, 3-4. During normal operation of the main cooling system, cold helium entering from the lower core cavity plenum flows upward through the core and is heated. Hot helium leaving the core flows through the upper core cavity plenum. It then passes through the hot duct and into the steam generator cavity. Upon entering the steam generator cavity, helium flows upwards through an annulus, which is formed by the cavity wall and the steam generator shroud. At the annulus exit, flow direction is changed and the hot helium flows downward through a flow distribution baffle and then across the helical steam generator tube bundle. Cold helium from the steam generator enters the main helium circulator, and after discharge is returned, via the cold duct, to the lower core cavity plenum.

\section{Downflow Plant}

The PCRV arrangement and helium flow path are shown in Fig. 3-5. During normal operation of the main cooling sysmen, cold helium entering from the upper core cavity plenum flows downward through the core. After passing through the core, the heated helium enters the lower core cavity plenum, reverses direction, and flows upward through the outer radial shield annulus. It then leaves the core cavity via the hot duct and enters the steam generator cavity. Helium then passes downward past a flow distribution baffle and flows across the helical steam generator tube bundle. After leaving the steam generator, the helium enters a bypass coolant duct, which takes it to the main helium circulator inlet. Upon discharge, helium enters the upper core cavity plenum via the cold duct.

During operation of the shutdown cooling system (SCS), the same flow path is used because the components are the same: the steam generator performing as a helium/water heat exchanger, and the main helium circulator driven by an electric pony motor. 


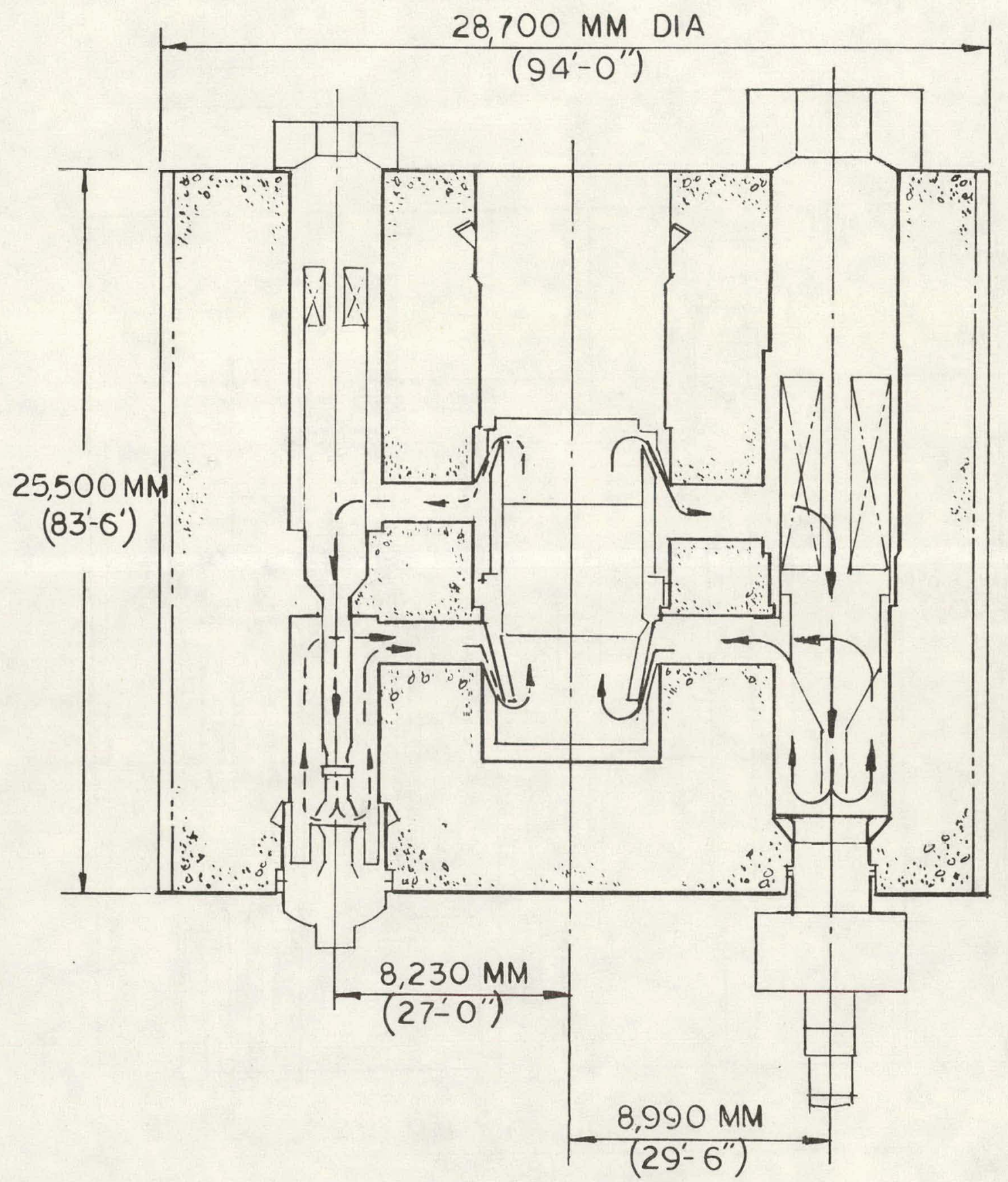

Fig. 3-4. Upf1ow PCRV arrangement 


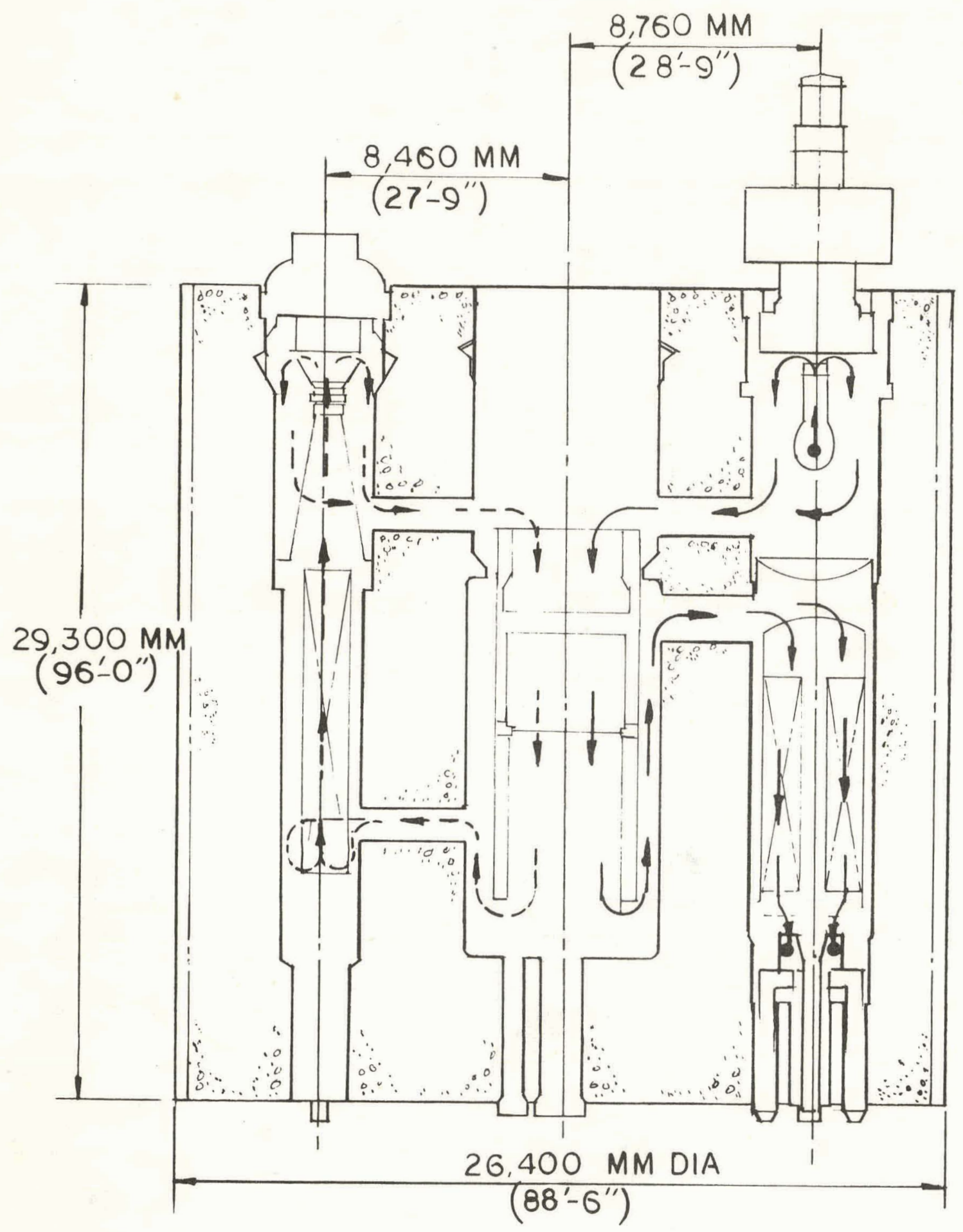

Fig. 3-5. Downflow PCRV arrangement 
$\underline{\text { Upflow Plant }}$

During auxiliary cooling system operation, the helium follows a similar flow path. However, in this case hot helium passes through the auxiliary loop hot duct and, upon entering the auxiliary cooling loop cavity, flows upward through an annulus; the annulus is formed by the cavity wall and the shroud of the CAHE. Atop the annulus, flow direction is reversed and hot helium passes across the helical CAHE tube bundle. After discharge from the auxiliary circulator, cold helium flows through the auxiliary loop cold duct and enters the lower core cavity plenum.

The PCRV is cylindrical structure $25.500 \mathrm{~mm}$ ( $83 \mathrm{ft} h$ in.) high and $28,700 \mathrm{~mm}$ (94 ft 0 in.) in diameter, as shown in Fig. 3-4. The $6710 \mathrm{~mm}$ (22 ft 0 in.) diameter core cavity contains the core, core support structure, and shielding. Radial coolant ducts at the top and bottom of the core cavity connect the upper and lower plenum to the steam generator and auxiliary cooling loop cavities. The steam generators are located in the upper portion of the steam generator cavity with the main helium circulators mounted in the bottom head of the PCRV. To enhance natural circulation through the core auxiliary cooling system (CACS) the CAHEs are mounted
Downflow Plant

During auxiliary cooling system operation, hot helium after leaving the core enters the lower cavity plenum and flows downward. It then reverses direction, flows partially upward through the outer radial shield annulus, and passes via the auxiliary loop hot duct into the auxiliary loop cavity. After a short downward passage through the annulus between the CAHE shroud and the cavity wall, helium reverses its direction and flows upward through the bayonet type tube bundle of the CAHE. It then enters the auxiliary circulator and, after discharge, the cold helium returns to the upper core cavity plenum via the auxiliary loop cold duct.

The PCRV is a cylindrical structure $29,300 \mathrm{~mm}$ (96 ft 0 in.) high and $27,000 \mathrm{~mm}$ (88 ft $6 \mathrm{in.)}$ in diameter as shown in Fig. 3-5. The $6730 \mathrm{~mm}(22 \mathrm{ft}$ 1 in.) diameter core cavity contains the core, core support structure, and shielding. Radial hot and cold ducts, both at the upper end of the core cavity, connect to the steam generator cavities. Radial ducts, cold in the upper and hot in the lower plenum of the core cavity, connect to the auxiliary cooling loop cavities. The steam generators are located in the lower portion of the steam generator cavity with the main helium circulators mounted atop the PCRV. The CAHEs are 
in the uppermost part of the auxiliary cooling loop cavities. The auxiliary circulators are located in the PCRV bottom head. Three equally spaced vertical pipe chases, traversing the entire PCRV height, and located between the steam generator and auxiliary cooling loop cavities, serve to route feedwater to the steam generators and cooling water to the CAHES . also mounted in the lower portion of the auxiliary cooling loop. cavity with the auxiliary circulators mounted in the upper head of the PCRV. Both steam generators and CAHEs have bottom entry and bottom exits.

\subsection{CAVITY LINER, PENETRATIONS, AND CAVITY CLOSURES}

All cavities, interconnecting ducts, and penetrations in the PCRV have stee1 liners. Together with PCRV penetrations and closures, they transmit loads arising from the core, reactor internals, and component supports to the PCRV concrete. They also serve as a leaktight membrane to limit leakage of the reactor coolant. The liners are constructed of continuously welded carbon steel. The liners are anchored to the concrete by studs welded to the liner and embedded in the concrete. Cooling tubes are welded to the concrete side of the liner. To maintain the temperature of the concrete adjacent to the liner below allowable limits, specified by applicable codes, a thermal barrier is provided.

PCRV closures, and those portions of PCRV penetrations unbacked by concrete, are part of the primary coolant pressure resisting boundary. They permit access into the vessel, and limit leakage of impure helium out of the PCRV. To minimize leakage through closures during operation, three types of designs are used: (1) a closure integrally welded to a penetration, as typically provided at piping penetrations, (2) a closure joined to a penetration with a welded membrane type seal, as utilized at the steam generator upper closure, and (3) closures joined tó penetrations by bolts, flanges, and two concentric 0-ring seals, as utilized at control rod penetrations. 
Upflow Plant

The core cavity closure utilizes a large rotatable concrete plug assembly with closely spaced penetrations, a welded membrane seal attached to the liner, and a toggle holddown system. The rotating plug assembly is shown in Fig. 3-6. The primary or inner component is the actual plug; it contains all the necessary control rod drive and instrument tree penetrations, together with two dedicated penetrations. The center of rotation of the plug is offset from the center of the core by one-half the total required eccentricity. The plug is surrounded by the secondary component, an eccentric shielding ring structure which, when separately rotated, causes displacement of the plug, resulting in the required total displacement of the penetrations.

Two sets of drive motors, speed reducers, support rings, and fourpoint contact bearings with integral gears are used for rotation, one set for the plug and one set for the shield structure. During plant operation, two large forgings and several smaller ones are used to develop the pressure-resisting load path from the plug to the toggles. While the vessel is pressurized, i.e., during plant operation, elastomer 0 -rings are used
Downflow Plant

The core cavity closure consists of a concrete plug in which there are 67 closely spaced penetrations, as shown in Fig. 3-7. Nineteen are occupied by control rods; the remainder provide access for attachment and lock actuation between core assemblies and the grid plate. The holddown system is similar to that of the upflow. It comprises a series of 44 toggles that are inserted in circumferential grooves around the top of the closure and the core cavity. Leaktightness is assured by welding a membrane seal between the closure and 1iner.

The upper closure of the steam generator cavity utilizes a steel plug and holddown ring. The latter is bolted to the penetration. This configuration is relatively compact and able to accommodate the large diameter main helium circulator penetration and the electric motor, which is attached to the plug. The lower end of the steam generator cavity is closed by the PCRV concrete with penetrations for the feedwater inlet and superheated steam outlet pipes.

The auxiliary cooling loop upper closure consists of a steel structure with flow restrictor; it provides also a mounting for the auxiliary circulator. 


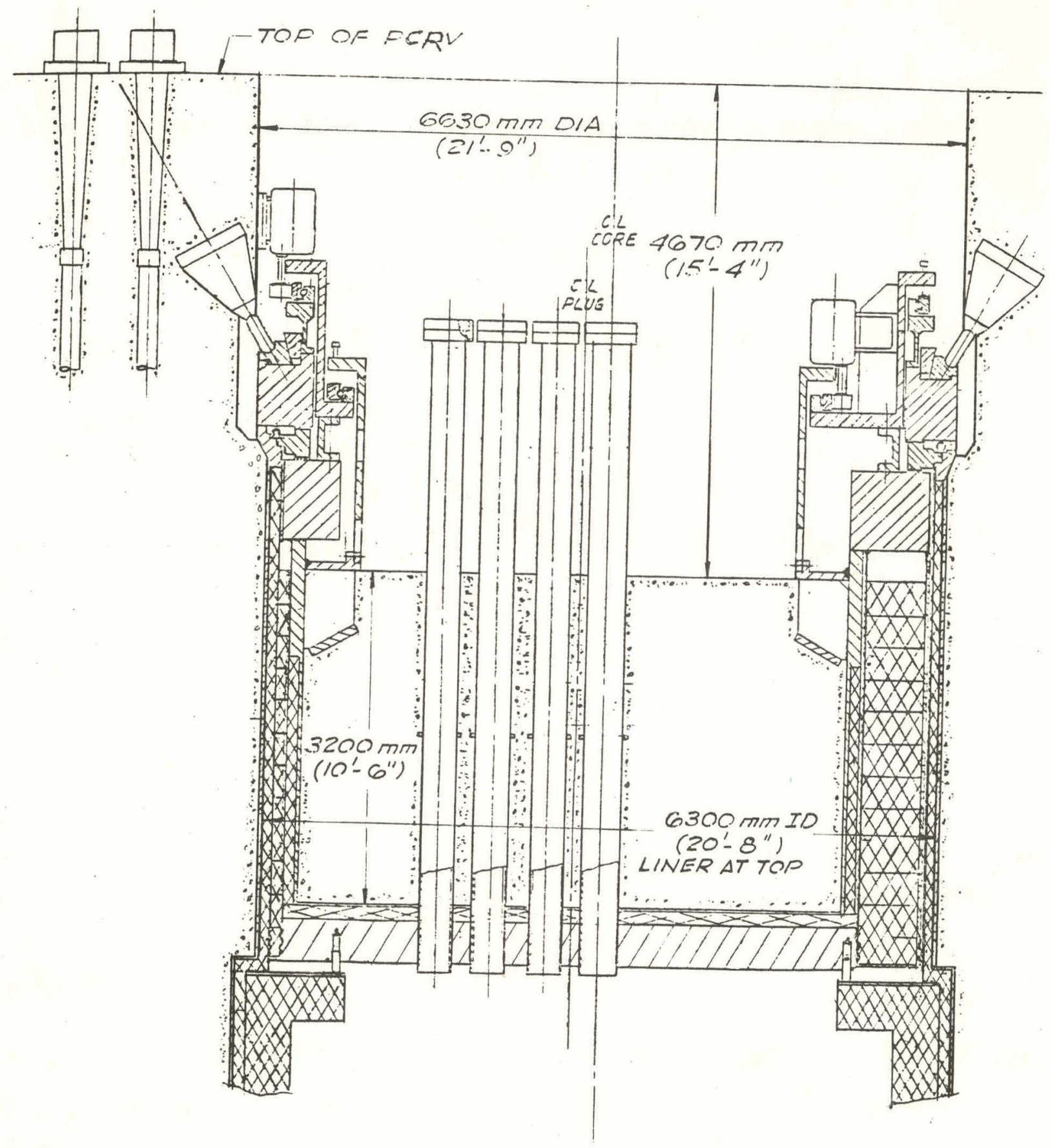

Fig. 3-6. Double rotating plug for upflow 


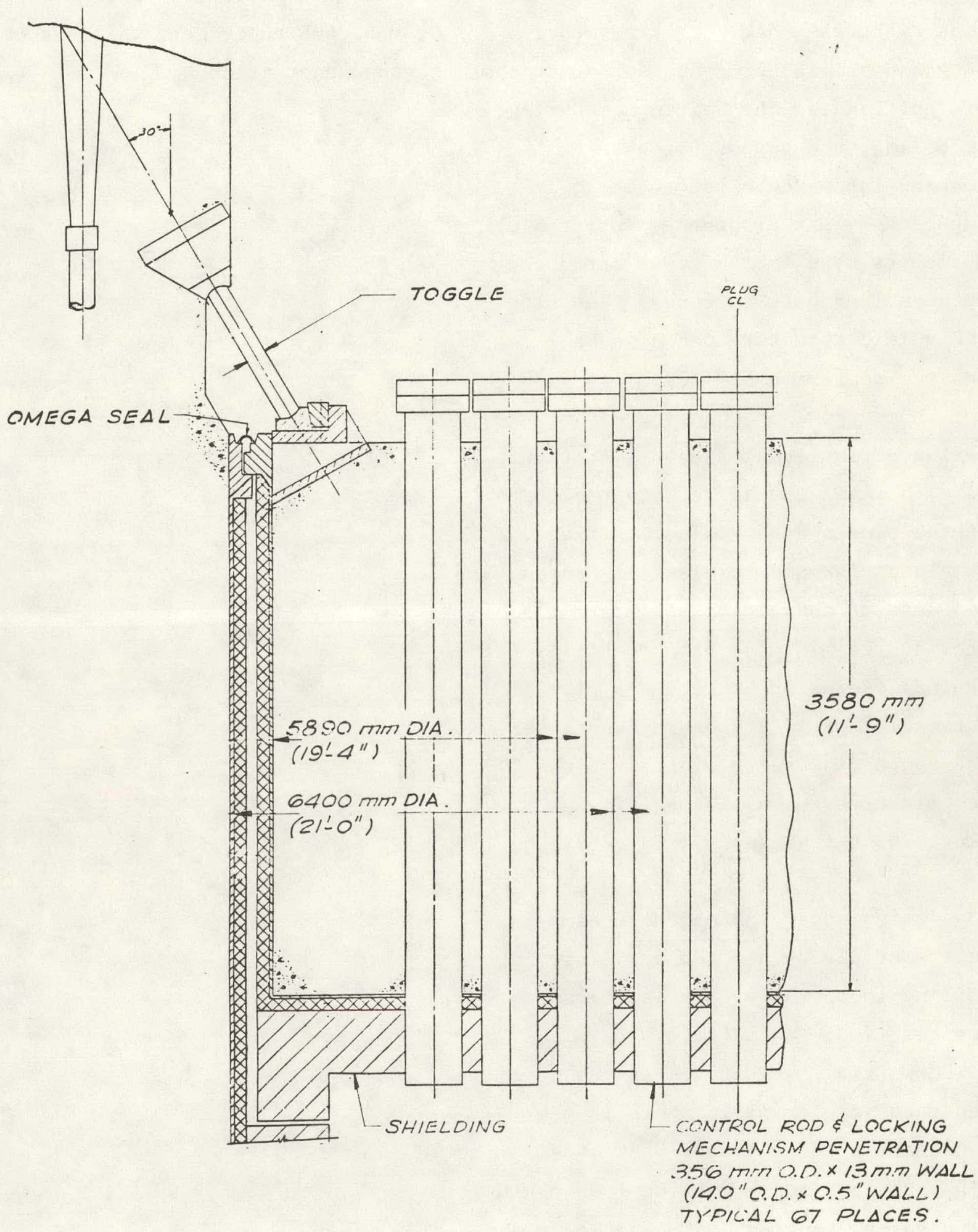

Fig. 3-7. Downflow fixed core cavity plug 
at two load path surfaces to achieve leak tightness. At this time, the plug and shield structure support rings are not loading the bearings. During refueling, the support rings are lowered into and bolted to the bearings. For leak tightness, inflatable seals are used in the gaps introduced between load path surfaces. The plug and shield structure can also be lowered approximately $102 \mathrm{~mm}$ (4 in.) for the purpose of changing either the 0-ring or inflatable seals. At that time, a metal C-seal between the bottom of the plug and the adjacent fixed shielding is used for leak tightness. Two sets of convection seals are also provided to minimize differential thermal expansion between the plug, rotatable shield structure, and liner. The convection seals also limit the temperatures to which the primary elastomer O-ring seals will be exposed.

At the upper end of the steam generator cavity and the auxiliary cooling loop cavity, similar closure designs, i.e., a concrete plug with holddown ring, are used. In the steam generator cavity plug, there is one penetration for the superheat steam pipe; the auxiliary cooling loop cavity plug has no penetration. The lower end of the steam generator cavity and the
The lower penetration closure is formed by the CAHE tubesheet, which is welded to the penetration. 
auxiliary cooling loop cavity has a circulator penetration closure and flow restrictor, both made of steel.

\subsection{CORE SUPPORT STRUCTURE}

\section{Upflow Plant}

The core support structure, shown in Fig. 3-8, consists of the grid plate, core lateral restraint, and the grid plate support structure.

The grid plate is a $4570 \mathrm{~mm}$ (180 in.) diameter, $533 \mathrm{~mm}$ (21 in.) thick flat plate. The vertical seismic response characteristics of the grid plate determine its thickness. There are 397 holes, each $172 \mathrm{~mm}$ (6.772 in.) in diameter, for locating and supporting fuel, blanket, control, and reflector/ shield assemblies. Supported from the top side of the grid plate is a core lateral restraint barrel with an outside diameter of $43 / 0 \mathrm{~mm}$ (180 in.), $4110 \mathrm{~mm}$ (162 in.) height and $44 \mathrm{~mm}$ (1.75 in.) wall thickness. Fitted core formers between the outer row of the reflector/shield assemblies and the core barrel provide the lateral restraint. A $100 \mathrm{~mm}$ (4 in.) thick pressure equalization system (PES) plate is fastened to the top of the grid plate. Approximately 100 tubes, $3 \mathrm{~mm}(0.125 \mathrm{in.})$ outside diameter, are
Downflow P1ant

The core support structure, shown in Fig. 3-9, consists of the grid plate core lateral restraint and the grid plate support structure.

The grid plate is a $4950 \mathrm{~mm}$ (195 in.) diameter, $610 \mathrm{~mm}$ (24 in.) thick flat plate; deflection limitations of the grid plate determine its thickness. There are 397 holes, each $172 \mathrm{~mm}$ (6.772 in.) in diameter for locating and locking fue1, blanket, control, and reflector/shield assemblies into position. Suspended from the lower side of the grid plate is a core lateral restraint barrel 4220 mm (166 in.) inside diameter, $1630 \mathrm{~mm}$ (64 in.) long, and $44 \mathrm{~mm}$ (1.75 in.) wall thickness. Fitted core formers between the outer row of the reflector/ shield assemblies and the core barrel provide the lateral restraint. A $100 \mathrm{~mm}$ (4 in.) thick pressure equalization system (PES) plate is fastened to the top of the grid plate. Approximately 100 tubes, $3 \mathrm{~mm}$ (0.125 in.) outside diameter, are routed from the plate to the helium purification system. 


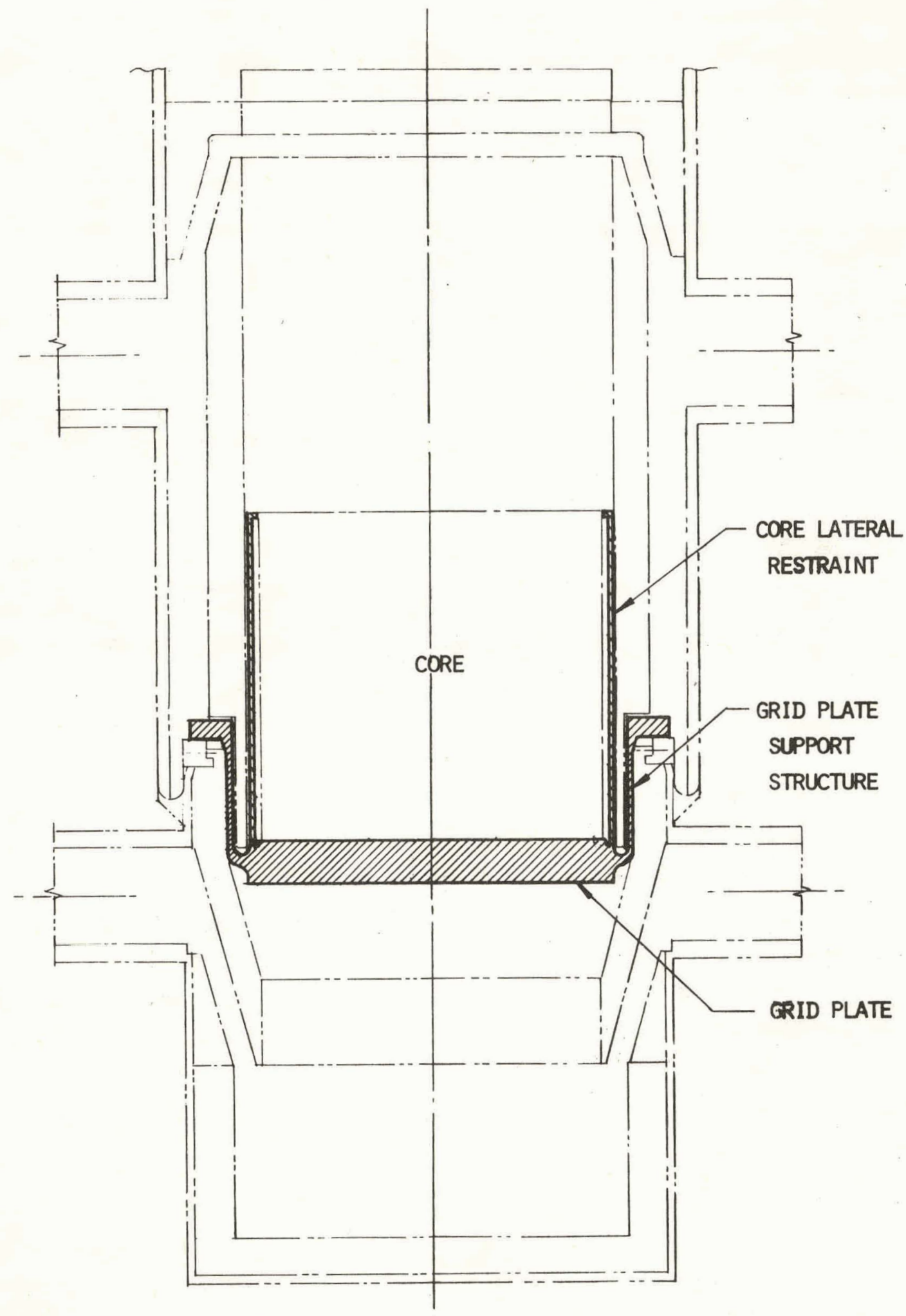

Fig. 3-8. Core support structure for upflow 


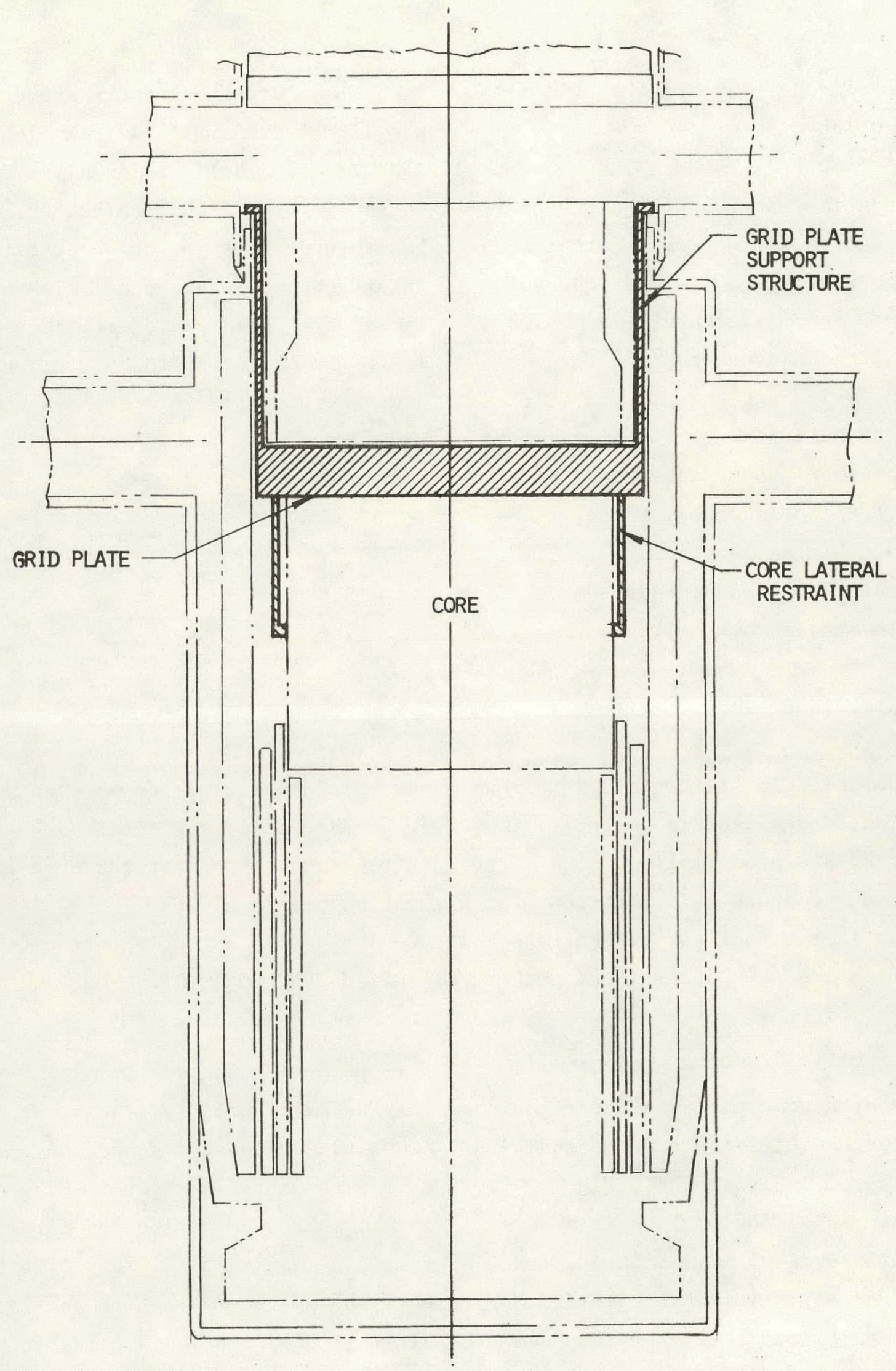

Fig. 3-9. Core support structure for downflow 
routed from the plate to the helium purification system.

The grid plate support structure consists of a cylindrical section with a flange resting on and fastened to the liner thermal sleeve. The cylindrical section connects to a toroidal section, which attaches to the grid plate. A series of small holes in the toroidal section permits bypass of cold helium for cooling the support structure and the radial shield assembly segments. A11 components are made of type 316 stainless steel.
The grid plate support structure is a cylinder $2900 \mathrm{~mm}$ (114 in.) high by $4500 \mathrm{~mm}$ (177 in.) outside diameter and $44 \mathrm{~mm}$ (1.75 in.) wall thickness. It has an upper flange, which rests on and is attached to the thermal sleeve of the liner. The grid plate is welded to the lower end of the cylinder. All components are made of type 316 stainless steel.

\subsection{SHIELDING}

The shielding is divided into four major shielding areas: upper plenum shielding, radial shield assembly, lower plenum shielding, and the two-row radial reflector/shield assemblies. The latter are required to protect the core lateral restraint structure. In addition, for the upflow plant only there are exit shield sections in the fuel and blanket assemblies. These and the reflector/shield assemblies are part of the core and are discussed later.

\section{Upflow Plant}

The arrangement of the upper and lower plenum shielding and the radial shield assembly is shown in Fig. 3-10. The basic shielding section is a boxlike structure $406 \mathrm{~mm}$ (16 in.) thick and made of $51 \mathrm{~mm}$ (2 in.) type 316 stainless steel plates. It is reinforced with internal stiffeners and has vent holes.

\section{Downflow Plant}

The arrangement of the upper and lower plenum shielding and the radial shield assembly is shown in Fig. 3-11. The basic shielding section for most shielding segments is a box-like structure $406 \mathrm{~mm}$ (16 in.) thick and made of $51 \mathrm{~mm}$ (2 in.) type 316 stainless steel plates. It is reinforced with internal stiffeners and has vent holes. 


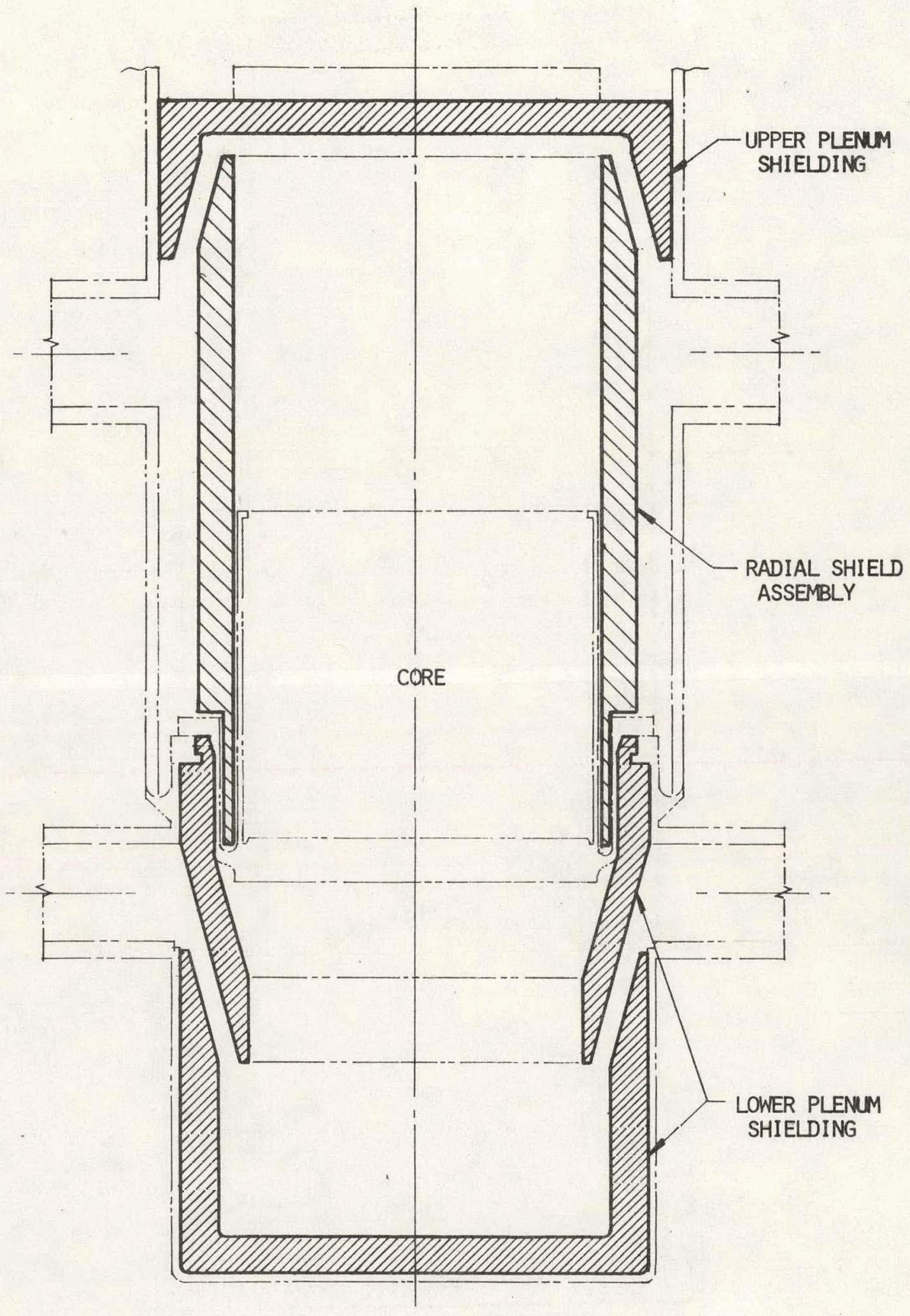

Fig. 3-10. Shielding arrangement for upflow 


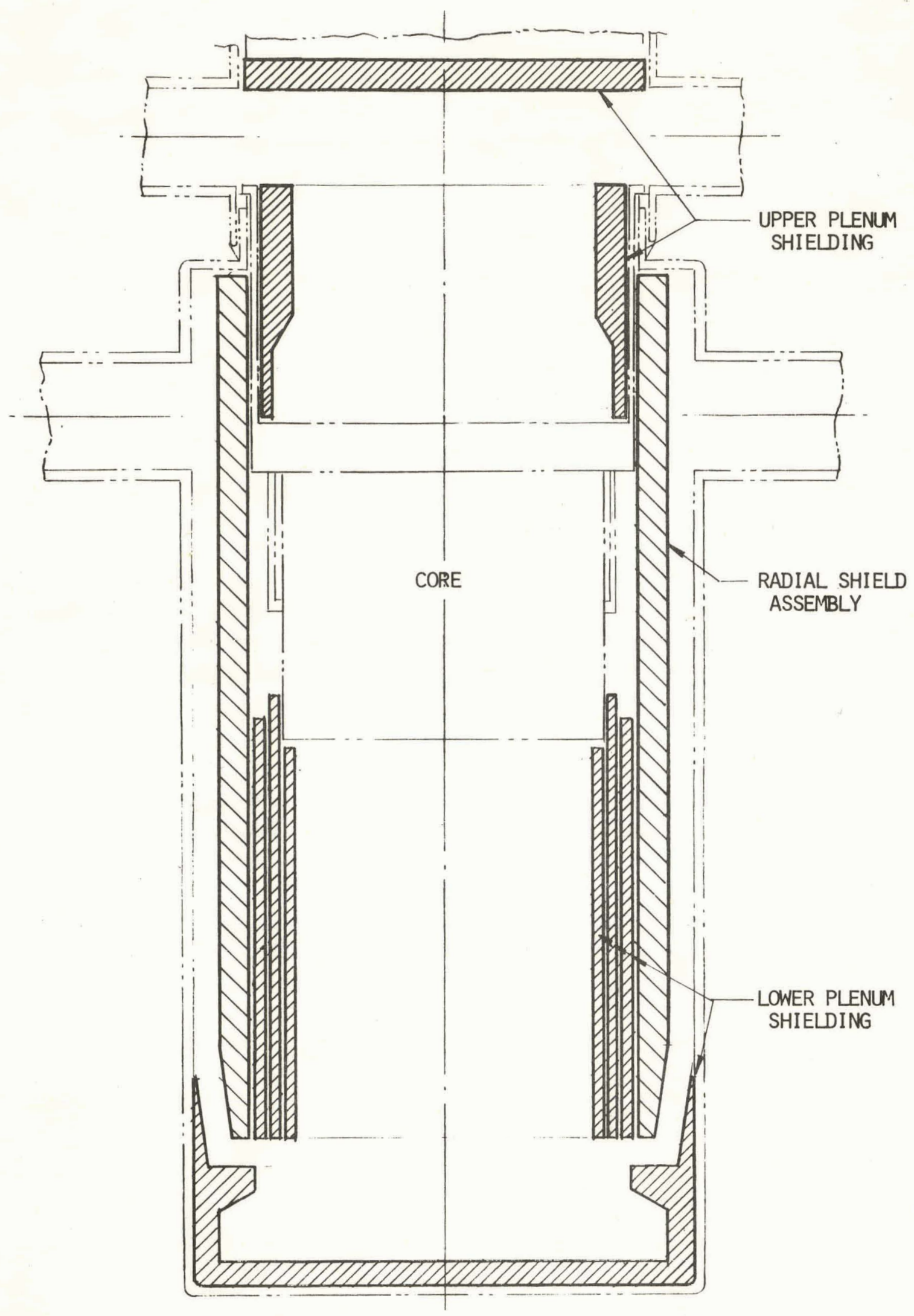

Fig. 3-11. Shielding arrangement for downflow 
The upper plenum shielding consists of two sections. Its function is to protect the upper liner side wall and the inlet ducts. One section is a disc-like structure, which is attached to the bottom portion of the reactor cavity closure. The other is a segmented cylinder, and extends from the top of the hot ducts to the bottom of the core cavity closure. It is attached to the liner at the upper side wall above the hot ducls, and is tapered at its lower end.

The radial shield assembly, composed of 12 fixed segments, is located adjacent to the core barrel. It extends from above the grid plate support structure to about $5180 \mathrm{~mm}$ (17 ft) above the top of the core. The extension is required to prevent uncollided neutron streaming into the hot ducts. Each is approximately $13,700 \mathrm{~mm}$ (45 ft) 1ong, and supported from the liner wall by struts. The upper portion of the radial shield assembly is tapered to provide, together with a corresponding taper on the upper plenum shielding cylinder, a flow path for the helium into the hot ducts.

The lower plenum shielding has several sections. There is first the segmented circular shield forming the
The upper plenum shielding consists of two sections. Its function is to protect the core support cylinder and the inlet ducts. One section is a disclike structure, which is attached to the bottom portion of the reactor cavity closure. The other is a segmented cylinder whose outer diameter fits inside the core support cylinder. It has scalloped cutouts to provide access for core shield assembly locking equipment.

The radial shield assembly, composed of 12 fixed segments, is located adjacent to the core barrel. The segments are about 11,300 mm (37 ft) long and extend downward from near the top of the core cavity. They are supported from the liner wall by struts.

The lower plenum shielding has several sections. First there is the segmented circular shield forming the bottom of the core cavity. To it is connected an axial wraparound shield section. The latter extends upward and overlaps slightly with the radial shield assembly from above. The remaining section is the inner radial shield. There are three rows of rectangular shield elements, which are dimensionally compatible with the fuel handling machine. The two outer rows consist of solid stainless steel. The 
bottom of the core cavity. To it is connected an axial wraparound shield section. The latter extends upward and stops just below the cold ducts; it is tapered at its upper end. Adjacent to the axial wraparound shield are conical shield segments. They extend from the grid plate support structure downward past the cold ducts, and are supported from the thermal sleeve of the liner. Their purpose is to prevent uncollided neutron streaming into the cold ducts. Their lower ends form, together with the taper on the axial wraparound shield, an annular flow path for the cold helium. An additional function of the conical shield segments is to act as a secondary grid plate support. inner row consists of graphite and boronated graphite surrounded by a stainless steel shell. The outer row is supported by the outer radial shield assemb1y sections. Each successive inner row receives its support from the adjacent outboard row.

\subsection{THERMAL BARRIERS}

The thermal barrier is a ceramic fiber insulation system attached to the interior surface of the PCRV. It is designed to prevent, in conjunction with the liner cooling system, degradation of the PCRV concrete. Heat losses from the primary coolant system are also minimized by the thermal barrier. The class and thickness of the thermal barrier are selected in accordance with the expected hot face temperature. The general thermal barrier arrangements for the upflow and downtlow plants are shown in Figs. 3-12 and 3-13, respectively.

\subsection{CONTROL ROD DRIVE}

There are 15 control rod and 4 shutdown rod drive locations. The control and shutdown rods are located on the centers of the regions consisting of a central control assembly surrounded by six fuel assemblies. Six of the control 


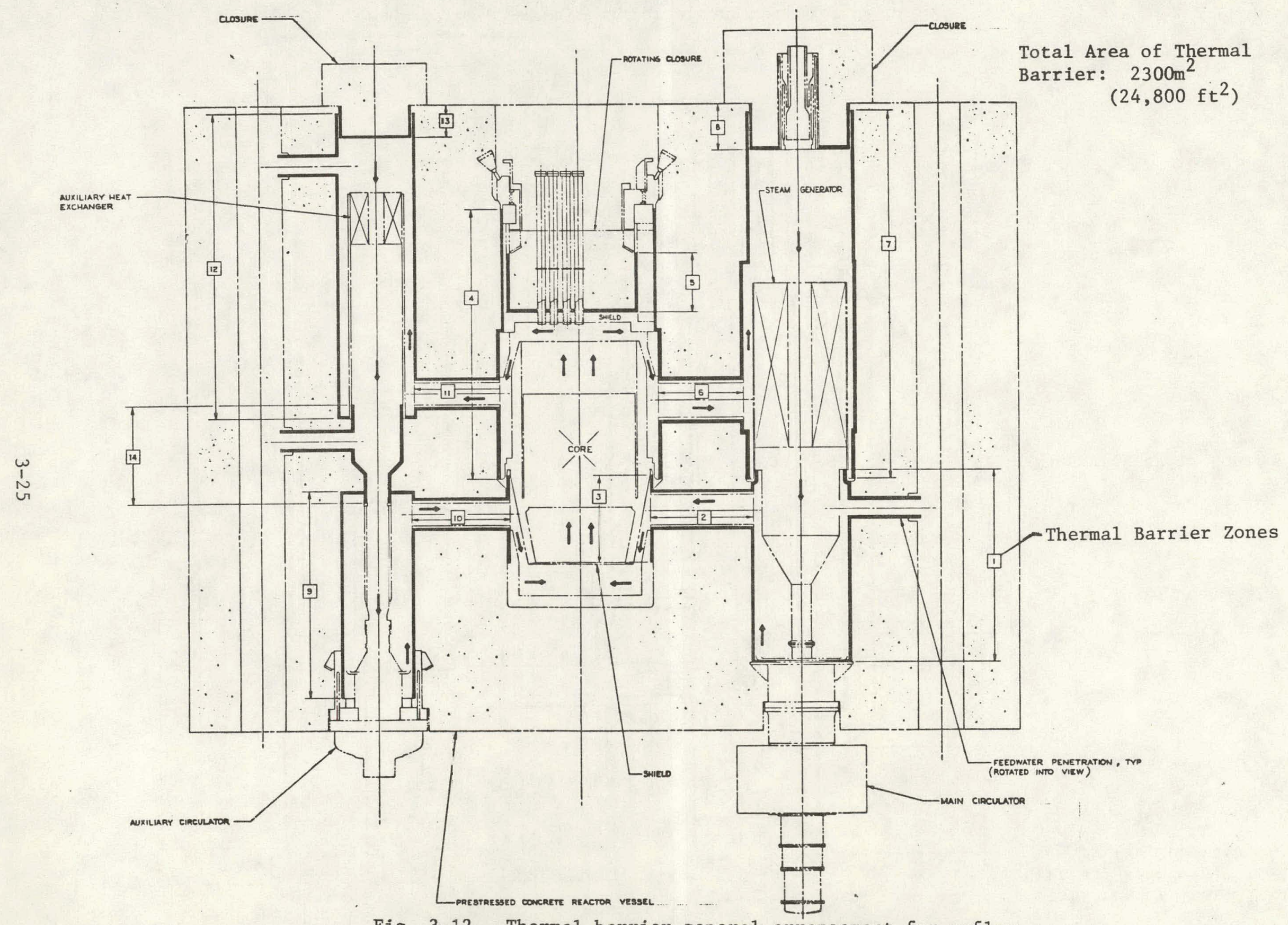

Fig. 3-12. Thermal barrier general arrangement for upflow 


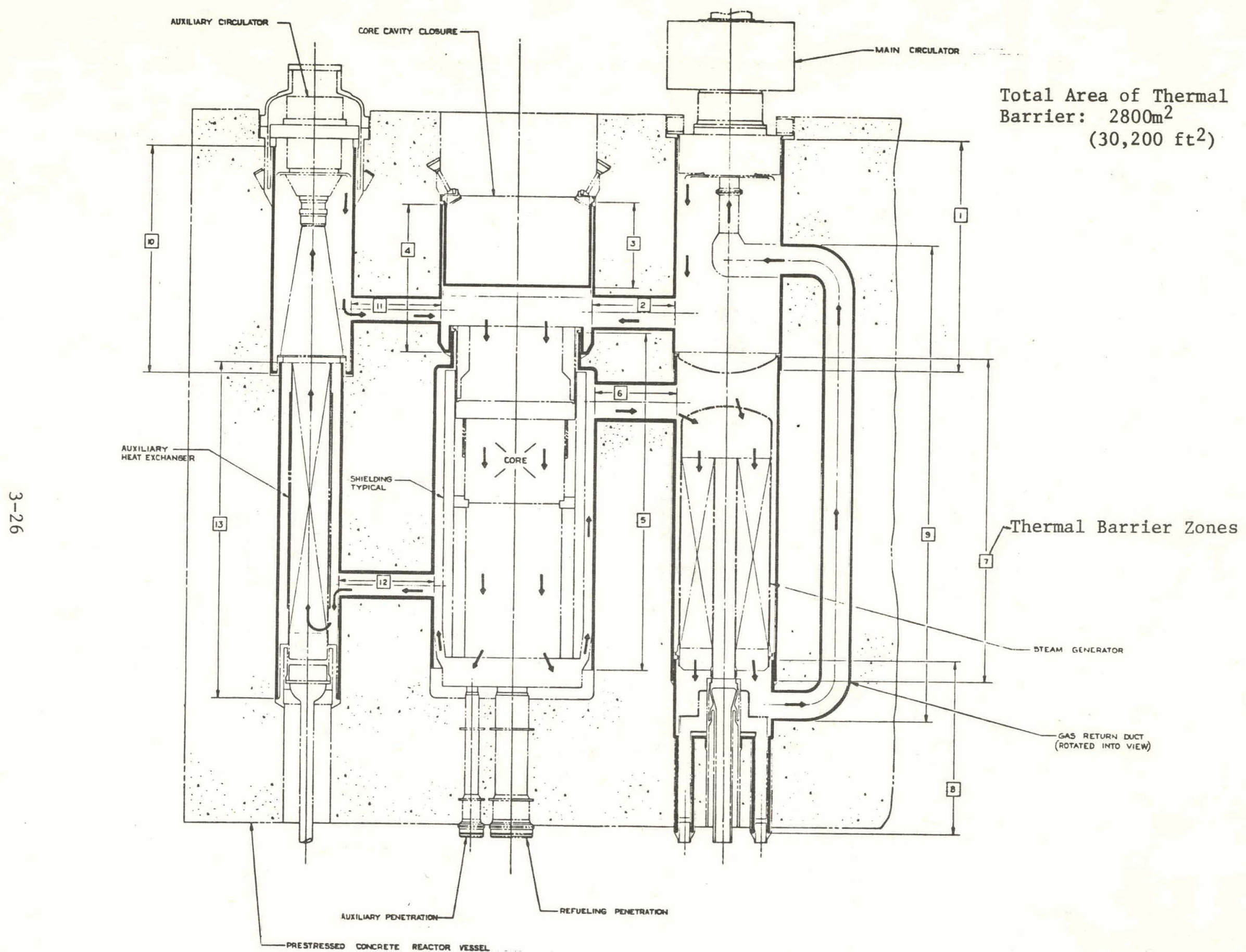

Fig. 3-13. Thermal barrier arrangement for downflow 
assemblies at the core fuel boundary are surrounded by only five fuel assemblies. The control rod drive assembly consists of an electric-motor-powered, screwoperated mechanism driving a rigid linear translating driveline member connected to a control rod. Reactor trip is performed by deenergizing an electromagnet, allowing the driveline and the control rod to fall free from the linear actuator mechanism. Controlled deceleration of a reactor trip is performed by transferring the free fall energy of the driveline into rotationally accelerating a free spinning flywheel. The lincar actuator mechanism assembly and the driveline extension member are designed as a single integral unit. The linear actuator mechanism portion is contained within the water-cooled top head penetrations. Only the driveline mechanism portion is exposed to the reactor cavity environment. The top head penetrations extend a distance above the top of the concrete closure as dictated by the length of the contained drive mechanism. The tops of the penetrations are capped and sealed by bolted closure plates. In addition, secondary plates, spanning groups of penetrations, are bolted to the primary closure plates. These secondary plates provide a protective barrier against damage to the control rod drive penetrations from external missile sources. They also provide a holddown function to prevent separation of a penetration stub for a postulated circumferential wall failure.

To monitor outlet gas temperatures from the control, fuel, and blanket assemblies, thermocouple leads are routed through guide channels, integral with the control rod driveline guide structure, extending down to the top of the core interface plane. Each of the 19 control sud drive penetrations provide temperature monitoring for seven core assemblies. Temperature monitoring of the blanket assemblies outside the fuel boundary requires additional penetrations to accommodate instrument tree structures similar to those at the control rod locations.

\section{Upflow Plant}

The driveline extension member of the control rod drive mechanism is shorter than its downflow counterpart because of the decreased height of the upper reactor cavity plenum. The drive 
mechanism components exposed to the reactor cavity are designed for the outlet helium temperature environment.

\subsection{INSTRUMENT TREE WITH ASSOCIATED COMPONENTS}

\section{Upflow Plant}

The instrument trees for rotating plug refueling provide only temperature monitoring instrumentation guidance to the core and serve as control rod driveline guide shrouds. Thirty-seven instrument trees are required to instrument the core. Nineteen of the instrument trees serve as guide and support structures for the control rod drives. The remaining 18 installations serve only as instrumentation guides for the blanket portion of the core. The instrument trees are supported and guided by an open honeycomb type grid structure spanning the top of the core and supported on the core lateral restraint barrel (Fig. 3-14). To allow rotation of the closure plug for refueling, the grid structure is raised slightly, which also raises al1 instrument trees and drives. This is accomplished by applying lifting mechanisms to six of the outermost instrument trees. The entire installation rotates with the closure plug.
Downflow Plant

The core assemblies are retained and locked at their upper end to a grid plate. The lock and unlock operation between the core assembly and the grid plate is performed by push-puil rods. The instrument trees are integral with the core lock actuator assemblies. Sixty-seven core lock actuator assemblies are required to retain the core. Nineteen of the lock actuator assemblies serve as guide shrouds and support containment for the control rod drives, and provide temperature sensing instrumentation guide channels for these regions. The lock actuation rods are led axially upward alongside the guide shrouds containing the temperature monitoring instrument leads. Both the lock actuation rods and temperature instrumentation leads terminate near the top end of the penetrations through the upper closure plug. To provide temperature monitoring for the entire core, including the blanket assemblies, requires that 37 of the 67 lock actuation installations contain temperature monitoring instrumentation. Replacement 


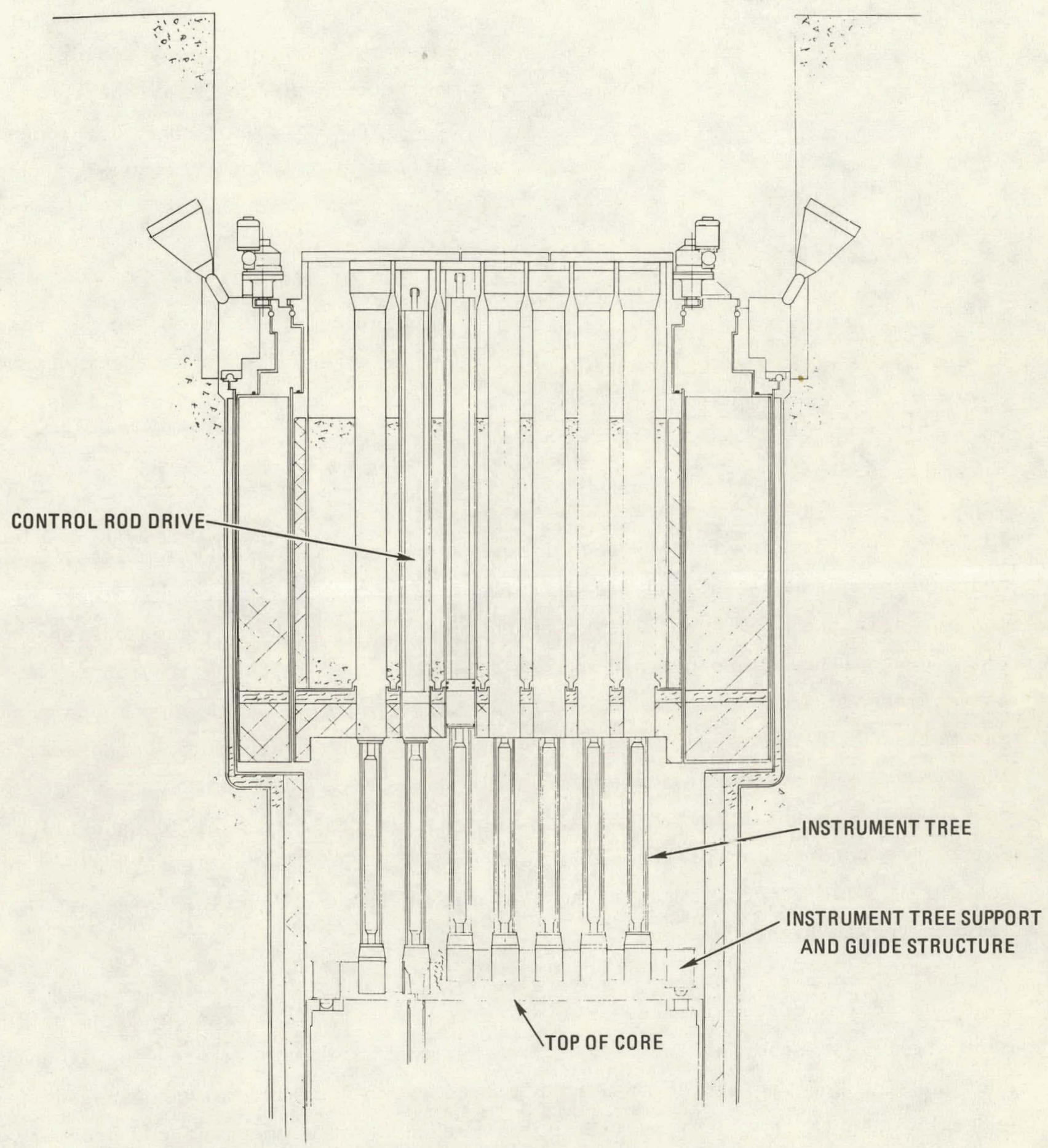

Fig. 3-14. Control rod drive and instrument tree arrangement for upflow 
capability of the temperature sensors

is a requirement because of limited life

expectancy. The temperature sensor

assembly is removable as a single ele-

ment extending from near the top end

of the penetration downward through its

instrument tree guide channel, and down

through the core assembly to the bottom

end outlet duct.

Figure 3-15 illustrates the reac-

tor arrangement showing the instrument

tree/1ock actuator installations.

\subsection{FUEL ASSEMBLY}

The reactor core is composed of fuel assemblies, blanket assemblies, control and shutdown assemblies, and radial reflector/shield assemblies. The core arrangement used in the study was similar to that contained in Ref. 4 and consisted of (1) a central fuel zone containing 127 assemblies, of which 15 are control assemblies and 4 are shutdown assemblies; (2) a radial blanket zone containing 144 assemblies in 3 rows; and (3) a reflector/shield zone containing 126 assemblies in 2 rows. The design of reflector/shield assemblies represented a new area of development, as the baseline core did not contain reflector/shield assemblies. Major core parameters for the upflow and downtlow core assemblies are given in Table 3-1. The general arrangements for the upflow and downflow cores are illustrated in Figs. 3-16 and 3-17.

The design of the fuel assemblies for the downflow core and for the upflow core are illustrated in Fig. 3-18. Both assembly designs feature a hexagonal duct housing 264 metal clad fuel rods spaced by grid spacers. Principal differences between the two designs lie in the method of attachment of the assembly to the grid plate, the location of the pressure equalization system manifold for venting fission products from the fuel rod bundle, and the location of shielding provided in the assembly. 


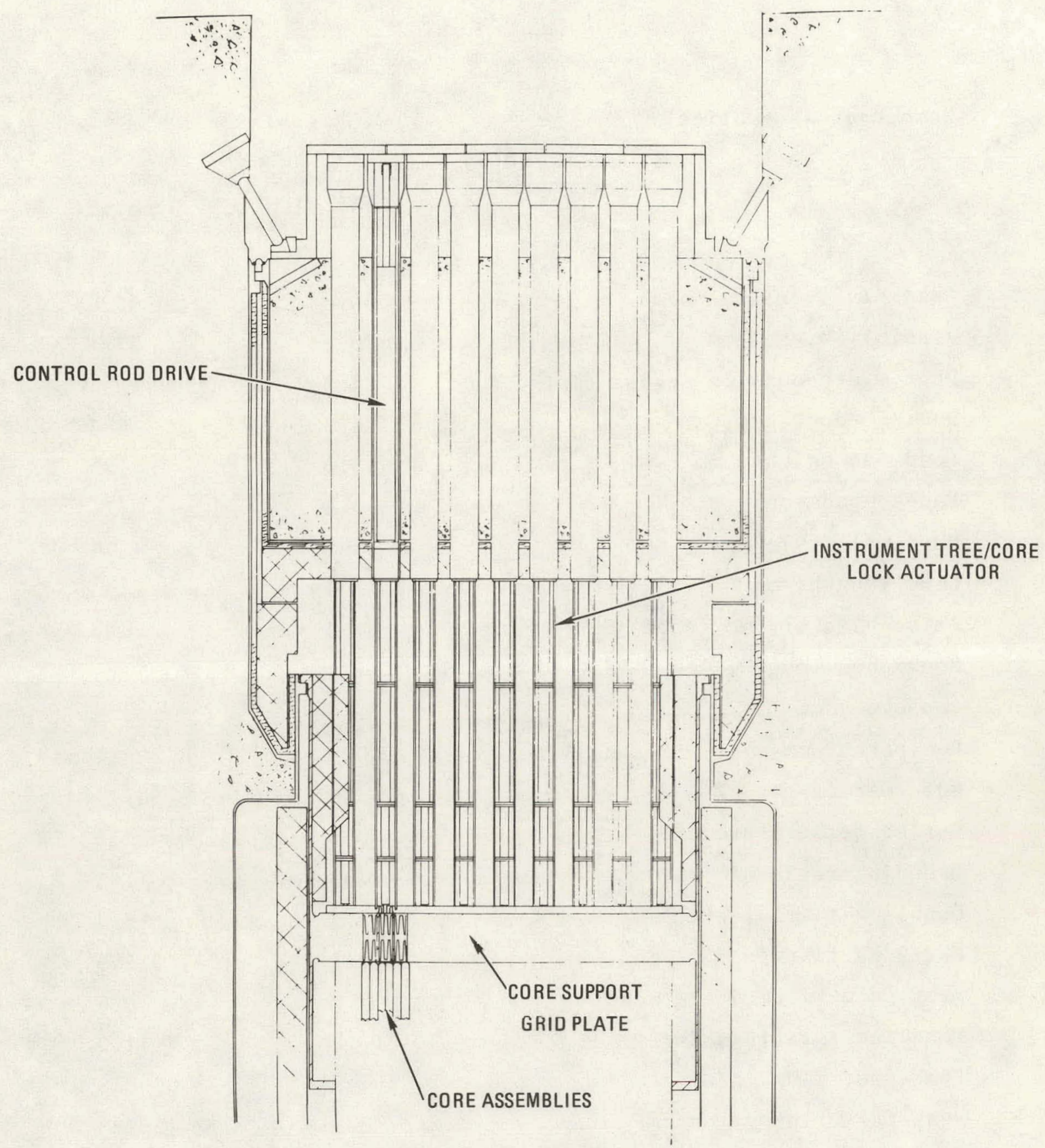

Fig. 3-15. Control rod drive and instrument tree/core lock actuator arrangement for downflow 
TABLE $3-1$

DESIGN BASIS CORE DATA FOR UPFLOW/DOWNFLOW COMPARISON

\begin{tabular}{|c|c|c|}
\hline & Upf1ow & Downflow \\
\hline Number of Assemblies & $\begin{aligned} 108 & \text { fue } 1 \\
15 & \text { control } \\
4 & \text { shutdown } \\
144 & \text { blanket } \\
126 & \text { shield - }\end{aligned}$ & $\begin{array}{r}7 \text { rows } \\
-3 \text { rows } \\
2 \text { rows }\end{array}$ \\
\hline Assemb1y overal1 length, mm & 4650.0 & 4208.0 \\
\hline Assembly pitch, mm & 190.8 & 187.1 \\
\hline Duct width outside across flats, mm & 184.0 & 180.4 \\
\hline Duct-to-duct gap, mm & 6.8 & 6.7 \\
\hline Load pad height, mm & 3.0 & 3.22 \\
\hline Pad-to-pad gap, mm & 0.8 & 0.26 \\
\hline Duct wall thickness, $\mathrm{mm}$ & 4 & 3.9 \\
\hline Core 1ength, mm & 1200 & 1130 \\
\hline Axial blanket, mm (each) & 450 & 450 \\
\hline Roughened length, \% & 75 & 75 \\
\hline Rod o.d., mm & 7.46 & 7.46 \\
\hline Rod pitch, mm & 10.6 & 10.4 \\
\hline Rod-to-duct gap, $\%$ & 51.36 & 51.36 \\
\hline Outlet temperature, ${ }^{\circ} \mathrm{F}$ & 1025 & 1025 \\
\hline Breeding ratio & 1.35 & 1.35 \\
\hline Doubling time, years & 17.5 & 16.7 \\
\hline $\mathrm{MW}(\mathrm{t}) / \mathrm{kg}$ fissile & 0.517 & 0.549 \\
\hline Average enrichment, $\%$ & 16.7 & 16.6 \\
\hline Max linear rating, $\mathrm{kW} / \mathrm{ft}$ & 11.2 & 11.9 \\
\hline Peak fast flux, $\mathrm{n} / \mathrm{cm}^{2} / \mathrm{s}$ & 2.86 E15 & $3.02 \mathrm{E} 15$ \\
\hline Peak fast fluence, $\mathrm{n} / \mathrm{cm}^{2}$ & $2.23 \mathrm{E} 23$ & 2.22 E23 \\
\hline Effective full power days & 902 & 850 \\
\hline In-pile time, actual years & 3.3 & 3.1 \\
\hline
\end{tabular}




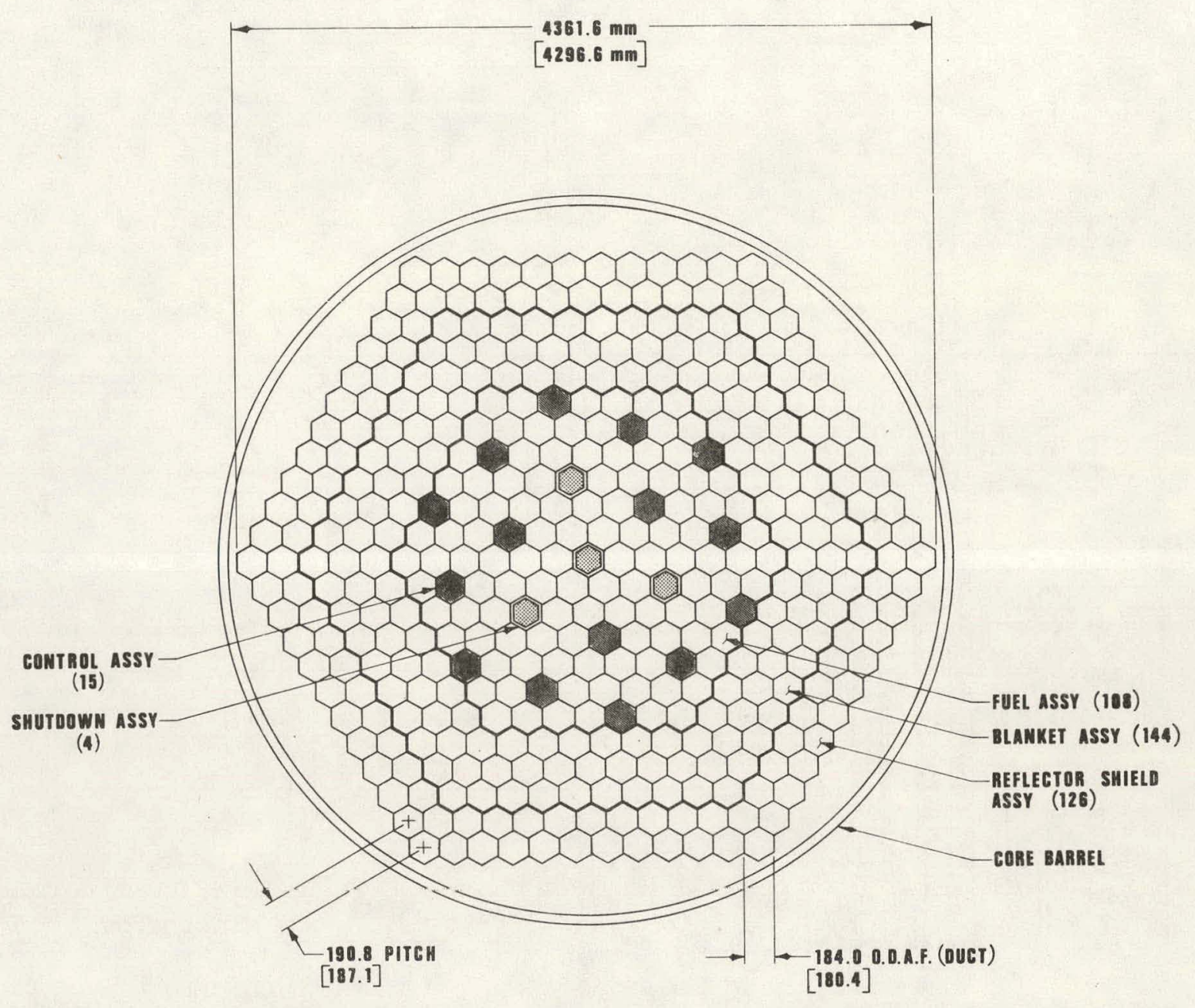

NOTE : UPFLOW CORE DIMENSIONS WITHOUT BRACKETS DOWNFLOW CORE DIMENSIONS WITH BRACKETS

Fig. 3-16. Plan view of upflow and downflow cores 


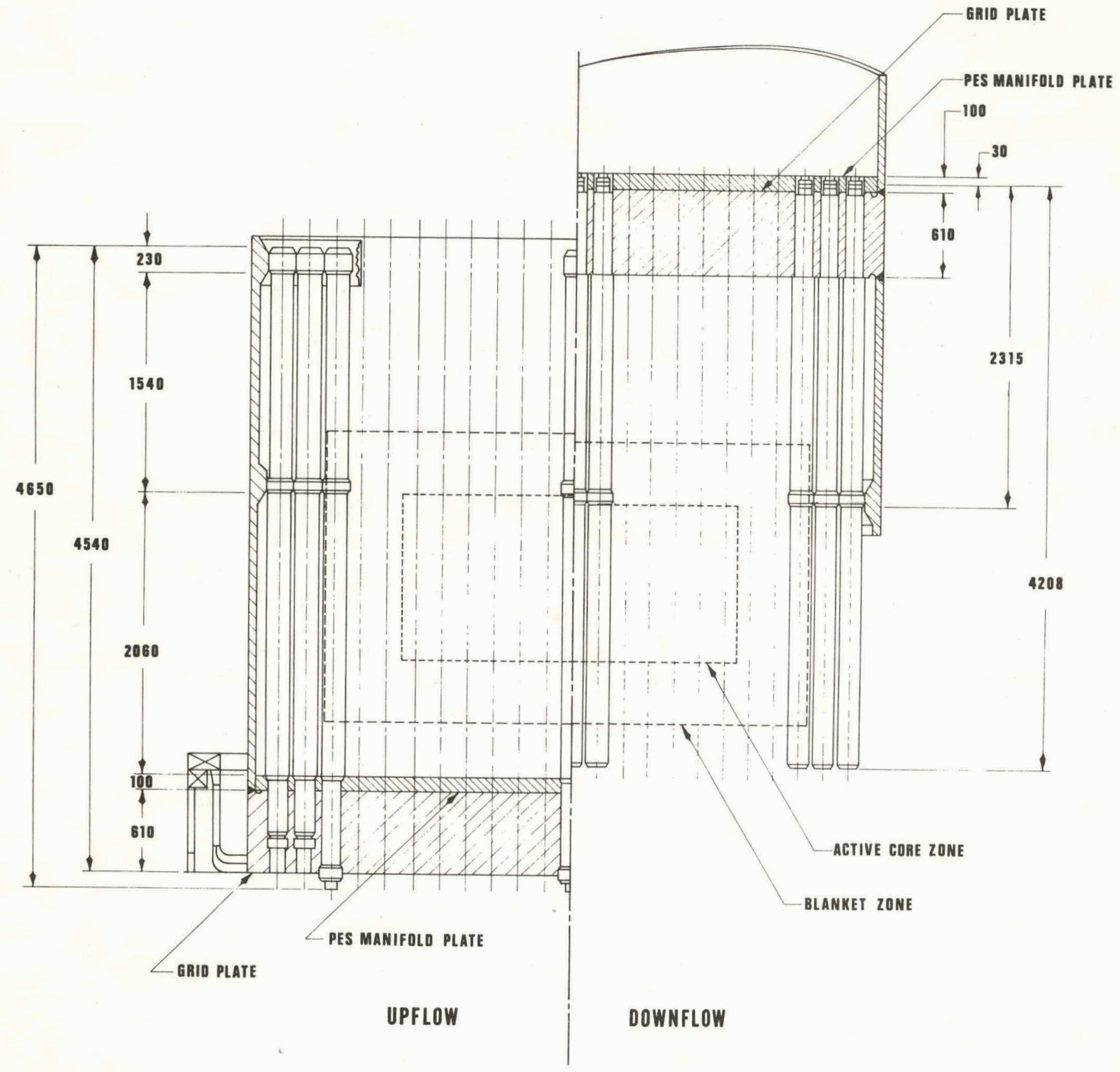

Fig. 3-17. Elevation view of upflow and downflow cores 


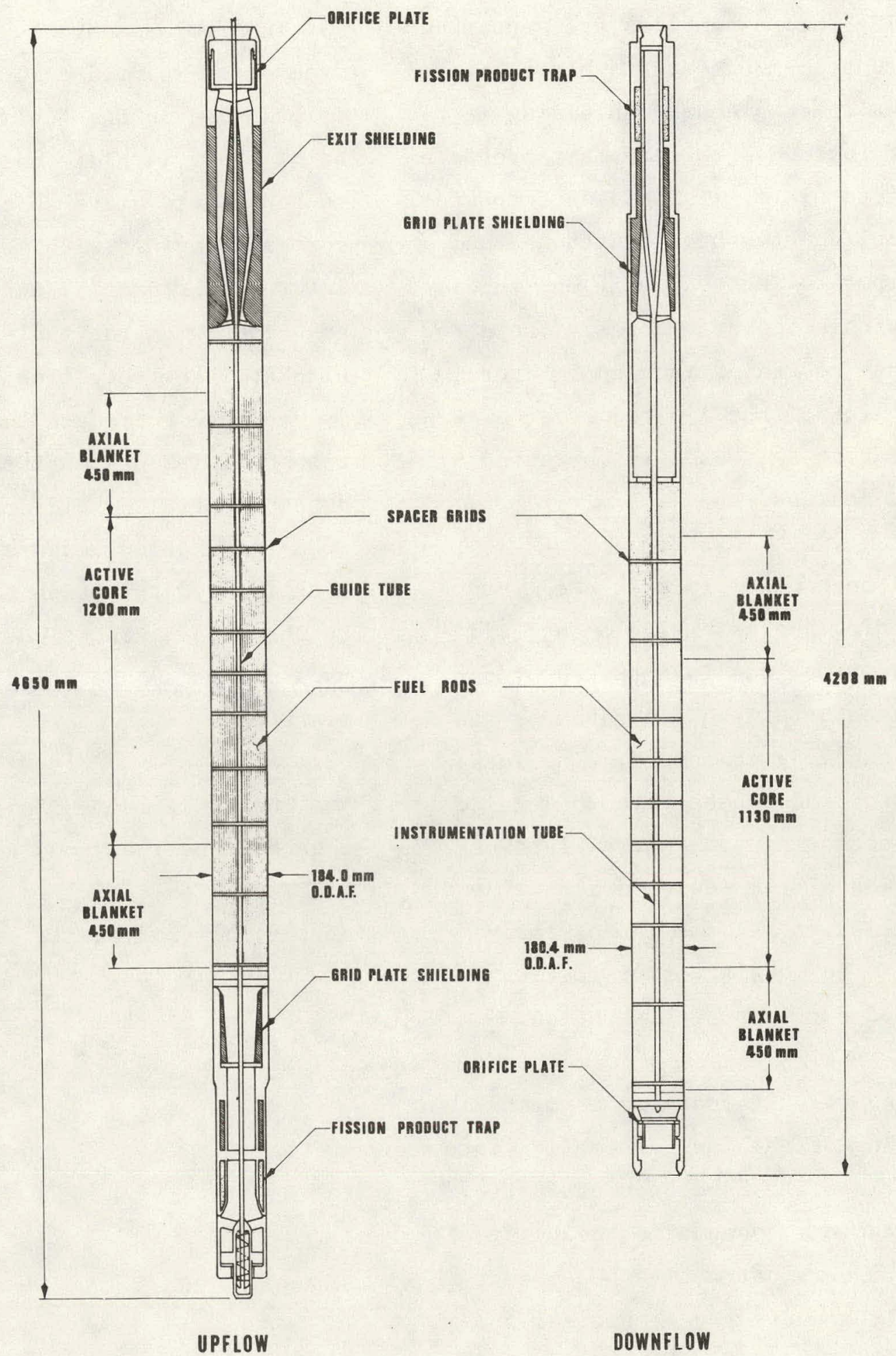

Fig. 3-18. Fuel assembly for upflow and downflow cores 


\section{Upflow Plant}

The fuel assemblies are supported by a bottom-mounted grid plate located in the inlet plenum. Shielding in the inlet region of the assembly protects the grid plate. The ducts of the fuel assemblies have been lengthened and incorporate integral exit end shielding within the assemblies. The core lateral restraint is a dual lateral restraint of the limited free bow type similar to that used in current U.S. LMFBR designs.

A mechanical lock is used for attaching the assembly to the grid plate. The lock is actuated by a "lock actuator rod" operated by the fuel handling equipment. The lock actuator rod passes through a guide tube occupying the central lattice position of the fuel rod bundle, and is pulled to release the assembly lock. The lock actuator rod is removed during plant operation.

Several alternatives to mechanical latching of the fuel assemblies into the grid plate have been evaluated. At least one, pneumatic balancing, appears very attractive because it greatly reduces the mechanical complexity of the assembly and, in particular, eliminates the need for any lock actuator rods. It is
Downflow Plant

The fuel assemblies are supported from a top-mounted grid plate. Space is provided in the fuel assemblies below the grid plate and above the core to house grid plate shielding. The core is provided with a "single point" lateral restraint at an elevation that coincides with the fuel-to-upper-axialblanket interface. The lateral restraint is designed to reduce the core seismic response without impairing duct fallaway as a potential core disruptive accident (CDA) mitigation measure. A mechanical lock is used to attach the fuel assembly to the grid plate. The lock is actuated by a mechanism operating above the grid plate.

The PES grid manifold (which manifolds. together the fuel rods for the collection of fission products) is located at the top of the fuel rod bundle. 
anticipated that such a holddown

scheme will be incorporated into the assembly design in the near future.

The PES grid manifold is located at the top of the fuel rod bundle. The rods are vented from their hot (exit) ends, rather than their cooler (inlet) ends. This is advantageous from the standpoint of venting performance, but entails considerable mechanical complexity. As a result of the mechanical complexities, a reevaluation of the grid manifold location will be performed. There is a reasonable probability that in the future the grid manifold location will be changed to the bottom of the fuel rod bundle.

\subsection{CONTROL AND SHUTDOWN ASSEMBLY}

The control assemblies are similar to the fuel assemblies, except that the central 127 fuel pins have been removed and replaced with a control rod and a control rod guide duct.

Design of shutdown assemblies was not undertaken. It is anticipated they would be somewhat similar to the control assemblies, except that the shutdown rod design would be slightly larger and the assembly would not contain any fuel rods.

\section{Upflow Plant}

The outlet end of the duct has been extended so that a withdrawn control rod can be fully contained within the control assembly. As in the fuel

\section{Downflow Plant}

Space is provided in the assemblies below the grid plate and above the core to house grid plate shielding and to contain a withdrawn control rod. 
assembly, this space has been utilized for the location of integral exit plenum shielding.

The control rod drive mechanisms are located above the core in the exit plenum.
The control rod drive mechanisms are located above the inlet plenum region with the control rod drives passing through the grid plate and into the control and shutdown assemblies. This provides a secure and positive alignment between the control rod drives and the control assemblies.

\subsection{BLANKET ASSEMBLY}

The blanket assemblies are similar to the fuel assemblies in many respects. The blanket assemblies differ from the fuel assemblies in that the blanket rod bundle consists of a smaller number of larger diameter rods than a fuel rod bundle, and is spaced by wire wrap rather than grid spacers. The PES grid manifold is located at the bottom of the blanket rod bundle.

\subsection{RADIAL REFLECTOR/SHIELD ASSEMBLY}

The radial reflector/shield assembly consists of a hexagonal stainless steel duct containing a wire-wrapped bundle of 19 cladded shield material rods. The rods are vented directly to the coolant.

Upflow Plant

A pneumatic balance-gravity holddown system is used.

\subsection{REFUELING SYSTEM}

\section{$\underline{\text { Upflow Plant }}$}

The refueling system concept is based on penetrations contained within a rotating plug assembly located in the top head of the PCRV. The
Downflow Plant

The assembly is held down by a mechanical locking system.

\section{Downflow Plant}

The in-vessel fuel handling machine operates from the central penetration in the bottom head of the PCRV, and consists of two telescoping elements. The lower 
arrangement of the rotating plug is such that when a fuel handling machine is placed over one of four penetrations, it can be axially aligned with any required core assembly. This technique provides the desirable "straight shot" approach to fuel handling, and at the same time places the fuel handling machine in a readily accessible position outside the PCRV. It also permits the application of substantial axial forces from ball screws to both withdraw and insert the core element.

The fuel handling machine is carried above the rotating plug assembly on a trolley running on a polar bridge in such a manner that the machine can be positioned over the appropriate penetration. The fuel handling machine and its functions are illustrated diagramatically in Fig. 3-19. The machine consists of two telescoping sleeves, each actuated by a pair of ball screws. An element grapple head, coupled in the inner sleeve by a latching arrangement, is carried by a secondary hoist.

For refueling, the control rod drive or instrument tree is first removed from the penctration through which access to the core is to be made element is cylindrical and is locked into the penetration during refueling. The upper element is an open-sided cylinder or U-shaped member, and incorporates a folding radial arm, a grapple assembly, and a grapple and hoist assembly. The radial arm is hinged in such a manner that it can be rotated through $90^{\circ}$ and locked in a horizontal position and supported from an assembly adjacent to the one being removed. The beam carries with it the assembly that grapples and handles the core assemblies. The grapple assembly runs on ways in the beam, is ball-screw actuated, and is driven by a motor housed in the lower cylindrical element.

The entire upper assembly is rotatable, driven also by motors in the lower element. Thus, by combined rotation of the upper assembly and translation of the grapple assembly along the beam, all assembly positions in the core, including the radial reflector/shield assemblies can be reached.

The radial arm is a twin beam configuration with the grapple assembly riding between the two beams. A rotating trunnion or turntable arrangement allows the radial arm to be folded while the grapple assembly maintains a vertical attitude. 

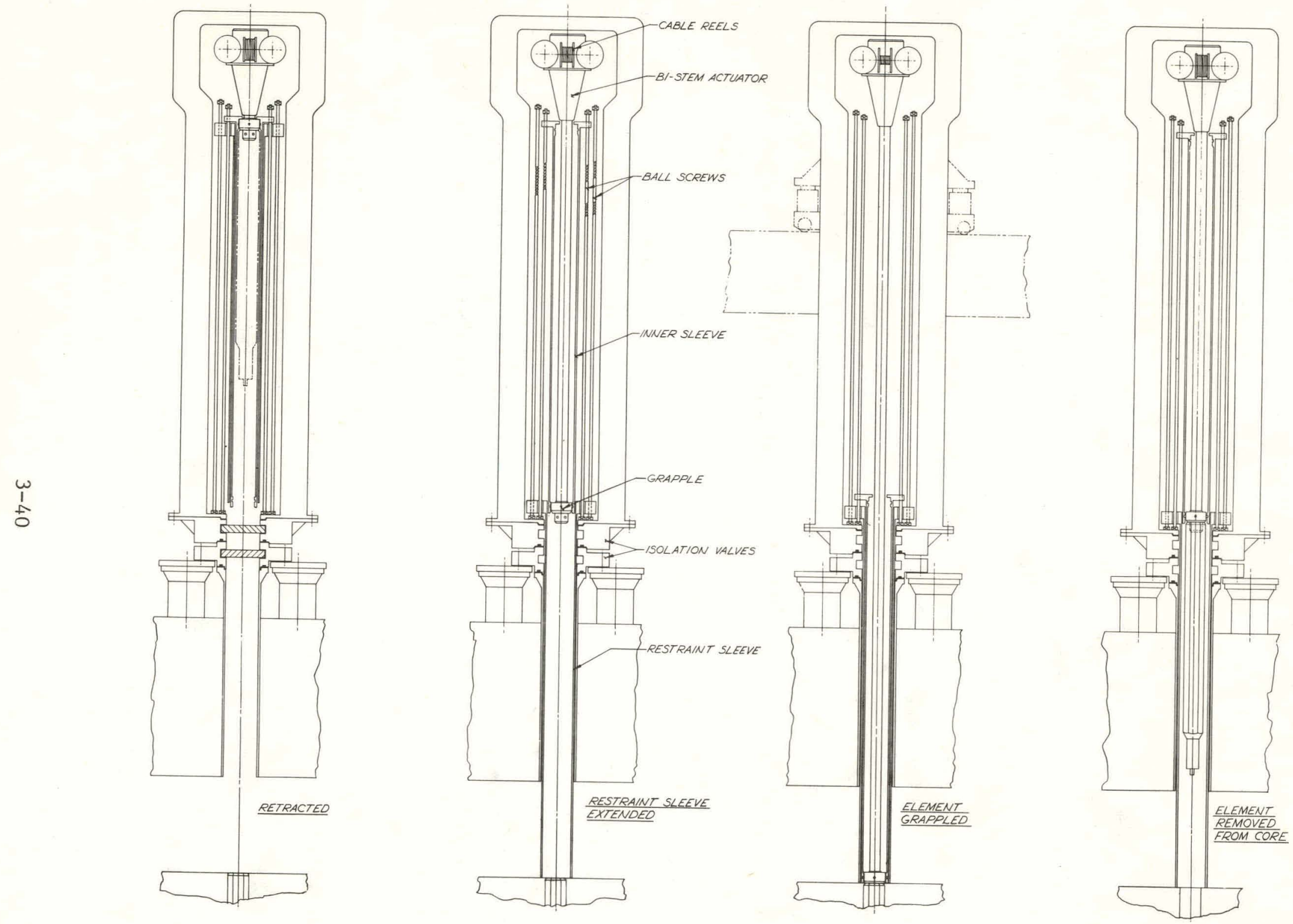

Fig. 3-19. Fuel handling machine for upflow 
and an isolation valve installed. The plug assembly is then rotated to place the axis of the penetration directly over the axis of the appropriate core element. The fuel handling machine is then moved into position and sealed to the isolation valve. Following engagement to the isolation valve and subsequent interspace purging, the outer sleeve is driven downward until it contacts the six elements surrounding the elements to be withdrawn. This restrains the adjacent elements should frictional forces develop during withdrawal, tending to raise them along with the grappled element. The outer sleeve also serves as a guide for the inner sleeve, which is next lowered into position along with the grapple head. Once the core element has been grappled, the sleeves are retracted in reverse sequence, the isolation valves closed, and the fuel handling machine disconnected.

The fuel handling machine is then moved over to an inclined transfer chute and carrier arrangement. At this position, the grapple head is uncoupled from the inner sleeve and the core element placed in a carrier and finally lowered through the inclined transfer chute directly into the storage pon 1 .
The purpose of the grapple and hoist assembly, which is attached to the top of the machine, is to regrapple and lower elements downward through the body of the machine into the fuel transfer cask below the PCRV. The assembly is pivoted on a vertical axis in such a manner that it can be rotated off center when a central fuel element is being handled.

From this point onward, the assemblies are transferred by the fuel transfer cask and the transporter to the fuel storage pool via the equipment hatch and spent fuel transfer port in a manner similar to the basic reference design.

Fig. 3-20 depicts the schematic arrangement of the in-vessel fuel handling machine and the sequence of its operation. The general arrangement of the downflow refueling system is shown in Fig. 321. 

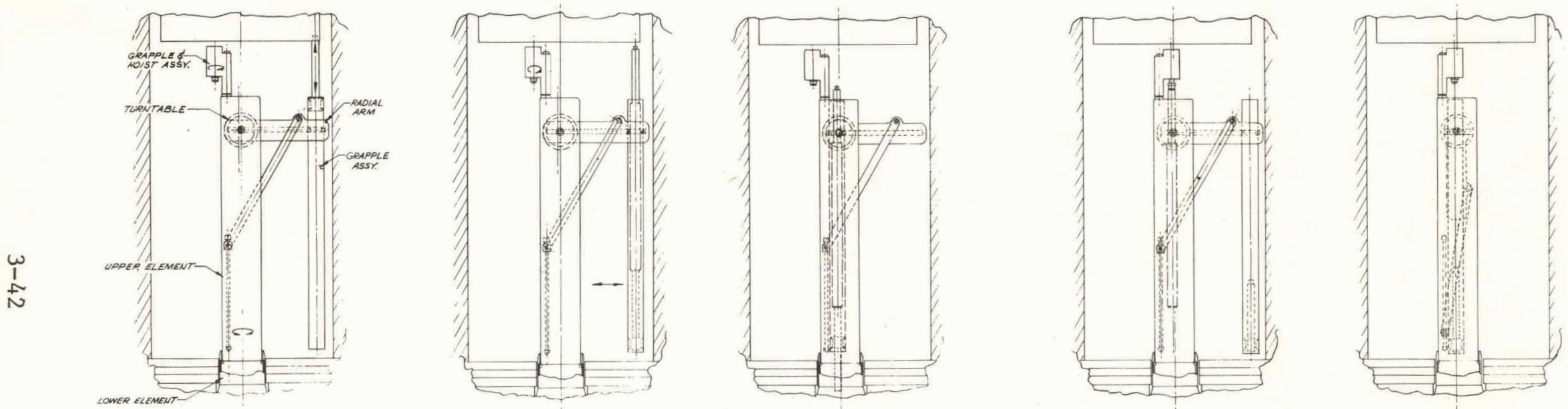

ELEMENT GRAPPLED ELEMENT WITHDRAWN

ELEMENT CENTERED

ELEMENT RE-GRAPPLED

INSTALLED POSITION

Fig. 3-20. Fuel handling machine and operational sequence for downflow 
In order to maintain the depth of water in the pool no greater than that required for shielding, an intermediate stage is introduced immediately below the PCRV (see Fig. 3-22). This takes the form of an in-place cask, which can be arranged to change the angle of inclination of the transfer chute. Means are provided to remove steam and moisture, which will be generated when a hot element is immersed in the storage pool water. The cask also provides a facility for loading new fuel in parallel with the transfer of spent fuel to the pool, thus minimizing the total replacement time required. In addition, the cask may function as a point from which a leaking fuel element may be diverted to a canning and sealing facility.

\subsection{STEAM GENERATOR}

Upflow Plant

The steam generator is a bottom-fed, top-exhaust, once-through unit with a helically wound tube bundle (Fig. 3-23). Feedwater is supplied from the bottom of the PCRV through a vertical pipe chase. It is then routed via a sideentry penetration into a single feedwater channel from where it enters the tubes. Flowing upward, in counterflow to the helium, the feedwater is converted to steam and

\section{Downflow Plant}

The steam generator is a bottom-fed, bottom-exhaust, once-through unit with a helically wound tube bundle (Fig. 3-24). Feedwater is supplied from the bottom of the PCRV through two separate penetrations. It enters the tube bundle via twin feedwater channels. Flowing upward, in counterflow to the helium, the feedwater is converted to steam and superheated. The superheated steam exits the tube bundle, turns through an 
superheated. The superheated

steam leaves the tube bundle and enters

the single steam channel, located with-

in the removable concrete plug, and

finally exits the steam generator.

Expansion loops are provided at the upper end of the tube bundle. Expansion loop tubes are routed behind a shield cone to prevent their exposure to the high-velocity, hot helium coming out of the crossduct. Both ends of the expansion loops are supported to restrict lateral seismic motions.

These supports also permit thermal expansion in the vertical direction. Low alloy steel of type 2-1/4 Cr-1 Mo is used for material of construction throughout, except for the superheater tubes, expansion loop, and superheater tubesheet. The overall helical tube bundle size is $3680 \mathrm{~mm}$ (12 ft 1 in.) diameter and $6710 \mathrm{~mm}$ (22 ft 0 in.) active length. The tube bundle and shroud assembly is bolted to the main support flange at the lower end of the tube bundle.

\subsection{CORE AUXILIARY HEAT EXCHANGER (CAHE)}

\section{Upflow Plant}

The CAHE is a once-through unit with a helically wound tube bundle, with a $2130 \mathrm{~mm}$ ( $7 \mathrm{ft} 0$ in.) diameter and $2060 \mathrm{~mm}$ (6 ft 9 in.) height (Fig. 3-25). expansion loop, and flows downward in a straight tube array. It exits the steam generator via a single steam channel located in the bottom head of the PCRV.

Low alloy steel of type $2-1 / 4 \mathrm{Cr}-1$ Mo is used for material of construction throughout, except for the superheater tubes, expansion 1oop, and superheater tubesheet. The overall helical tube bundle size is $3730 \mathrm{~mm}$ (12 ft 3 in.) diameter and $7920 \mathrm{~mm}$ (26 ft 0 in.) active length. The tube bundle and shroud assembly is bolted to the main support flange at the lower end of the tube bundle.

As in the upflow steam generator, alloy $800 \mathrm{H}$ is used for the superheater tubes and tubesheet, and the expansion loop.

\section{Downflow Plant}

The CAHE is a once-through unit with bayonet tubes. It is vertically positioned in the auxiliary cooling loop cavity (Fig. 3-26). Overall tube 


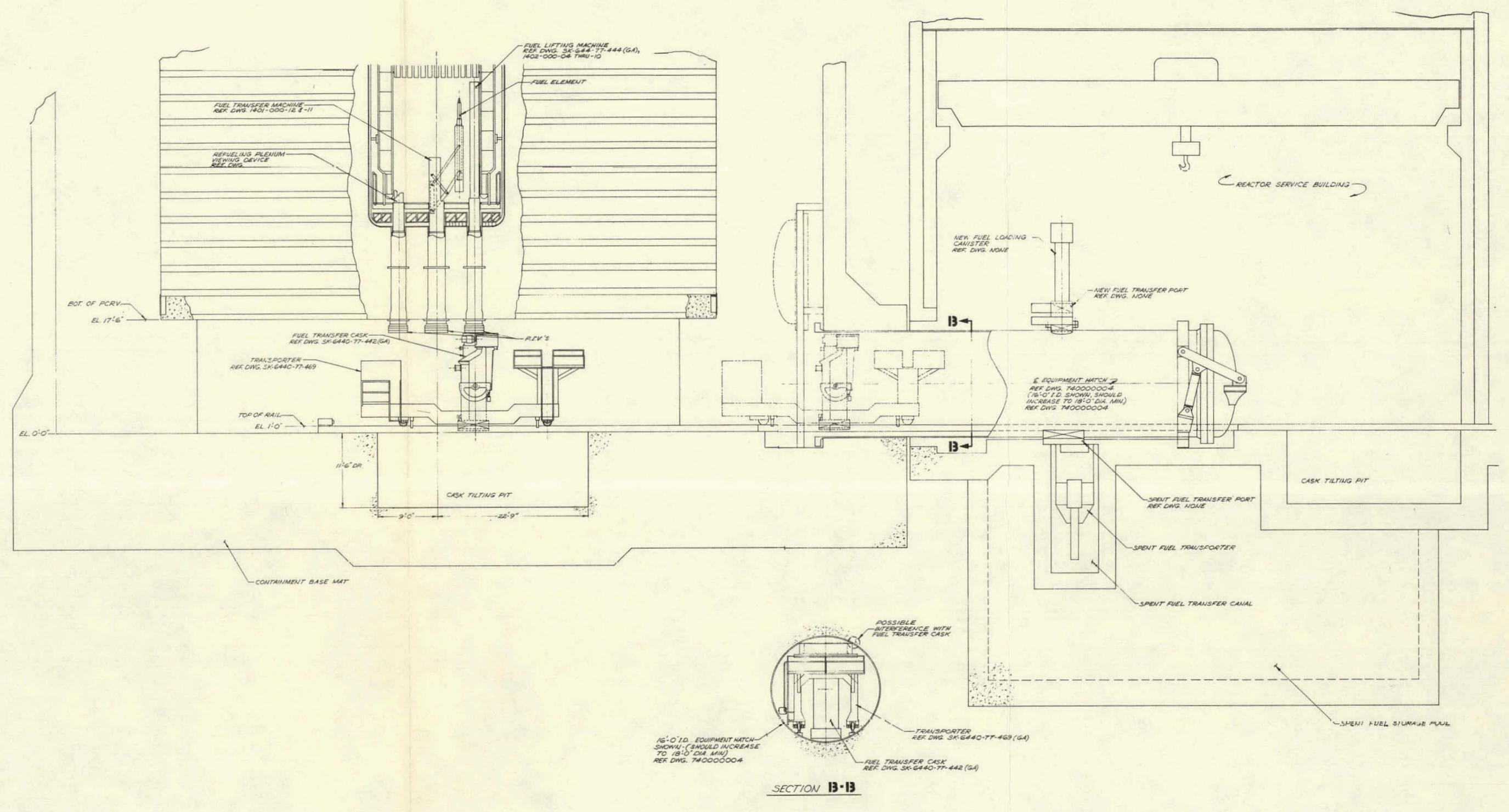

Fig. 3-21. General arrangement of downflow refueling system 
THIS PAGE

\section{WAS INTENTIONALLY LEFT BLANK}




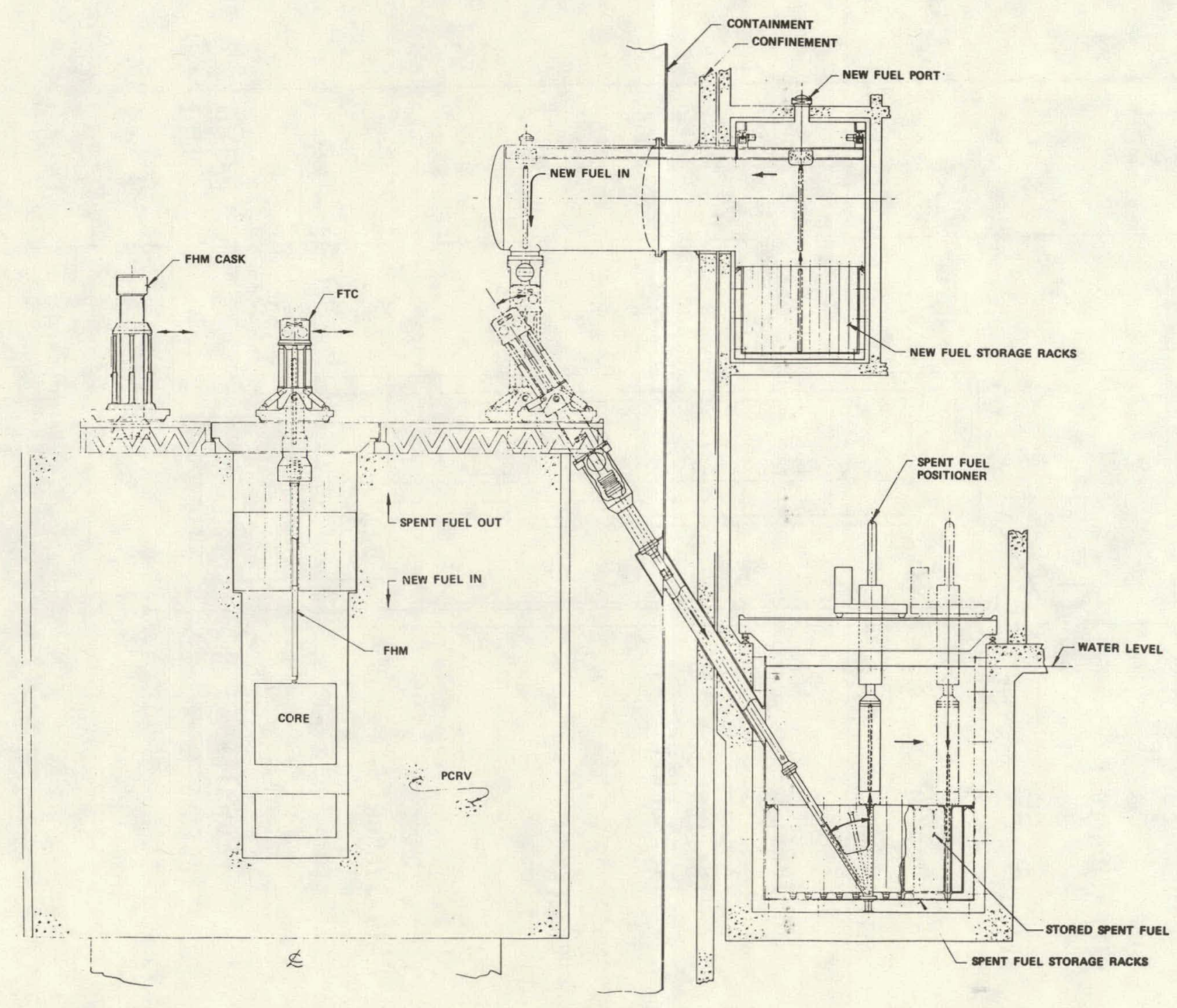

Fig. 3-22. General arrangement of upflow refueling system 


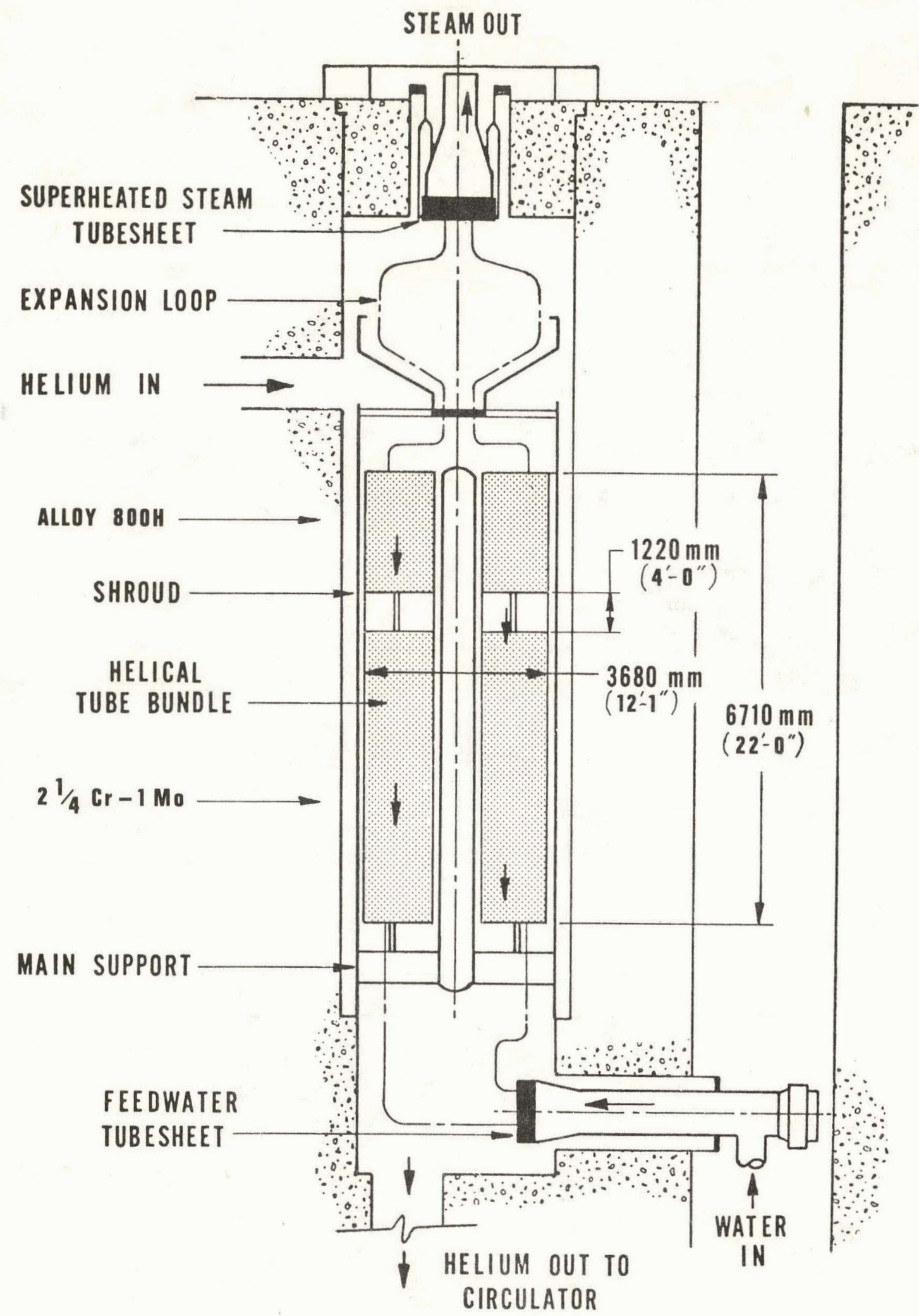

Fig. 3-23. Steam generator for upflow 


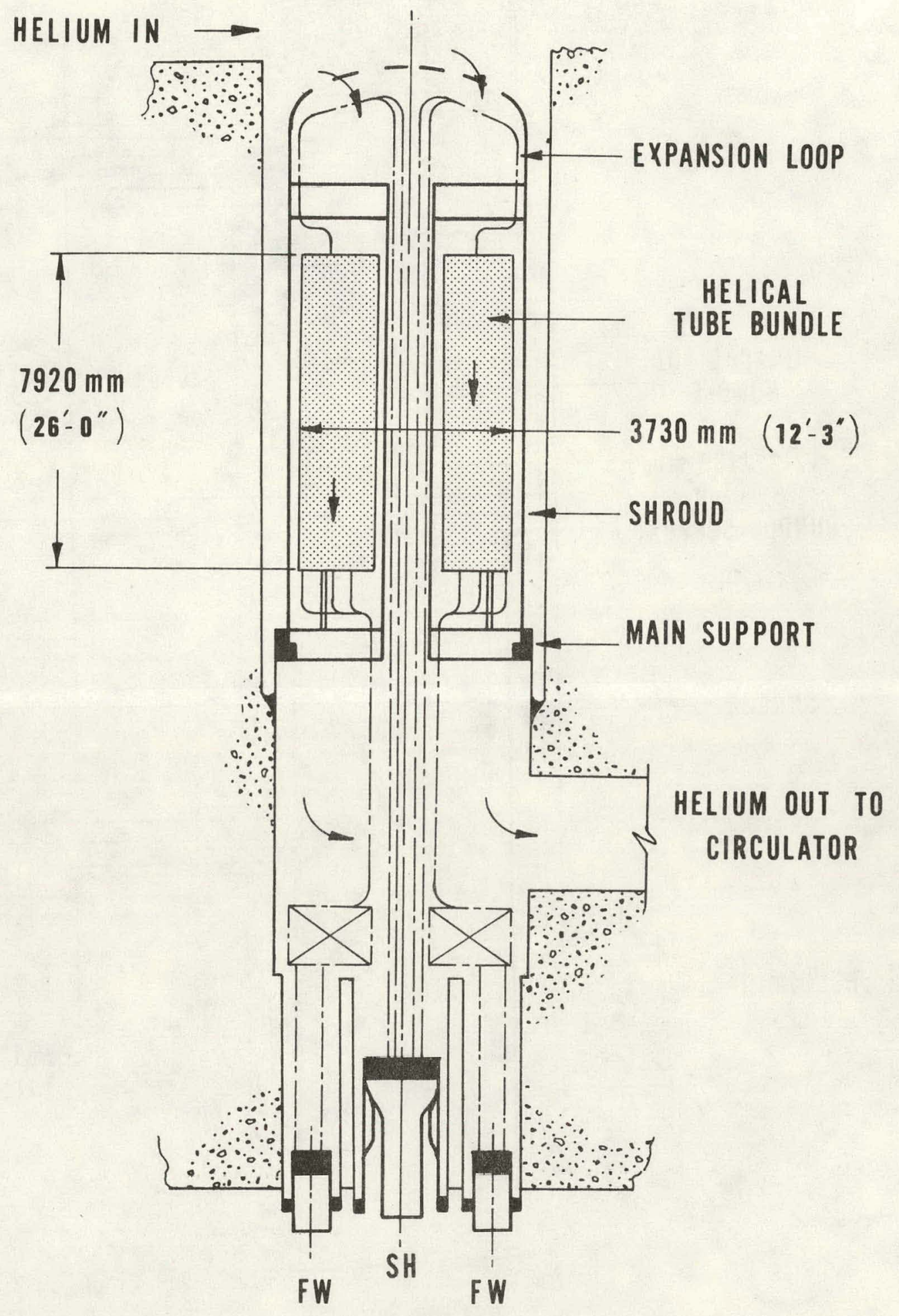

Fig. 3-24. Steam generator for downflow 


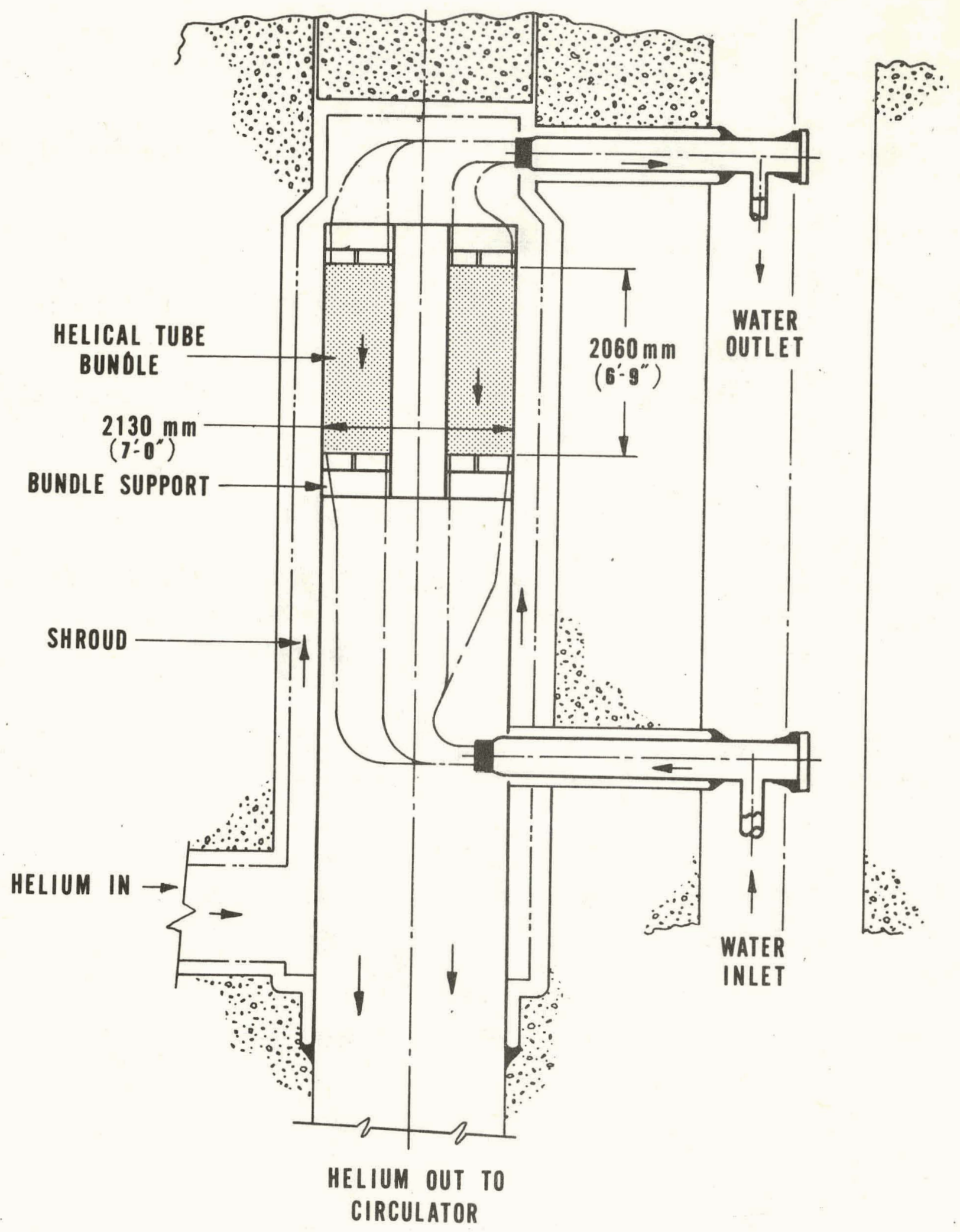

Fig. 3-25. Core auxiliary heat exchanger for upflow 


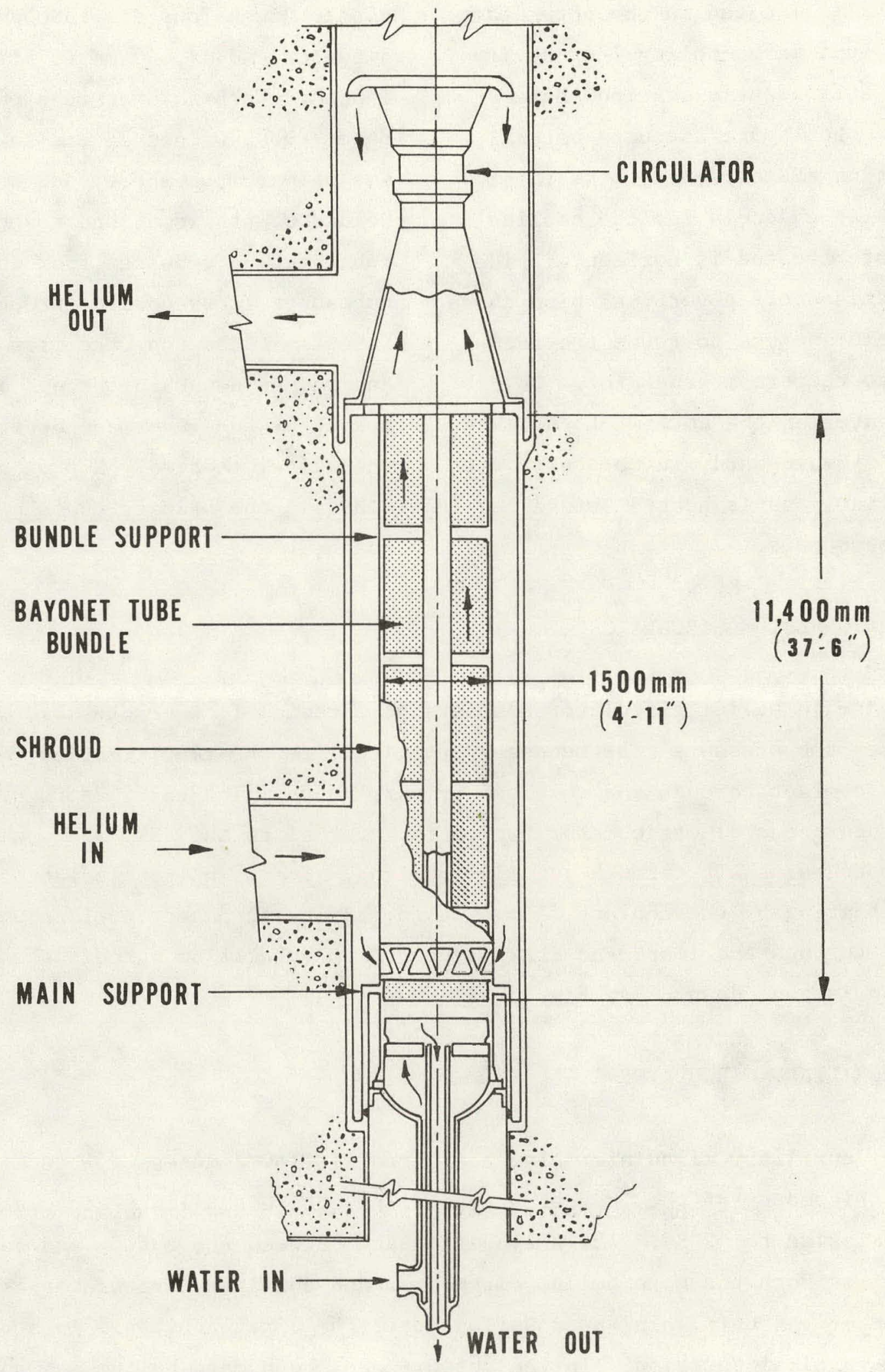

Fig. 3-26. Core auxiliary heat exchanger for downflow 
The CAHE is located in the upper part of the auxiliary cooling loop cavity and at sufficient elevation above the core to assure adequate natural convection RHR capacity. The inlet and outlet channels for the cooling water are located in horizontal side penetrations off a vertical pipe chase, which also serves to route the feedwater to the steam generator. Cold water entering the bottom of the tube bundle flows upward, in counterflow to the helium, and is heated before leaving the tube bundle. bundle dimensions are $1500 \mathrm{~mm}$ ( $4 \mathrm{ft} 11$ ir diameter and $11,400 \mathrm{~mm}$ (37 ft 6 in.) length. Each bayonet tube consists of an outer tube, welded at its lower end to the primary tubesheet, and an inner tube, . welded at its lower end to the secondary tubesheet. Feedwater from the secondary tubesheet flows upward through the inner tubes. At the top, the flow reverses and passes downward through an annulus formed by the inner and outer tubes, where it is heated. Hot water exits the CAHE via the primary tubesheet and channe1.

\subsection{MAIN HELIUM CIRCULATOR}

The main helium circulator consists of a radial flow compressor, which generates the pressure rise necessary to circulate the required flow rates of primary coolant through the core and primary loops. The circulators are driven by a synchronous electric motor, which is external to the PCRV and connected to the compressor shaft through a solid coupling. The main loop isolation valve is self-actuating by the coolant flow. It is gravity-actuated to close when there is no flow through the loop, and it will prevent reverse flow through the loop when the loop is shut down. See Fig. 3-27.

\subsection{AUXILIARY CIRCULATOR}

The auxiliary circulator also has a radial flow compressor, but is driven by an electric motor of the induction type. The entire auxiliary circulator is mounted inside the PCRV. The only difference between the upflow and downflow concept for both the main helium circulator and auxiliary circulator is the location of the unit. In the downflow core, the circulators are in a topmounted vertical position. In the upflow core, both main helium and auxiliary circulators are vertically bottom-mounted; as a result, the shaft thrust loads will be higher. 


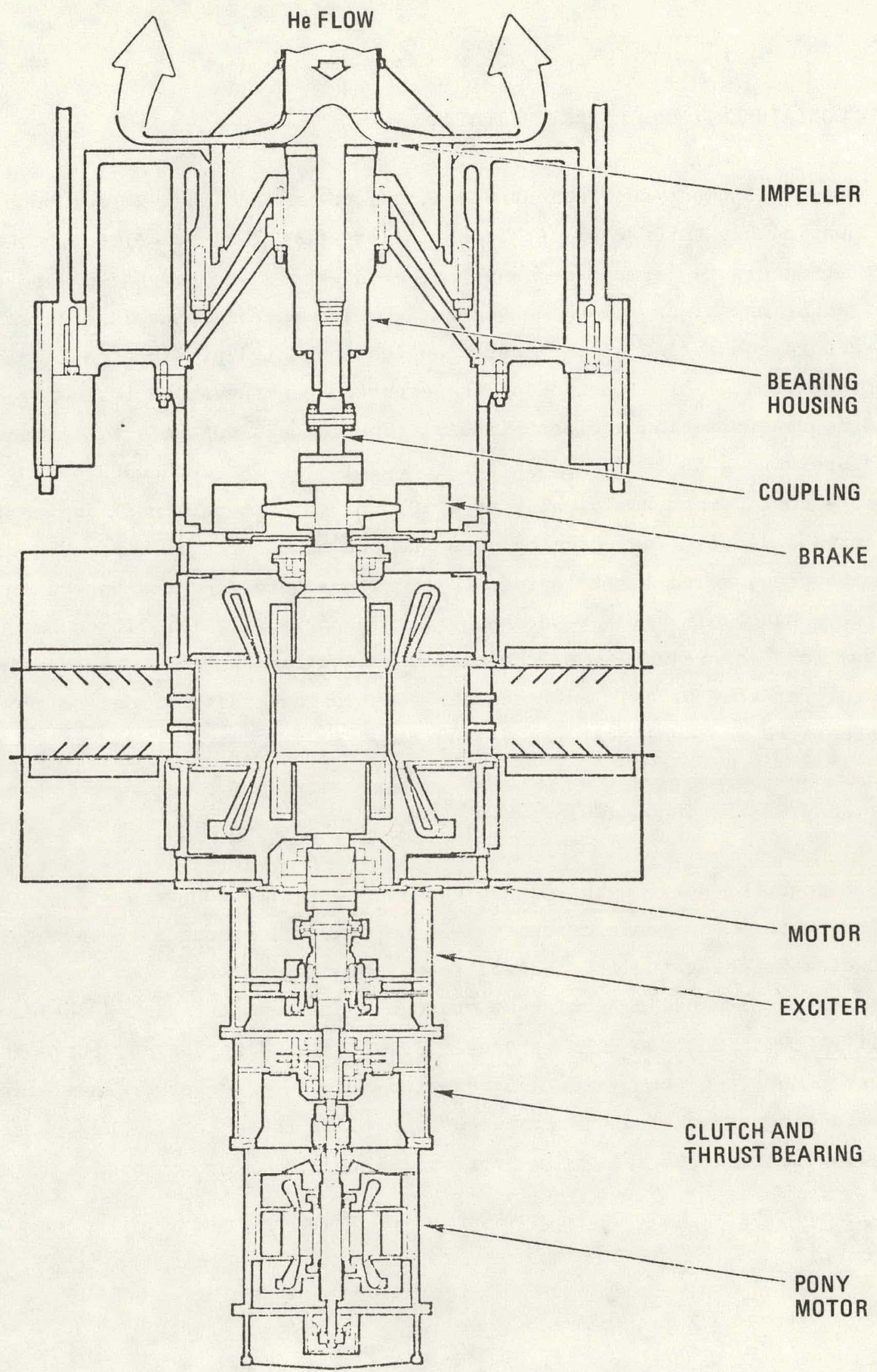

Fig. 3-27. Main helium circulator 


\subsection{CONTAINMENT/CONFINEMENT BUILDING}

The containment/confinement buildings, shown in Fig. 3-28 for both the upflow and downflow plants, are almost identical except for size. Although the upflow plant structure requires a somewhat larger diameter and height, the potential for size reduction exists. The containment/confinement building is a seismic category 1 structure consisting of an inner, low-leakage, high-pressure containment structure capable of withstanding the expected peak pressure following a design basis depressurization accident (DBDA). The containment is a free standing steel structure with a $38 \mathrm{~mm}(1-1 / 2 \mathrm{in.})$ thick wall. It is surrounded by a reinforced concrete confinement building, with a $1070 \mathrm{~mm}$ ( $3 \mathrm{ft} 6 \mathrm{in.}$ ) wall, which is designed for tornado loads. The space between the two structures is kept at a slightly negative pressure to limit leakage to the atmosphere. A cleanup system filters all the exhaust air prior to atmospheric discharge. To facilitate natural circulation for heat rejection to the ultimate sink (atmosphere), the confinement building for the upflow plant requires some design modifications to accommodate an integrated residual heat removal system.

\subsection{REACTOR SERVICE BUILDING}

The reactor service building provides the facilities required to refuel the reactor. It is a seismic category 1 structure, which houses the spent fuel pool, new fuel storage, refueling control room, shipping cask loading area, decontamination area, fuel handling equipment storage space, and irradiated fuel inspection facility. With respect to the reactor service building design, there is little difference between the upflow and downflow plants. However, refueling schemes are affecting the building arrangement. Some of these details may be seen in the refueling system description in Section 3.12 . 


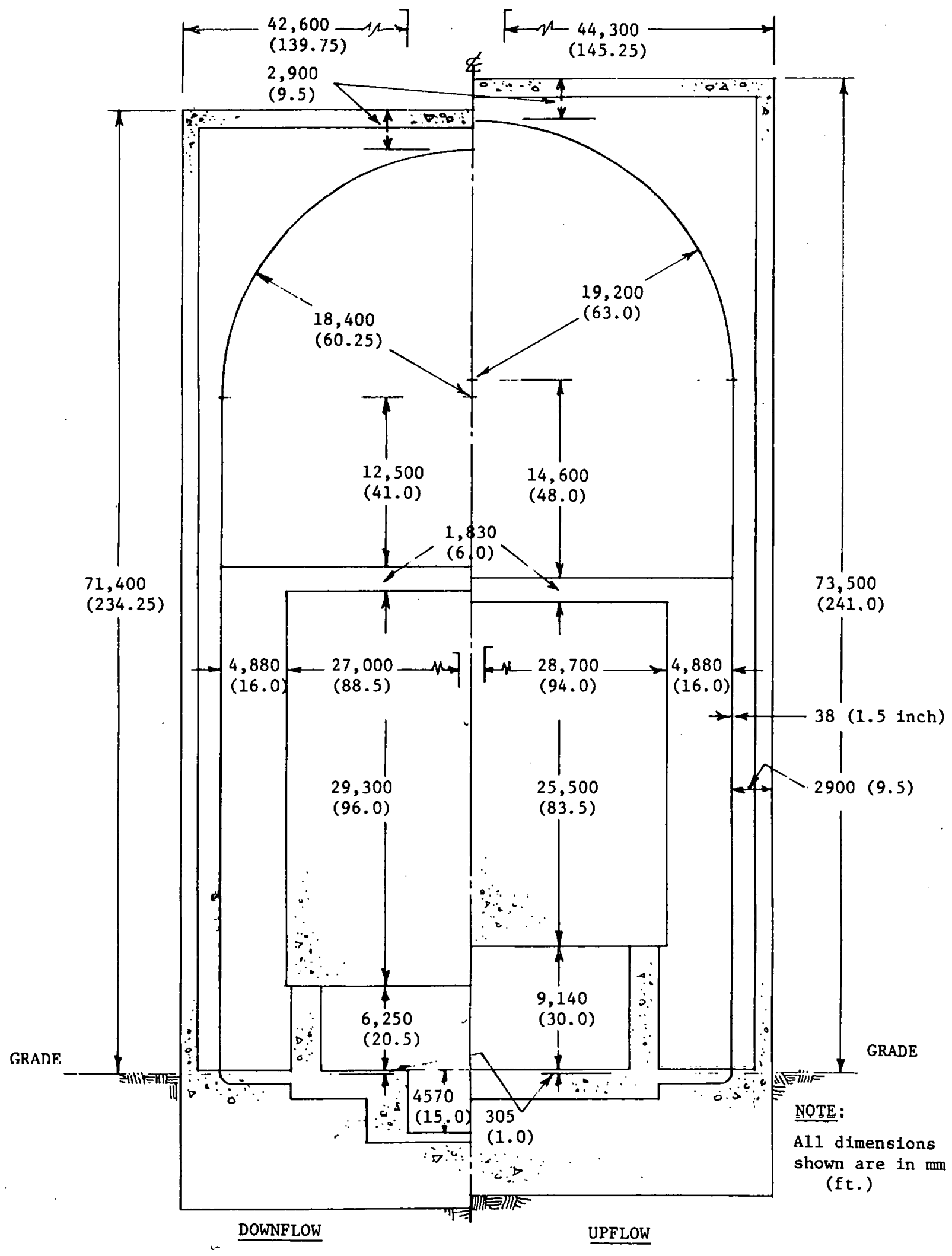

Fig. 3-28. Containment/confinement building for upflow and downflow 


\section{RESIDUAL HEAT REMOVAL BY NATURAL CIRCULATION}

The feasibility of using natural circulation under pressurized conditions for residual heat removal (RHR) from an upflow core to the ultimate heat sink, i.e., the atmosphere, was investigated. Of the various possible loop configurations of the current upflow design, natural circulation in the CACS loops has been identified as the preferred mode of operation. The PCRV arrangement shown in the interim report (Ref. 3) formed the basis for the analysis. The computer code RATSAM (Ref. 5) was used for the primary side system analysis, and a modified version of GAFTRN (MARK 4) for the water and air sides. The analysis, which also included a sensitivity assessment, covered a wide.range of postulated operating conditions. As the results it generated are too numerous to be all included in this report, only the major ones have been presented. A complete description of the natural circulation analysis and results are published in a separate report (Ref. 6).

\subsection{NATURAL CIRCULATION ANALYSIS}

From the onset of the investigation, it has been realized that this would only be a scoping analysis to check the potential of using natural circulation for RHR operation. The PCRV arrangement used for this analysis is shown in Fig. 4-1. The PCRV arrangement resulting from the GA/KWU design convergence effort (see Fig. 3-4) is considerably less attractive from a natural circulation point of view. Neither of the two designs was designed for natural circulation per se. If the recommendation to change to an upflow core is adopted, a new PCRV arrangement following specific guidelines to assure maximum utilization of natural circulation RHR from core to atmosphere will be required.

The PCRV arrangement shown in Fig. 4-1 has an elevation difference of $9540 \mathrm{~mm}(31 \mathrm{ft})$ and $4570 \mathrm{~mm}(15 \mathrm{ft})$ between the midpoints of the active core 


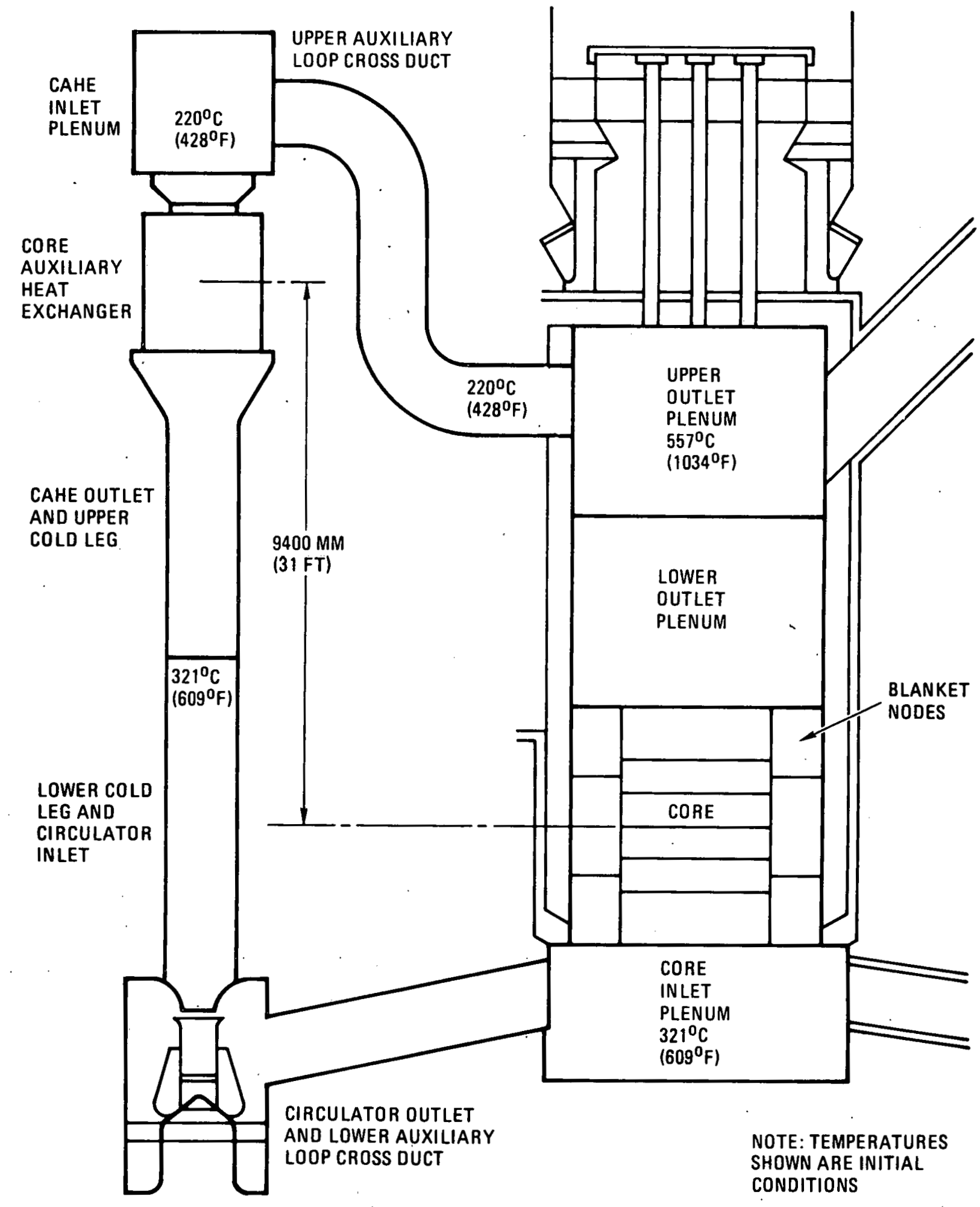

Fig. 4-1. Core auxiliary cooling loop model 
and the CAHE and steam generator, respectively. It is assumed that the loop isolation valves of the main and auxiliary cooling system are gravityactuated. During normal operation, the pressure head of the main helium circulator keeps the main loop isolation valves open and the auxiliary loop isolation valves closed. At the end of main helium circulator coastdown, if all forced circulation capability is lost, the main loop isolation valves are closed and the auxiliary loop isolation valves are opened by gravity. The set points of these valves are such that at above $5 \%$ main helium circulator speed, they maintain their normal operating position. Below this speed (in about 90 seconds) the pressure head diminishes sufficiently for gravity to initiate change of all loop isolation valves into their natural circulation position.

The sequence of events leading to initiation of natural circulation RHR in the auxiliary cooling loops commences with the loss of all electric power to the main helium circulators with concurrent reactor scram. It is assumed that all forced circulation capability of the main helium circulator motors and pony motors is lost, and that the auxiliary circulators fail to start. The primary system remains pressurized.

The key design parameters used in the natural circulation analysis as well as some initial CACS standby conditions are given in Appendix $C$. The natural circulation analysis using CACS loops is performed in two parts:

1. Natural circulation on the helium side was evaluated assuming forced circulation on the water and air sides was available.

2. The boundary conditions of natural circulation helium flow and inlet temperature were provided to the CAHE, and the natural circulation capability of the water and air sides was evaluated.

\subsubsection{Case 1: Primary Coolant Natural Circulation}

For this case, natural circulation becomes established very rapidly. After loss of power and reactor scram, the three main helium circulators 
coast down. At about 90 seconds after scram, the main loop isolation valves start closing. At 91 seconds, the auxiliary loop isolation valves are fully open. Three seconds after opening the auxiliary loop isolation valves, the flow in the core rises from practically zero to $3 \%$ of its normal design flow. This rapid initiation of CACS natural circulation limits the peak cladding temperature to $649^{\circ} \mathrm{C}\left(1200^{\circ} \mathrm{F}\right)$ in the maximum-powered fuel rod and to $1144^{\circ} \mathrm{C}$ $\left(2091^{\circ} \mathrm{F}\right)$ in the maximum-powered blanket rod; both peak temperatures, which include the hot spot factor, occur approximately 130 seconds after accident initiation. The temperature histories of the fuel and blanket assembly are shown in Fig. 4-2; the core outlet temperature history is shown in Fig. 4-3. There are some indications that a more sophisticated approach, i.e., using a detailed subchannel analysis rather than unit cell calculations, will reduce the temperature of the maximum-powered blanket rod by approximately 165 to $220^{\circ} \mathrm{C}\left(300\right.$ to $400^{\circ} \mathrm{F}$ ) and increase the maximum-powered fuel rod temperature by about 55 to $85^{\circ} \mathrm{C}\left(100\right.$ to $\left.150^{\circ} \mathrm{F}\right)$.

The rapid initiation of natural circulation in the auxiliary cooling loops is due to the low helium fluid inertia and also due to a somewhat favorable temperature profile established in the CACS loops during normal power operation. During normal plant operation and main helium circulator coastdown, the core pressure drop causes a leakage flow through the closed auxiliary loop isolation valves. As the cold helium from the core inlet plenum flows upward to the core outlet plenum, it passes across the CAHE tube bundles, where parasitic heat losses to the water reduce the helium temperature further. The difference in density between the cold helium in the auxiliary cooling loops and hot helium in the core cavity establishes a downward driving force in the auxiliary cooling loops, which with the opening of the auxiliary loop isolation valves initiates CACS natural circulation.

This analysis bears out the previous expectation that despite good fuel performance the blanket assemblies are limiting during a natural circulation cooling event. The reason for this is that during low flow, as in a shutdown condition, the flow shifts to the core because of its relatively low flow resistance. However, the power in the blanket does not decay as rapidly 


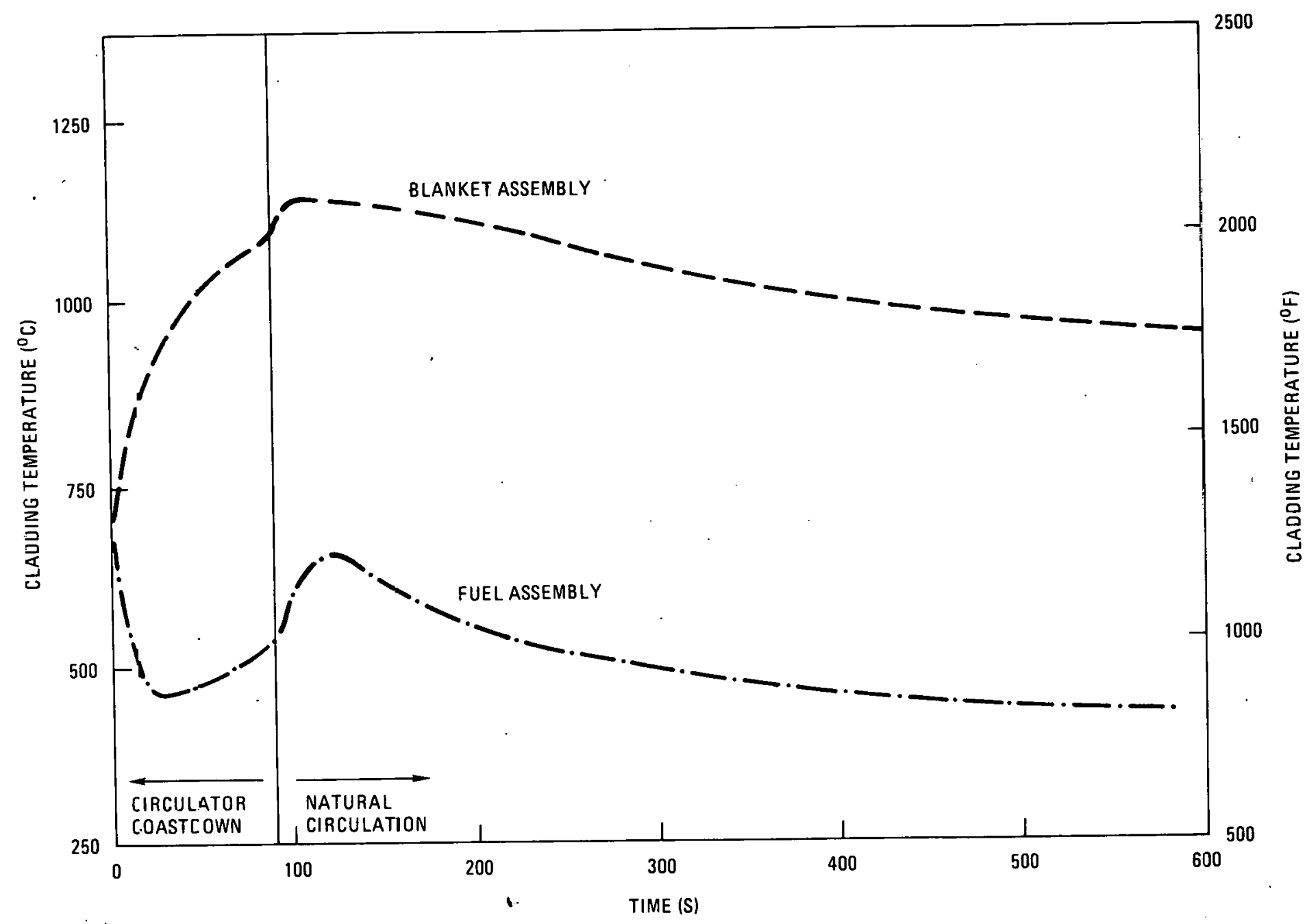

Fig. 4-2. Temperature history of maximum-powered fuel and blanket assembly (case 1) 


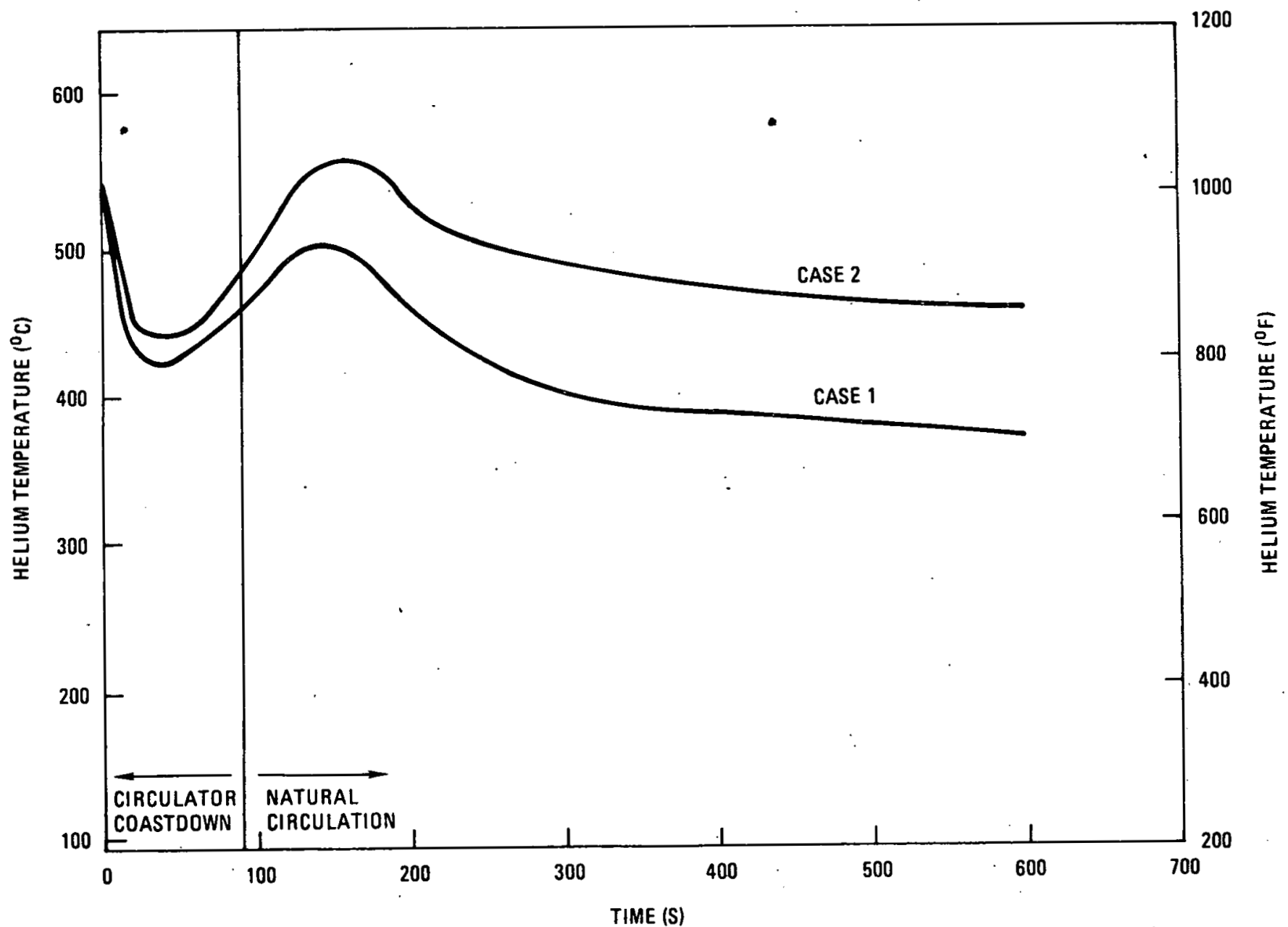

Fig. 4-3. Core outlet temperature history 
as the power in the core because the breeding products decay at a slower rate than the fission products. The overall effect is a distortion of the powerto-flow ratio. Because of the steep radial power gradient in the blanket assemblies, most of the blanket rods are more than adequately cooled. Only. the maximum cladding temperatures of the high-powered rods approach faulted limits. This is considered a generic problem equally applicable to the design basis depressurization accident. It is expected that a blanket assembly design modification will eventually overcome this performance limitation.

Of the many cases and conditions investigated, two were of major concern with regard to their effect on natural circulation performance of the auxiliary cooling loops: (1) transfer time from main to auxiliary cooling loops, and (2) failure of main loop isolation valves to close.

Transfer time from main to auxiliary cooling loops, by closing and opening of the appropriate gravity-actuated loop isolation valves, is closely related to a specific valve design. The results of an analysis indicate, as shown in Table 4-1 and Fig. 4-4, that within a reasonable time period peak cladding temperatures are not a strong function of transfer time. Transfer time thus does not appear to be too critical and may be adjusted to meet valve and circulator design requirements, e.g., required pressure drop and pressure drop margins to assure reliable loop isolation valve operation.

Failure of all three main loop isolation valves to close upon transfer to auxiliary cooling loop operation results in somewhat higher peak fuel and blanket rod temperatures (see Table 4-1 and Fig. 4-5). The failure of the main loop isolation valves to shut after loop transfer has thus only a moderate effect on maximum cladding temperatures. Buoyancy forces tend to limit the amount of bypass through the main cooling loops. The reason for this is that the main cooling loops are relatively colder than the core. As the steam generators continue to cool off, self-isolation of the main cooling loops occurs. 
TABLE 4-1

MAXIMUM CLADDING TEMPERATURES FOR

NATURAL CIRCULATION COOLING IN THE CACS

(MAXIMUM POWERED AND WITH HOT SPOT FACTORS)

\begin{tabular}{l|c|c}
\hline & Fuel Assembly & Blanket Assembly \\
\hline Case 1 & & $1166^{\circ} \mathrm{C}\left(2130^{\circ} \mathrm{F}\right)$ \\
Loop transfer at $50 \mathrm{~s}$ & $657^{\circ} \mathrm{C}\left(1215^{\circ} \mathrm{F}\right)$ & $1144^{\circ} \mathrm{C}\left(2091^{\circ} \mathrm{F}\right)$ \\
$\begin{array}{l}\text { Loop transfer at } 90 \mathrm{~s} \\
\text { (base case) }\end{array}$ & $649^{\circ} \mathrm{C}\left(1200^{\circ} \mathrm{F}\right)$ & $1210^{\circ} \mathrm{C}\left(2210^{\circ} \mathrm{F}\right)$ \\
$\begin{array}{l}\text { Loop transfer at } 180 \mathrm{~s} \\
\begin{array}{l}\text { Main loop isolation } \\
\text { valves fail to close }\end{array}\end{array}$ & $691^{\circ} \mathrm{C}\left(1276^{\circ} \mathrm{F}\right)$ & $1170^{\circ} \mathrm{C}\left(2138^{\circ} \mathrm{F}\right)$ \\
$\begin{array}{l}\text { Case 2 } \\
\begin{array}{l}\text { Natural circulation to } \\
\text { ultimate heat sink }\end{array}\end{array}$ & $699^{\circ} \mathrm{C}\left(1291^{\circ} \mathrm{F}\right)$ & $1248^{\circ} \mathrm{C}\left(2278^{\circ} \mathrm{F}\right)$ \\
\hline
\end{tabular}

Temperature Limits:

$\begin{aligned}\left.700^{\circ} \mathrm{C} 1292^{\circ} \mathrm{F}\right) & \text { Normal operating condition } \\ 800^{\circ} \mathrm{C}\left(1472^{\circ} \mathrm{F}\right) & \text { Upset condition } \\ 980^{\circ} \mathrm{C}\left(1796^{\circ} \mathrm{F}\right) & \text { Emergency condition } \\ 1260^{\circ} \mathrm{C}\left(2300^{\circ} \mathrm{F}\right) & \text { Faulted condition }\end{aligned}$




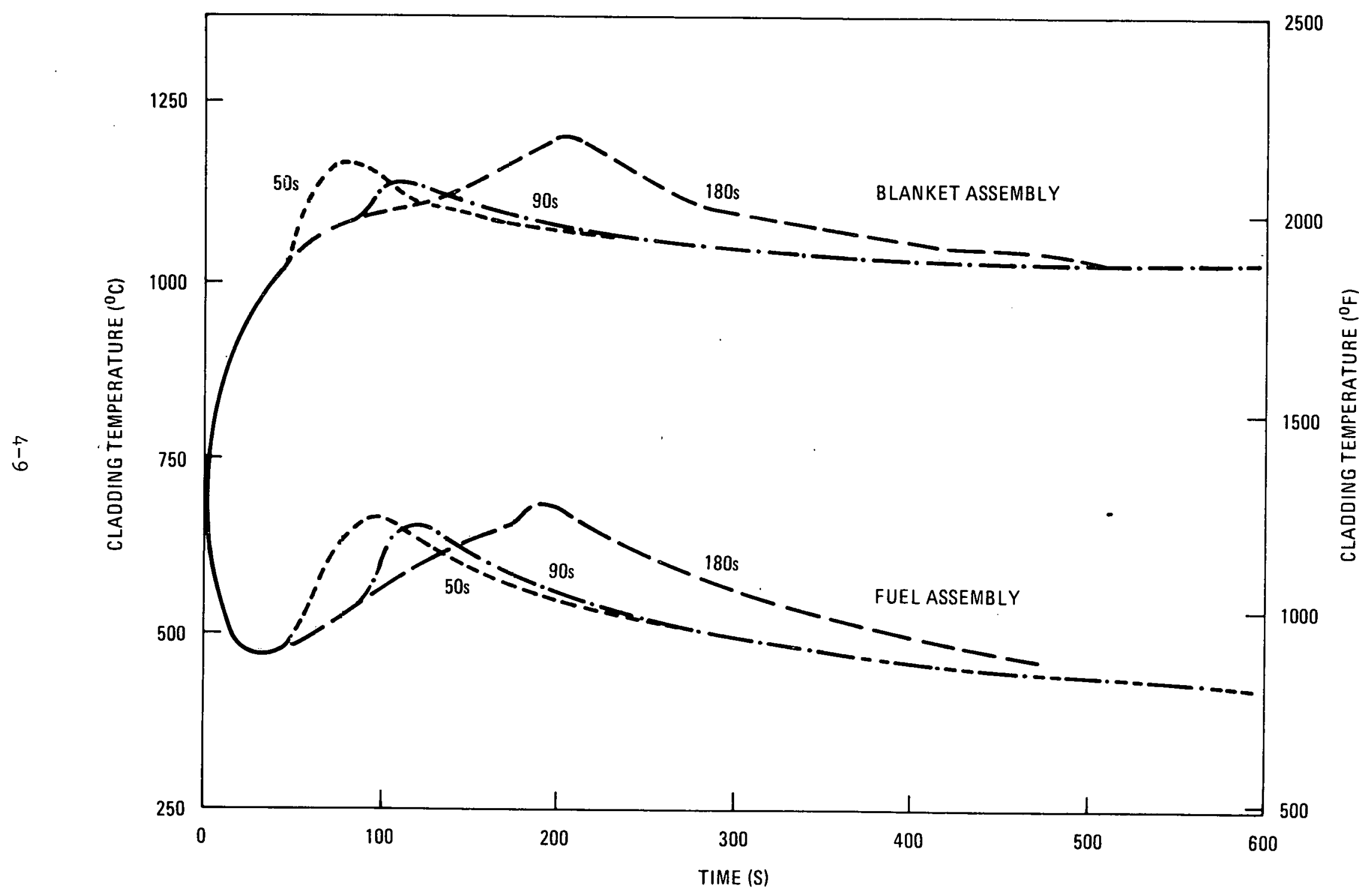

Fig. 4-4. Maximum cladding temperature as a function of loop transfer time (case 1), 


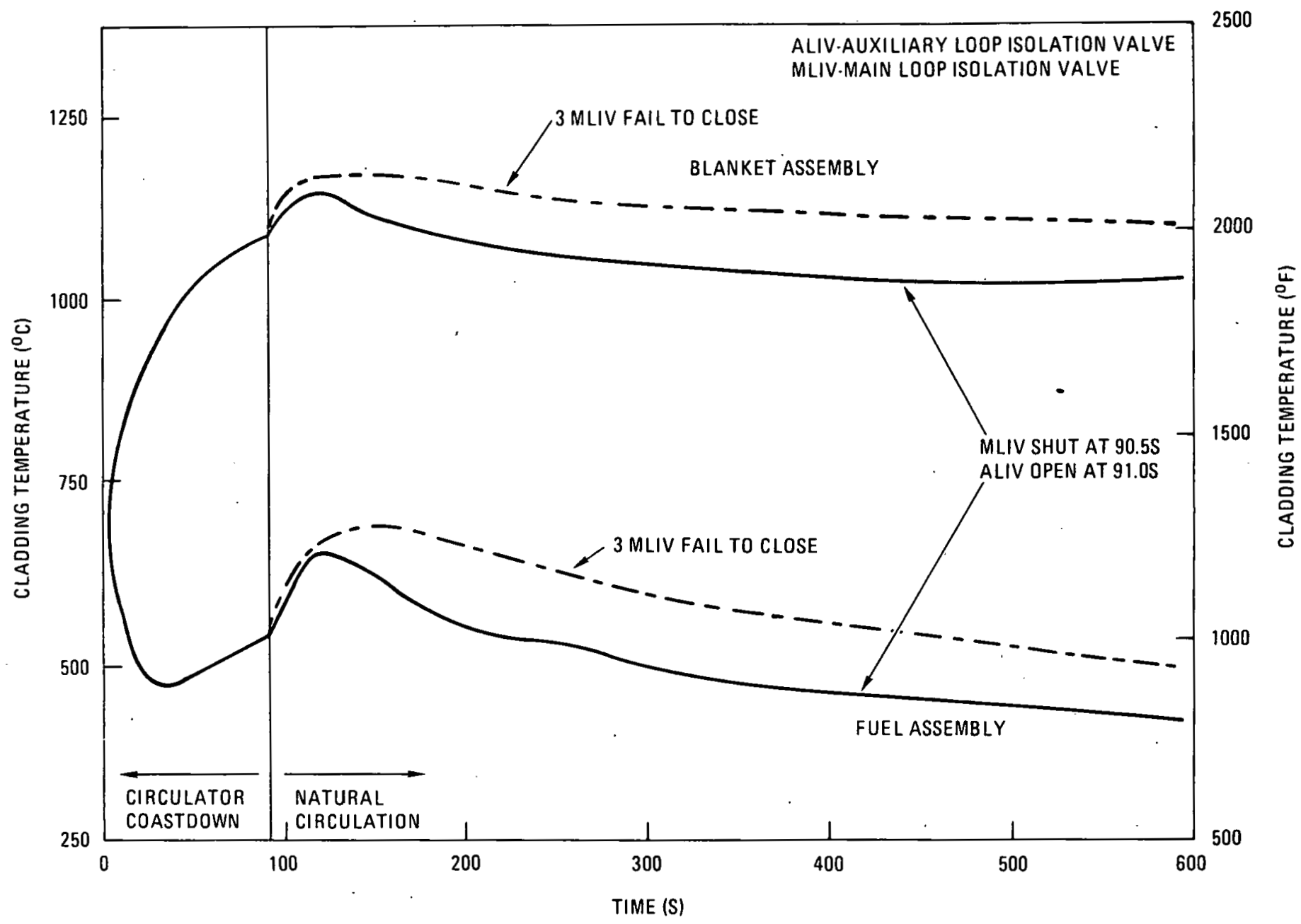

Fig. 4-5. Effect of loop isolation valve malfunction on maximum cladding temperature (case 1) 


\subsubsection{Case 2: Natural Circulation RHR}

A CACS design featuring natural circulation RHR from the core to the ultimate heat sink was analyzed to determine the necessary configuration and expected performance of a natural circulation backup system on the water and air sides. For this system to be effective, the density differential between the hot and cold legs of the working fluid - helium, water, and air - must be large enough during all anticipated operating conditions. The required elevation differences between the components of this heat transfer chain core, CAHE, and air loop cooler (ALC) - are shown in Fig. 4-6.

Because no integral computer code was available to simulate this configuration, the analysis was an iteration process between natural circulation calculations on the helium side, using RATSAM, and natural circulation calculations on the water and air sides, using AUXTRN (Ref. 7).

The initial phase of the accident, i.e., loss of power, reactor scram, and start of natural circulation on the helium side, is assumed to be identical and in the same time frame as case 1. However, for case 2 it is postulated that upon transfer from the three main cooling loops, one auxiliary loop isolation valve fails to open so that only two auxiliary cooling loops are available. The results of the analysis, summarized in Table 4-1, show a peak fuel rod and peak blanket rod temperature for the maximum powered rnds of $746^{\circ} \mathrm{C}\left(1375^{\circ} \mathrm{F}\right)$ and $1248^{\circ} \mathrm{C}\left(2278^{\circ} \mathrm{F}\right)$, respectively. The temperature histories of the fuel and blanket assembly are shown in Fig. 4-7; the history of the core outlet temperature is shown in Fig. 4-3.

The core auxiliary cooling water system (CACWS) is a pressurized, nonboiling system operating at $14.5 \mathrm{MPa}(2100 \mathrm{psia})$ pressure $\left[339^{\circ} \mathrm{C}\left(643^{\circ} \mathrm{F}\right)\right.$ saturation temperature]. In order to avoid local boiling, it is recommended that a margin of about 28 to $42^{\circ} \mathrm{C}$ ( 50 to $75^{\circ} \mathrm{F}$ ) should be maintained between the saturation temperature and the expected maximum water temperature. Results of a transient analysis have shown that with the heat exchangers in the current reference design, the margin has been exceeded; the maximum water temperature reached $332^{\circ} \mathrm{C}\left(630^{\circ} \mathrm{F}\right)$. 


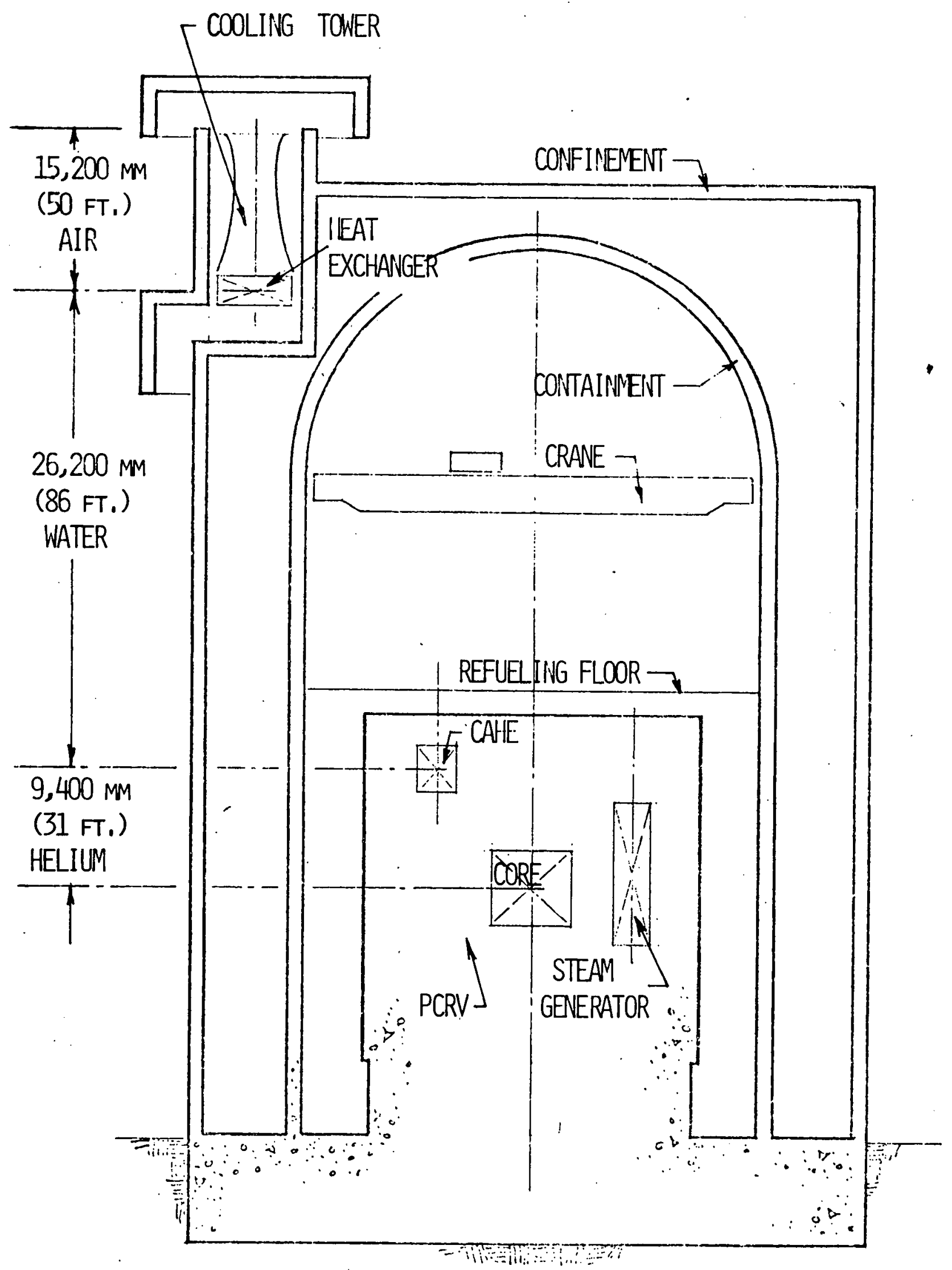

Fig. 4-6. Required elevation differences for natural circulation to ultimate heat sink 


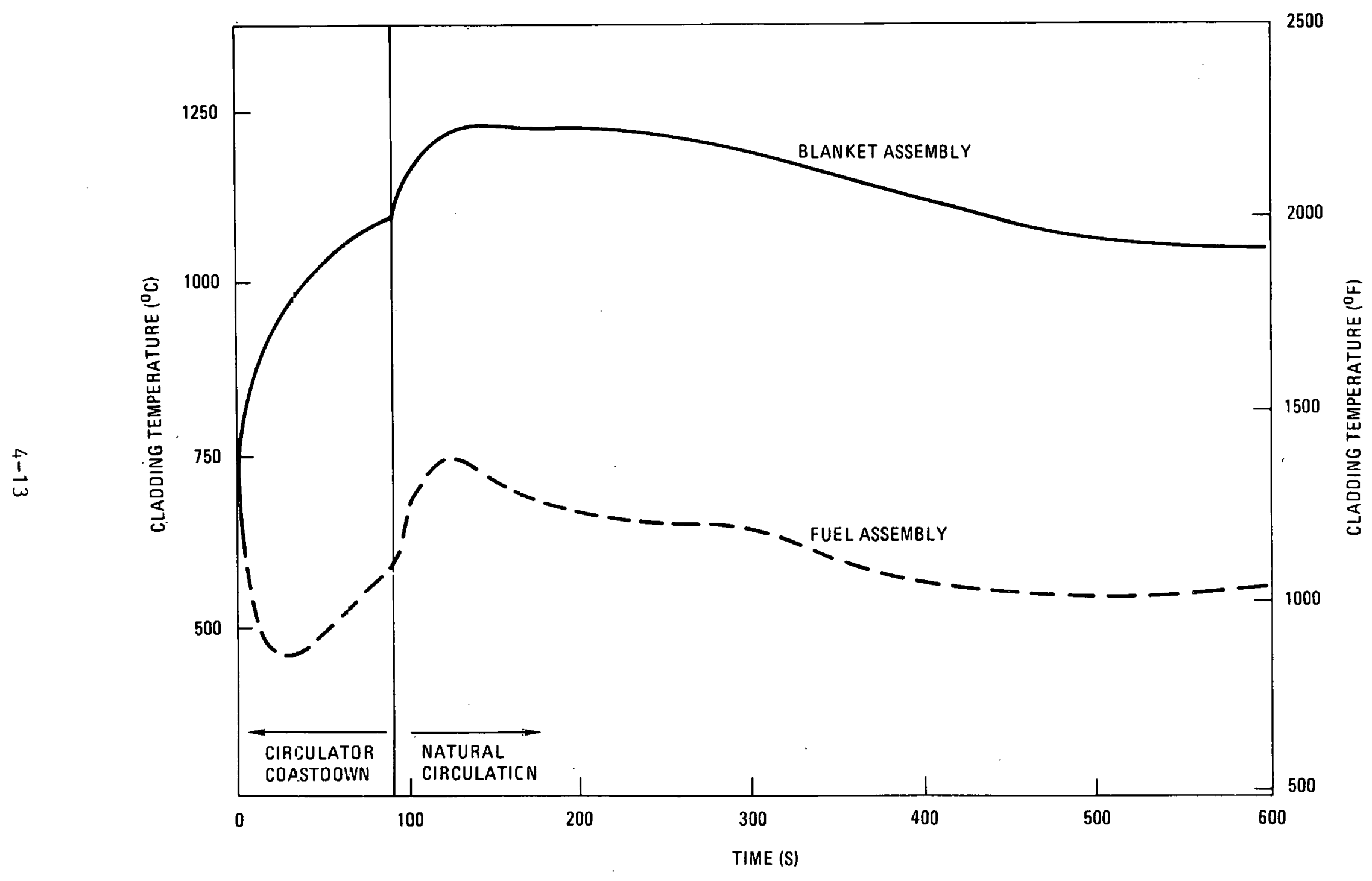

Fig. 4-7. Temperature history of maximum-powered fuel and blanket assembly (case 2) 
Several design alternatives to reduce the maximum water temperature and provide an adequate nonboiling margin were investigated. It appears that the most effective solution is the reduction of the water side pressure drop; one design concept having a considerable reduction of the water side pressure drop reached a maximum water temperature of $285^{\circ} \mathrm{C}\left(545^{\circ} \mathrm{F}\right)$. If a more realistic assumption is used, i.e., initially the water is in forced circulation, followed by a coastdown to natural circulation, the maximum water temperature with current reference design components reaches only $266^{\circ} \mathrm{C}$ $\left(510^{\circ} \mathrm{F}\right)$.

\subsection{RELIABILITY ANALYSIS}

The fundamental difference between the upflow and the downflow designs with respect to plant reliability arises from the capability of the upflow design to utilize natural circulation RHR in the CACS from the core to the ultimate heat sink, while the downflow design relies on forced circulation only. Therefore, the basic objective of the reliability analysis was to quantify the gain in reliability by having a natural circulation system in addition to the forced circulation systems. The current concept assumes that the MCS and SCS are forced circulation systems while the CACS can operate in either the forced or natural circulation mode. A secondary objective of the reliability analysis was to determine the adequacy of RHR reliability. For this purpose, a reliability objective was established and the RHR design reliability was evaluated against this objective. The scope of the analysis went thus beyond what was required for the upflow versus downflow assessment. A separate report (Ref. 8) covering the complete reliability update for the RHR system is being issued. Excerpts from this report are used to highlight relevant results of this work.

On the basis of NRC licensing guidance provided for the Clinch River breeder reactor, it has been the target to keep the expected cumulative probability of loss of coolable core geometry of the GCFR to less than $10^{-6}$ per reactor year; i.e., to treat such an occurrence as a beyond design basis accident. Since loss of coolable core geometry can result from a variety of initiators, it was necessary to suballocate this reliability 
target. The suballocation used for this evaluation is shown in Fig. 4-8. Accounting for other initiators resulted in an allocation for the cumulative total loss of RHR of $4 \times 10^{-7}$ per reactor year, which was further subdivided to account for major systems required to support the RHR function. Sufficient design information for a reliability analysis was only available for the heat removal trains (HRTs) and the power supply. However, these two are the elements of principal concern in the preconceptual design phase, and a combined cumulative failure probability of $10^{-7} /$ reactor year was used. The remaining allocations should only be considered as objectives with a larger allocation going to the control and instrumentation systems because at this point little is known about their requirements to prevent loss of coolable core geometry.

Since the reliability target is an expected, best estimate frequency for loss of coolable core geometry, statistically independent failure analyses were used to judge the design capability to meet the reliability objective. It is recognized that this requires a conscientious effort to eliminate as many sources of common cause failures as possible in the design process. This effort should be applied to both identical equipment within a system and to failures that can affect more than one system simultaneously. Since all sources of common cause failures cannot be eliminated by design, and because of the limited as well as conservative nature of state-of-the-art common mode failure quantification, it was considered prudent to perform commnn cause failure analyses to obtaill all Indfation of a conservative upper limit failure rate.

- Two systems were analyzed: (1) the current reference RHR system with SCS loops and (2) an improved RHR system with steam generator flooding capability by the SCS and a dedicated SCS power supply.

The GCFR design duty cycle and the umbrella transients were used as a guide to identify 47 individual initiators that require plant shutdown from normal power operation. RHR system success criceria were also established because after some scoping analyscs it became apparenl that the reference design would probably not meet the RHR system reliability criteria. The 


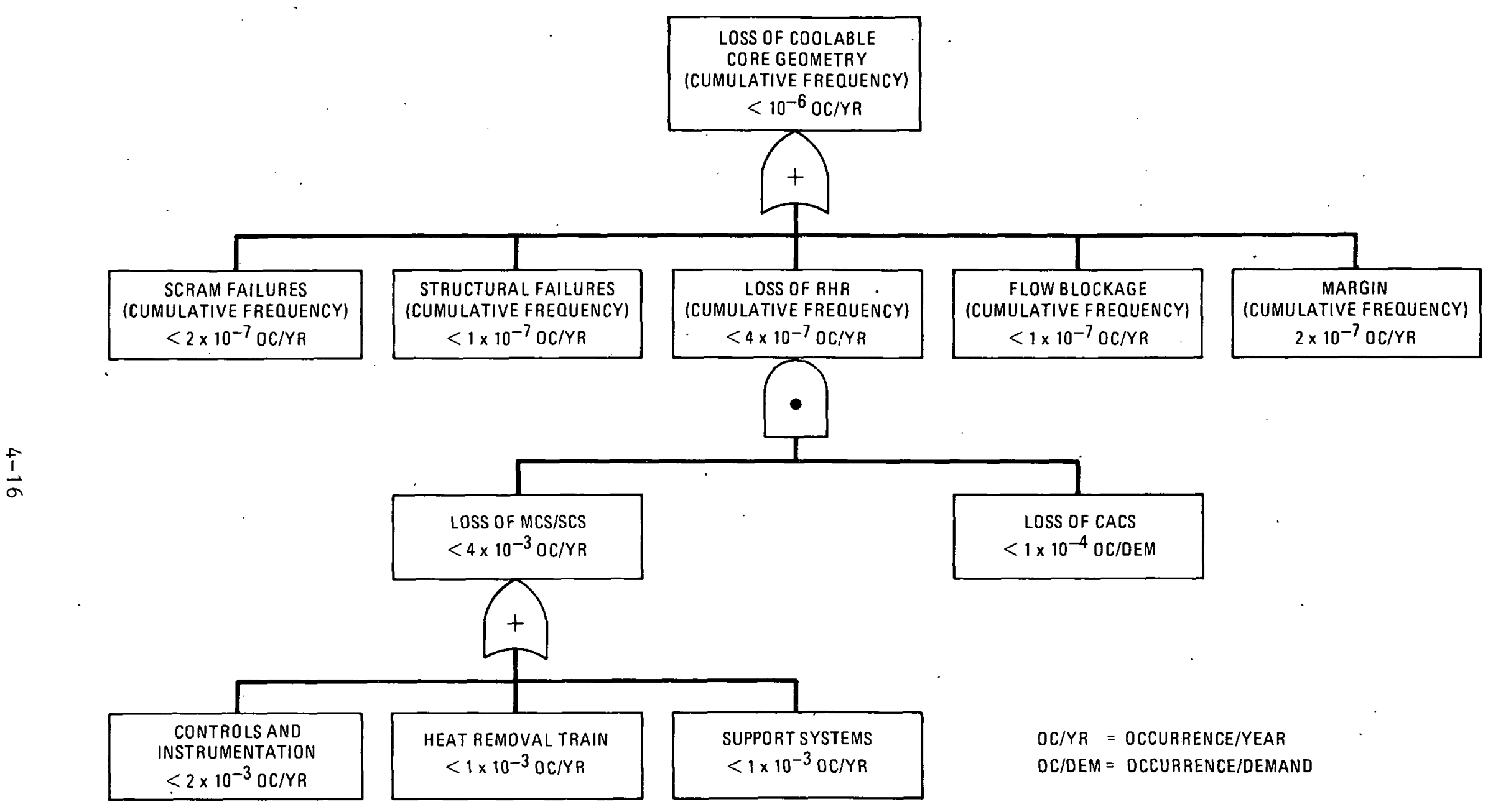

Fig. 4-8. Reliability allocation tree 
major effort was spent on the improved RHR system; only the results for the improved RHR system adopted in the final recommendations are reported here.

Throughout the reliability analysis of RHR system operation, it has been assumed that the power conversion system (PCS), e.g., steam generators, main helium circulators, normal feedwater trains, etc., will be utilized whenever available. Next in the RHR operational sequence is the SCS, followed by forced circulation CACS and finally natural circulation CACS. Following completion of maintenance and/or repair of the PCS, it is assumed to be returned to RHR service. Only the heat removal trains and power supplies were analyzed. Control and instrumentation as well as pneumatic/hydraulic and component cooling water systems were not included.

The results of statistically independent failure probability analyses show that natural circulation offers only a small gain in RHR reliability over forced circulation, i.e., by a factor of about 2.5. This small reliability gain is explained by several factors, all of which point to ways in which more effective use of natural circulation can be made. First, the electric power supply of the improved RHR design had been upgraded to the point where RHR failures in the forced circulation mode were no longer controlled by power supply reliability. The fact that natural circulation does not depend upon the availability, therefore, had only a small impact on the reliability gain. Secondly, the four sequential levels of defense for RHR have made the RHR function less vulnerable to failures of systems to start the RHR operation, relative to the running system reliability for long downtime events. Thirdly, for the analysis performed, the RHR failure probability is dominated by long downtime events. These long downtime events are also those which require PCRV depressurization during which natural circulation is not effective on the helium side. In principle, the reliability gain is then due to the natural circulation capability on the water and air sides during depressurized RHR operation. The 47 duty cycle events analyzed yield an expected annual downtime of 1050 hours for a mature plant; of these 1000 hours result from depressurized conditions. The major contributors to this long depressurized downtime are refueling (700 hours) and heat exchanger problems (220 hours). These downtimes include about a 
$30 \%$ to $50 \%$ margin over the best estimate times for refueling and steam generator repair.

Furthermore, this downtime estimate does not include operator training, maintenance beyond the refueling downtime, shutdowns due to technical specifications, and NRC-dictated or other unforeseen downtime." The unaccounted for downtime will mostly increase pressurized downtime and reduce the dominance of RHR reliability by depressurized conditions.

The common cause failure probability is improved by a factor of 4 due to natural circulation because common cause RHR failures are much less dominated by depressurized events." This is an indication that natural circulation provides enhanced resistance to design errors and supports the value of natural circulation in providing core cooling diversity. Tables 4-2 and 4-3 summarize the independent and common cause RHR failure probabilities for the dominating events (see Table 4-4).

Since the greatest RHR system unreliability is contributed by long downtime events requiring depressurization of the PCRV for which natural circulation of helium is not available, the concept of repressurizing the PCRV when necessary to reestablish natural helium circulation was suggested as a means to reduce the RHR system failure probability. Four major assumptions were made to permit a scoping analysis of this feature:

1. Repressurization is only effective for controlled (intentional) depressurization of the PCRV and not for uncontrolled (accidental) PCRV depressurization.

2. Repressurization can be accomplished in the time available before excessive cladding temperatures occur.

3. The repressurization system was assumed to have a reliability of 1.0 since no specific design was available for analysis. 
TABLE 4-2

INDEPENDENT FAILURE PROBABILITY FOR DOMINATING EVENTS - SEE TABLE 4-4

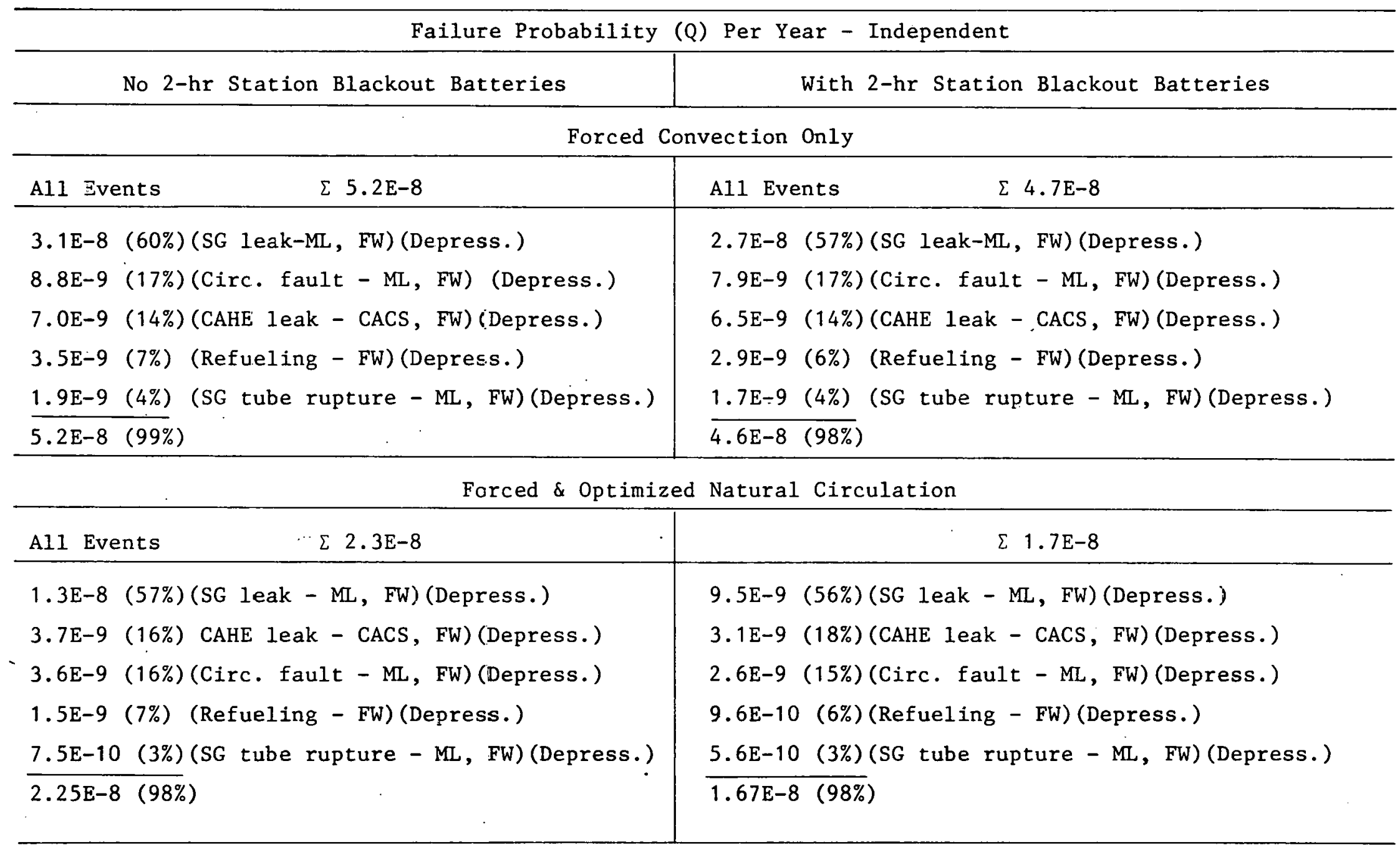


TABLE $4-3$

COMMON CAUSE FAILURE PROBABILITY FOR DOMINATING EVENTS - SEE TABLE 4-4

Failure Probability (Q) Per Year - Common Cause

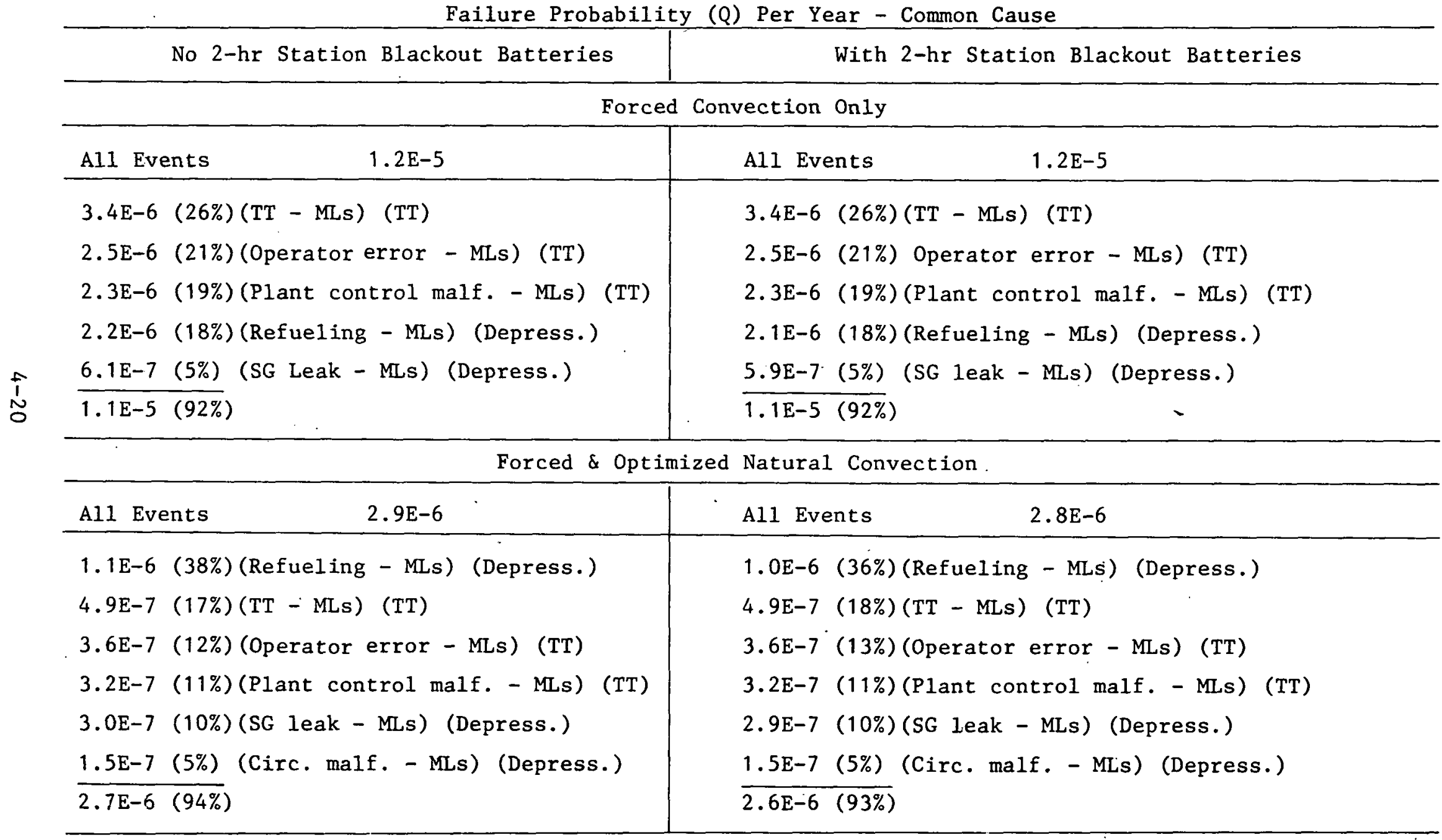


TABLE 4-4

DOMINATING EVENTS

TLOFW - Total Ioss of feedwater
LOSP - Loss of offsite power
TT - Turbine trip
SG - Steam generator
SSE - Safe shutdown earthquake
CAHE - Core auxiliary heat exchanger
UPS - Uninterruptible power supply
ML - Main loop (MCS)
FW - Feedwater (MCS)


4. The only active function required to establish natural circulation is the opening of the auxiliary loop isolation valve and no electrical power, including the UPS, is required.

These assumptions are optimistic and the results are only an indication of the maximum gain in RHR system reliability that can be expected from repressurization. The results show that repressurization of the PCRV increases the reliability gain for statistically independent failures to 15 and for common cause failures to 7 . The controlling events without repressurization are not eliminated by repressurization; only the probability of the same controlling events is reduced.

In conclusion, it can be said that there is a strong belief that the full benefit of natural circulation is expected to be larger than the numerical results would indicate for the following reasons:

1. For common cause events, the RHR system failure rate contribution from pressurized and depressurized events is about equal. A substantial increase in pressurized downtime would cause the pressurized events to control the common cause RHR system failure rate and increase the importance of natural circulation to guard against common cause failures or design errors.

2. Natural circulation as a last line of defense can probably be designed such that it requires no control action and no instrumentation. Therefore, the dependence on controls and instrumentation for a system with natural circulation may be significantly reduced. This could mean a large benefit of natural circulation.

3. Early-GCFR plants, and particularly the demonstration plant, will have higher initiating event frequencies and failure rates as well as being more susceptible to common cause failures. A naturally circulating RHR system will provide an inherent defense against such early plant design deficiencies which are an unavoidable part of the system commercialization process. 
4. With natural circulation, it is possible to eliminate some of the safety equipment, particularly in the emergency power supplies, without a significant loss of RHR reliability. This equipment was principally added to achieve adequate reliability of forced circulation systems without natural circulation.

\subsection{LICENSING POSITION ON RHR AND NATURAL CIRCULATION COOLING}

The licensing criteria for RHR systems in the GCFR upflow core design are based primarily on NRC's position that in the design of a fast reactor the probability of accidents leading to severe core damage or core melt shall be so low as to justify their exclusion from the design basis accident spectrum. To meet this requirement, the $\mathrm{NRC}$ has required that the $\mathrm{Clinch}$ River Breeder Reactor Plant (CRBRP) provide at least two independent, diverse, and functionally redundant RHR systems for safe shutdown of the plant. In the design of the GCFR, this criterion is satisfied by (1) an SCS that provides residual and decay heat removal when the nonsafety class equipment of the main loop cooling system is not available, and (2) the CACS, which provides residual and decay heat removal following all design basis events.

With the downflow core design, forced circulation cooling is required for both the SCS and CACS. Since both these systems employ turbomachinery with electric motor drives to circulate helium through the core and heat exchangers, an acceptable degree of diversity may not be achieved between the SCS and CACS. With an upflow core design, the potential for using natural circulation cooling for safe shutdown of the plant provides an alternate system operating mode that is different from a forced circulation cooling system. This higher degree of diversity is expected to make the upflow GCFR plant easier to license. However, the NRC probably will take the position, as they did on the CRBRP, that credit will not be allowed for RHR natural circulation capability until sufficient experimental bases to validate design tools are provided. 
The licensing position for natural circulation is as follows:

1. It is expected that natural circulation will be accepted by the NRC in the plant design bases if the analytical models can be experimentally verified to a sufficient degree of confidence prior to NRC completion of the construction permit review and with reasonable assurance of successful completion of $R \& D$ by construction completion. Some additional verification testing is expected to be allowed during the startup program. If the verification plan. cannot be accomplished, then the NRC would accept only forced circulation in the design bases for satisfying the RHR design criteria.

2. The natural circulation verification program must be establisted in accordance with the NRC position on the reporting and evaluation of design verification programs for safety-related systems. The minimum information required in such a program is:
a. Definition of design bases
b. Program description
c. Acceptance criteria
d. Backup position

Applicable information for R\&D programs and the plant operating experience of other projects can also be included. With regard to the latter, natural circulation performance data of a gas-cooled reactor are considered particularly applicable. 


\section{SAFETY ASSESSMENT}

Core disruptive accidents (CDA) and post accident fuel containment (PAFC) were studied to determine the possible impact of core-flow direction on accident scenarios and consequences. In addition, possible licensing positions were solicited. The study covered the following:

1. Determination of core inelt accident consequences without features to prevent recriticality.

2. Evaluation of early accident termination mechanisms that would prevent recriticality.

3. Evaluation of damage propagation potential for local flow blockage accidents.

4. Comparison of post-accident fuel containment feasibility.

The information developed during the study was considered too extensive for inclusion in this report. Therefore, only the highlights and results are summarized together with an assessment by the Licensing Division. A. more detailed descripliun of the entire work scope covering uptlow/ downflow CDA and PAFC is presented in Ref. 9.

\subsection{CORE DT.SRUPTTVE ACCIDENTS}

The Safety Evaluation Branch developed phenomenological accident descriptions with sequence diagrams for four accident classes having the potential to lead to CDA conditions:

1. Protected loss of flow (PLOF) 


\section{Loss of f1ow (LOF)}

\section{Transient overpower (TOP)}

4. Flow blockage in a single fuel assembly

Previous and current work in LMFBR accident investigations have indicated the difficulty of analyzing CDA behavior and consequences. Present computer programs are capable of analyzing the first recriticality, but after that event, in the so-called transition phase, the problem becomes numerically intractable.

PLOF is considered the most severe accident case; it is also a highvapor fraction accident. The cause of this is the hardening of the neutron spectrum for several reasons, and the strong sensitivity to the Doppler effect. Slumped core configurations and histories were calculated. Argonne National Laboratory (ANL), in parallel, performed a fuel vaporization and energy release parameter study. In combining these results with GA's core slumping analysis, a quantitative and qualitative determination of the timing and extent of fuel vapor and energy releases was made for both core flow directions. Transition phase behavior is generic for all fast breeder reactors. Upflow might be more susceptible to the transition phase; however, it is a change in degree but not in kind of consequences mitigation. Energetics is considered small and judged not a problem. Fuel vaporization is the concern. Prior to the transition phase, about $10 \%$ of the core may be vaporized for both the upflow and downflow cores.

Early accident termination to prevent recriticality was also investigated. These studies of concepts for in-core termination of CDAs were inconclusive or negative indicating major difficulties in assuring early termination with either the upflow or the downflow core. Early accident termination by duct fallaway was considered feasible in the downflow core with a single-point restraint and an increased duct gap. However, the consequences in a downflow core without duct fallaway are more severe than 
in an upflow core without mitigation. The changes from a downflow to an upflow core require a reassessment of the GCFR development program from "early accident termination and low consequences" goals to containing accident consequences. An investigation of the mitigation potential of the PCRV and the containment/confinement system will thus receive more emphasis. However, the possibility of a combination of an acceptable in-core termination and containment/confinement system measures will continue to be investigated.

CDAs involving failure to scram were found to be of lesser consequence and exhibit a smaller degree of sensitivity to flow direction.

For the PLOF accidents, the VENUS code was used by ANL to calculate the unmitigated PLOF power history of the entire core; the power profiles in the different fuel assemblies were used to calculate the fuel melting and drainage rates. It was assumed that the distinction between upflow and downflow unmitigated PLOF consequences, through the first recriticality, was not. significant. Depending upon the assumed accident scenario, recriticality is expected at about 900 to 1000 seconds followed by a prompt critical excursion that can vaporize between $3 \%$ to $10 \%$ of the core fuel. These values are sensitive to PCRV pressure and assumed time of loss of all flow after shutdown. The $10 \%$ vapor fraction is representative of $0.1 \mathrm{MPa}$ ( 1 atm) pressure and loss of all flow after an initial shutdown period. Corresponding energy releases for the $3 \%$ to $10 \%$ fuel vapor fraction vary between about 90 and $400 \mathrm{MW}-\mathrm{s}$. The work potential is not sufficient to damage the PCRV, which has about a $4000 \mathrm{MW}-\mathrm{s}$ capability, but could damage PCRV internals. The major concern is the amount of fuel vapor that could be released into the containment via the pressure relief valve train.

Two mitigating options to avoid recriticality were investigated: fuel drainage and the addition of neutron poison in solution. Results of an analysis showed that about $60 \%$ of the fuel must be removed to assure permanent subcriticality. Internal and external drainage paths were considered; however, crust formation by refreezing may block the drainage path. Upflow cores are considerably more susceptible to this phenomena than 
downflow cores because, in contrast to the downflow core, shielding in the path of molten steel is located in the cold core inlet region. Thus heat transfer between molten steel and shielding is enhanced, accelerating freezing. The conclusion was that the internal and external fuel drainage concepts are either infeasible or involve major design disadvantages.

The addition of neutron poison in solution, europium $\left(\mathrm{Eu}_{2} \mathrm{O}_{3}\right)$ being the best candidate, was by itself found unattractive. A series of two-dimensional diffusion theory calculations were performed to determine the amount of europium necessary to maintain a completely molten core subcritical. The result of the analysis showed that to avoid recriticality, in excess of $20 \%$ by volume of the molten fuel pool must be europium. This equates to about 2 metric tons of europium that must be readily available to be dumped in the molten fuel mass. Additional work in combining drainage and poison may have some merit.

Duct fallaway in a downflow core (with a one-point core lateral restraint) appears potentially feasible; however, a change in the core design and dimensions (larger gaps between core assemblies) with corresponding core performance penalties may be required. There are additional concerns: uncertainties whether fuel crumbling will lead to recriticality before duct fallaway, and it is almost certain that a commercial plant will require a two-point core lateral restraint.

TOP and LOF, two unprotected accidents, were investigated with respect to flow and support direction. A qualitative analysis has determined that the TOP consequences are insensitive to flow direction and ought to be substantially less than an LOF. The key uncertainties in TOP consequence determination are cladding failure location, fuel particle sweepout from the core, and primary side damage from dispersed fuel.

Best estimates for unprotected LOF accident fuel vapor fraction and energy release are one to two orders of magnitude below the PLOF. This consequence assessment has been performed by ANL using the accident analysis code SASGAS, which attempts to treat the phenomena mechanisticaily 
rather than conservatively. The upflow has been compared to the downflow for two potentially sensitive phenomena: (1) cladding motion versus residual coolant flow and (2) fuel motion versus residual coolant flow. Additionally, fuel plugging potential in the inlet nozzle region of an upflow core was studied. The major analytical uncertainty pertains to the potential for swelling fuel columns to block neutron streaming paths and add a positive prompt reactivity mechanism. Within the model and phenomenology uncertainties, neither the flow direction nor support direction made a significant difference in the results.

A complete, instantaneous flow blockage in a single fuel assembly was investigated to determine the potential for damage propagation to adjacent fuel assemblies. It was found that cladding blockages in the lower axial blanket similar to those during a PLOF are possible. In this case, a molten fuel pool is expected to build up and begin to melt through the duct wall of the blocked assembly. Assuming a $10 \%$ residual flow after reactor trip, it was calculated that the duct walls in the unblocked, adjacent assemblies would melt and lead to welding together of the seven-assembly group, which has the blocked assembly at its center. The sequence of events beyond duct melting is highly uncertain. The relatively short time between detection and damage propagation appears to preclude operator intervention. An increased residual flow in the unblocked assemblies may prevent damage propagation.

A downflow core designed for duct fallaway during a PLOF is expected to automatically provide an early accident termination mechanism without damage propagation. When the molten pool raises the duct wall temperature to its yielding point, the assembly, under ils uwn welght, would drop from the core. This was calculated to occur prior to melting of neighboring assemblies.

\subsection{POST-ACCIDENT FUEL CONTAINMENT}

Upflow and downflow plant designs were evaluated and compared against PAFC requirements. Supporting analyses were performed to determine core 
debris volumes as a function of meltdown progression, and to define the time of occurrence for the various postulated PCRV failure modes.

In the downflow plant, failure of all active cooling systems will lead to a core meltdown. Natural circulation of helium does not prevent core meltdown, but can provide a heat removal mechanism from a core melt on the cavity floor. In contrast, in the upflow plant, natural circulation of helium is one important mode of operation to prevent core melting. Once core meltdown commences, natural circulation of helium through the main or auxiliary loops is no longer considered available for PAFC cooling because it did not prevent core melting in the first place.

The results of the downflow PAFC analysis show that the PCRV offers a good potential for containing debris from a molten core as long as liner cooling is available and either one CACS loop is in operation or natural circulation of helium at a residual pressure of $0.6 \mathrm{MPa}$ (6 atm) or greater is available. However, active cooling is required for long-term molten fuel containment in the PCRV. An additional concern is that removal of the bottom head penetration plugs during refueling operation degrades any invessel PAFC capability.

The volume of molten core debris accumulating at the bottom of the core cavity following a core meltdown in an upflow plant depends on the assumed failure modes of the core support structure. The relative position of the core debris to the grid plate strongly influences the failure of the grid plate's center section (containing fuel, blanket, and control assemblies). which may occur in a time frame from 3 to 9 hours after a core melting initiates. Subsequent failure of the remaining grid plate and other reactor internal structures is marginal without either forced or natural circulation of helium. With only liner cooling available, the time of failure is a function of the thermal barrier thickness and occurs between 100 and 120 hours. Emergency measures to resume some degree of cooling by helium should be possible within this long time period. 
Assuming a minimum core mass accumulating at the bottom of the core cavity, the volume for the upflow debris (grid plate center portion; fuel, blanket, and control assemblies) is about twice as large as for the downflow (fuel, blanket, and control assemblies); i.e., $27 \mathrm{~m}^{3}\left(950 \mathrm{ft}^{3}\right.$ ) and $13 \mathrm{~m}^{3}$ (460 $\mathrm{ft}^{3}$ ), respectively. Exactly the opposite would be the case if one assumes a total meltdown of the core and all reactor internals. An approximation yields a debris volume of about $269 \mathrm{~m}^{3}\left(9500 \mathrm{ft}^{3}\right)$ for the downflow and $144 \mathrm{~m}^{3}\left(5100 \mathrm{ft}^{3}\right)$ for the upflow plant.

One important aspect of the study covered the investigation of possible PCRV failure modes, i.e., breach of the primary system pressure barrier. It was postulated that following loss of liner cooling, the molten debris could penetrate through the concrete to the first row of tendon tubes and destroy the tendons holding down the core cavity closures. It would take about 31 hours in either the upflow or downflow PCRV to reach the tendons and thus cause depressurization of the PCRV. The PCRV failure mode analysis was carried past this point to investigate other causes. The results of the analysis are summarized in Table 5-1. The current downflow plant has more failure modes because of the additional refueling penetrations in the PCRV bottom head which are not present in the upflow plant.

\subsection{LICENSING POSITION ON CDA AND PAFC}

It became apparent that after a study of NRC's review and their position taken on the Clinch River Breeder Reactor Plant (CRBRP), a major concern was the maintenance of containment integrity following a postulated core melt and/ or CDAs. This requirement arose from NRC's basic position that a fast reactor should achieve a level of safety comparable to current generation light water reactor (LWR) plants. Major attention was drawn to the prevention of accidents leading to core melt and disruption, and loss of containment system integrity.

The postulated CDAs that were studied and the functional requirements for the GCFR containment system design thus follow closely those developed 
TABLE 5-1

COMPARISON OF POSTULATED PCRV FAILURE MODES

\begin{tabular}{|c|c|c|}
\hline Cause of PCRV Failure & $\begin{array}{c}\text { Time of Failure } \\
\text { (After Accident Initiation) } \\
\text { (h) }\end{array}$ & $\begin{array}{l}\text { Applicable to } \\
\text { Upflow or Downflow }\end{array}$ \\
\hline Failure of first row of PCRV tendons & 31 & $\mathrm{UF}$ and $\mathrm{DF}$ \\
\hline $\begin{array}{l}\text { Failure of PCRV concrete (near fuel in } \\
\text { refueling gap) }\end{array}$ & 40 & $\mathrm{DF}$ \\
\hline $\begin{array}{l}\text { Failure of PCRV concrete (near locking } \\
\text { ring of refueling plug) }\end{array}$ & 80 & $\mathrm{DF}$ \\
\hline $\begin{array}{l}\text { Failure of lower shoulder of refueling } \\
\text { plug }\end{array}$ & $>200$ & $\mathrm{DF}$ \\
\hline $\begin{array}{l}\text { Failure of locking ring of refueling } \\
\text { plug }\end{array}$ & $>200$ & $\mathrm{DF}$ \\
\hline $\begin{array}{l}\text { Failure of PCRV lower head by melting } \\
\text { one-half of concrete }\end{array}$ & 256 & $\mathrm{UF}$ and $\mathrm{DF}$ \\
\hline $\begin{array}{l}\text { Failure of PCRV lower head by melting } \\
\text { of full concrete thickness }\end{array}$ & 1150 & $\mathrm{UF}$ and $\mathrm{DF}$ \\
\hline
\end{tabular}


for the CRBRP. These recommendations are generic for both the upflow and downflow plants, and can be stated as follows:

1. To the extent practicable, the analyses of beyond-design-basis events, such as CDAs, shall have limited influence on and be studied independently of plant design, which uses design basis accidents. Also, modifications to the plant design to enhance CDA accommodation shall not compromise any safety system.

2. The containment system integrity (design leak rate) shall be ensured for a minimum of 24 hours following a CDA using realistic, prudent analyses with conservative estimates of energy release, fuel vapor fractions, and core fraction.melted. After 24 hours, measures that can reasonably reduce and limit the residual risk shall be employed. Engineered safety features need not be provided to protect the containment. 


\section{SYSTEM AND COMPONENT COMPARISON}

\subsection{EVALUATION CRITERIA}

Early in the study a set of general evaluation criteria was established to serve as a guide. These evaluation criteria, summarized in Table 6-1, were used for the comparison and/or evaluation of systems, components, and design features of the upflow and downflow design concepts. In most instances, the entire set of the evaluation criteria was not applicable, as only a few were required to assess the differences as well as the pros and cons of a particular design element.

\subsection{UPFLOW VERSUS DOWNFLOW COMPARISON}

To obtain a systematic outline for the comparison and evaluation of the upflow and downflow design concepts, an evaluation form following the outline of Table 6-1 was developed, and about 40 design elements considered critical selected. The design element could either be a system, component, or an analytical investigation. As the study approached its conclusion, the cognizant engineers of the design elements were requested to fill out these torms, one tor uptlow and one for downflow, and submit them to the Technical Management Committee (TMC) for review. A typical filled-out evaluation form is shown in Fig. 6-1.

After the TMC reviewed the evaluation forms of the individual design elements, a series of meetings with the responsible managers and design/ analytical engineers was scheduled. In these meetings, details of their evaluations were discussed and outstanding questions related to various problem areas resolved. At the end of each of these meetings, the cognizant manager stated.his summary evaluation and recommendation as regards upflow versus downflow design for his àrea of responsibility [design element(s)]. The contents of the evaluation forms and the results of the review meetings 
TABLE 6-1

EVALUATION CRITERIA

A. Technical Feasibility

1. Current technical feasibility

- The extent to which the technical feasibility of the design of a given system or component is considered to be established at the time an evaluation is required, i.e., as of now. Determinations of technical feasibility must take into account the status of requirements and interface information and the degree of design maturity, usually through knowledge of comparable situations and exercise of judgment.

2. Future technical risk

- The risk, as the program proceeds, that system/component technical design, or performance, or required development, will be unacceptable.

B. Safety and Licensing

1. Safety

- The extent to which the design is safe from an engineering ". point of view.

2. Licensing

- The extent to which the design is licensable based on GA's assessment of. NRC's point of view.

C. Operating Characteristics

1. Availability

- Availability includes both scheduled and unscheduled outages. For unscheduled outages, consider both the probability of the outage and the time to restore operation.

2. Maintenance and In-Service Inspection

- How does the design provide for required ISI and for both likely maintenance and access for unlikely repair?

3. Operability

Operability relates to startup, shutdown, part-load operation, and maneuvering. 
TABLE 6-1 (continued)

D. Development Program

- This grouping includes the impact of the subject system or component upon the development program including the demonstration plant capital cost and the schedule.

1. Schedule

2. $R \& D$ program cost

3. Demonstration plant capital cost

- Increments to the capital cost of the demonstration plant can be viewed as increments to the overall GCFR development program cost. To first order, fuel cycle cost increments affecting only the demonstration plant can be neglected.

E. Commercial Plant and Fuel Cycle Aspects

1. Commercial plant capital cost, fuel cycle cost, and resource utilization

- The anticipated economics of commercial plants are influenced by alternative demonstration plant design concepts and technical approaches. The application of this criterion will mainly involve projection of the demonstration plant capital costs to the commercial plant.

Determinations should consider differences in fuel cycle cost and fuel resource utilization.

2. Scalability

- All concepts must be technically feasible scaled up to commercial sizes. Where alternatives have different characteristics at demonstration and commercial plant sizes, the commercial sizes are to be emphasized. 


\section{GCFR UPFLOW / DOWNFLOW EVALUATION}

NAME OF DESIGN ELEMENT: THERMAL BARRIER (UPFLON) COGNLZANT ENGINEER: A. HUCKNALL DATE: 2/20/79
DESCRIPTION OF DESIGN ELEMENT: (UPFLOW-DOAN)

(See General Arrangement Dwg. 024765)

The thermal barrier is a ceramic fiber insulation system attached to the interior surfaces of the vessel. Its 'primary function, which is performed in conjunction with the liner cool ing system, is to prevent
degradation of the vessel structure. Heat losses from the primary coolant are also minimized by the degradation of the vessel structure. Heat losses from the primary coolant are also minimized by the
themal barrier.

\begin{tabular}{|c|c|c|}
\hline $\begin{array}{l}\text { CRITERLA } \\
\text { NUMBER }\end{array}$ & $\begin{array}{l}\text { EVALUATION } \\
\text { CRITERLA }\end{array}$ & EVALUATION OF DESIGN ELEMENT \\
\hline \multicolumn{2}{|c|}{$\begin{array}{l}\text { Overall Evaluation } \\
\text { (based on following items) } \\
\text {-8 word } 1 \text { imit: }\end{array}$} & No major problems are expected. \\
\hline \multicolumn{2}{|c|}{ A. TECHNICAL FEASIBILITY } & \\
\hline A.1 & $\begin{array}{l}\text { Current Technical } \\
\text { Feasibility }\end{array}$ & Feasibility is well established for normal high temperature helfum environment. \\
\hline A.2 & Future Technical Risk & $\begin{array}{l}\text { Technical risks can be identified only with extending the present operational boundaries, } \\
\text { thereby increasing severity of operational environment (temperature, radiation etc). } \\
\text { or introduction of new design requirements such as floodability of internals. }\end{array}$ \\
\hline \multicolumn{2}{|c|}{$\frac{\text { B. SAFETY AIL LICENSING }}{1}$} & $\begin{array}{l}\text { Primary Safety Criteria of Thermal Barrier is to prevent impairment of PCRV Structural } \\
\text { integrity. To assure life-long safety and reliability the thermal barrier is designed } \\
\text { for low stresses at maximum load conditions with redundancy and multiple load paths. }\end{array}$ \\
\hline B.2 & Licensing & $\begin{array}{l}\text { The thermal barrier is not a code component and relatively few issues were raised durino } \\
\text { early DHQL licensing. All issues were satisfied during ACRS review. Similarly, for } \\
\text { the GCFR, the thermal barrier should not be an issue in licensability. }\end{array}$ \\
\hline \multicolumn{2}{|c|}{ C. OPERATING CHARACTERISTICS } & \multirow[b]{2}{*}{$\begin{array}{l}\text { No problems expected, based on } 100 \% \text { availability up to this point demonstrated } \\
\text { with FSV operation. }\end{array}$} \\
\hline c.l & Avallability & \\
\hline C.2 & Maintenance and ISI & $\begin{array}{l}\text { No maintenance requirements through plant lifetime. ISI will meet the ASME Code } \\
\text { requirements of Subsection IGH proposed for Section XI, Div. } 2 \text {. }\end{array}$ \\
\hline C. 3 & Operability & N/A \\
\hline D. $\mathrm{DEV}$ & VELOPMENT PROGRAM & $\begin{array}{l}\text { From six months to one year extension of accident conditions test program, beyond } \\
\text { that needed for downflow may be required. (Probably not on critical path, however) }\end{array}$ \\
\hline 0.2 & R\&O Program Cost & Estimated to be approximately $\$ 500 \mathrm{~K}$ greater than downflow configuration. \\
\hline 0.3 & $\begin{array}{l}\text { Demonstration Plant } \\
\text { Capital Cost }\end{array}$ & Not expected to be significantly different from the cost of downflow vessel. \\
\hline \multicolumn{2}{|c|}{ 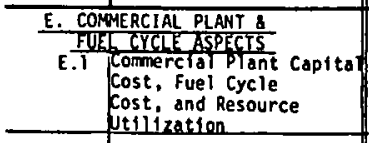 } & N/A \\
\hline E.2 & Scalability & $\begin{array}{l}\text { Size and multiple component design of thermal barrier does not effect } \\
\text { limits of scalability. }\end{array}$ \\
\hline
\end{tabular}

Fig. 6-1. GCFR upflow/downflow evaluation form 
were synthesized to obtain for each design element a comparison between the upflow and downflow plants (see Table 6-2).

As far as overall plant performance is concerned, the nominal plant requirements are identical for both the upflow and the downflow plants. The impact of core flow direction on plant performance was investigated and found to be minimal.

The summary assessment of the comparison between the upflow and downflow plants led the TMC to the recommendation to change the current GCFR reference design to an upflow plant. The principal factors leading to this recommendation are detailed in the next section. 
TABLE 6-2

COMPARISON BETWEEN UPFLOW AND DOWNFLOW PLANTS

\begin{tabular}{|c|c|c|}
\hline Design Element & Upflow Plant & Downflow Plant \\
\hline PCRV & $\begin{array}{l}\text { Except for some cavity closure and component location } \\
\text { difference between the two PCRV designs. The PCRV co }\end{array}$ & $\begin{array}{l}\text { related size variations, there is no basic } \\
\text { cept is feasible and licensable. }\end{array}$ \\
\hline Core cavity closure & $\begin{array}{l}\text { The dual rotating plug assembly permits straight- } \\
\text { line refueling. Although considered feasible, } \\
\text { the expected problems are formidable and } \\
\text { practicality is questioned. Major areas of con- } \\
\text { cern include: seal and resealing, access for } \\
\text { periodic in-service inspection and seal replace- } \\
\text { ment, fabrication and installation tolerances, } \\
\text { annual disconnect of thousands of service lines. } \\
\text { The dual rotating plug assembly is a very expensive } \\
\text { component and requires an extensive development } \\
\text { program. }\end{array}$ & $\begin{array}{l}\text { This plug is stationary. It consists of a steel } \\
\text { shell structure filled with concrete. It has } 67 \\
\text { penetrations for the control rods and. instrument } \\
\text { trees, i.e., } 30 \text { more than the rotating plug. The } \\
\text { design is considered acceptable and no major risks } \\
\text { are anticipated; it is the preferred concept. }\end{array}$ \\
\hline $\begin{array}{l}\text { Cavity liners, } \\
\text { penetrations, and pod } \\
\text { cavity closures }\end{array}$ & $\begin{array}{l}\text { Liner configurations are somewhat different from } \\
\text { downflow but of comparable complexity. Has } \\
\text { simpler geometry around area of core support } \\
\text { sleeve. The major difference is the required pre- } \\
\text { cision machining and installation accuracy for the } \\
\text { core cavity closure (rotating plug). } \\
\text { Closure configurations are different from down- } \\
\text { flow but of comparable complexity. Most are con- } \\
\text { crete closures. Overali upflow has some } \\
\text { advantages. }\end{array}$ & $\begin{array}{l}\text { Line configurations are somewhat different from } \\
\text { upflow but of comparable complexity. Has fewer } \\
\text { bends and offsets in main and auxiliary loop } \\
\text { cavity liners. Requires extra duct between steam } \\
\text { generator exit and main helium circulator entry } \\
\text { plenum. } \\
\text { Closure configurations are different from upflow } \\
\text { but of comparable complexity. Most are steel } \\
\text { closures. }\end{array}$ \\
\hline $\begin{array}{l}\text { Grid plate and core } \\
\text { lateral restraint }\end{array}$ & $\begin{array}{l}\text { Vertical seismic response characteristics of grid } \\
\text { plate determine its thickness; it is somewhat less } \\
\text { than for downflow. Other design options offer more } \\
\text { freedom to cope with manufacturing and scale-up } \\
\text { problems. PES tube routing not established. Two- } \\
\text { point core lateral restraint. }\end{array}$ & $\begin{array}{l}\text { Deflection limitations determine grid plate thick- } \\
\text { ness. Scale-up is major concern. One-point core } \\
\text { lateral restraint. Component not considered to } \\
\text { be a decider. }\end{array}$ \\
\hline $\begin{array}{l}\text { Grid plate support } \\
\text { structure }\end{array}$ & A rather complex design with many problem areas. & $\begin{array}{l}\text { This is a simple structure and comparatively well } \\
\text { defined. It has lower fluence and more effective } \\
\text { cooling. It is slightly preferred. }\end{array}$ \\
\hline
\end{tabular}


TABLE 6-2 (continued)

\begin{tabular}{|c|c|c|}
\hline Design Element & Upflow Plant & Downflow Plant \\
\hline Upper plenum shielding & $\begin{array}{l}\text { This shielding has a comparatively simple design } \\
\text { geometry; no structural problems are anticipated. } \\
\text { Component not considered a decider. }\end{array}$ & $\begin{array}{l}\text { Complex shielding geomerry is required to pro- } \\
\text { vide access for core shield assembly locking } \\
\text { equipment and also to avoid interference with grid } \\
\text { plate support cylinder. }\end{array}$ \\
\hline Radial shield assembly & $\begin{array}{l}\text { A Eeasible design with no major structural } \\
\text { problems anticipatec; however, parallel bypass } \\
\text { cooling with inlet telium may be difficult. }\end{array}$ & $\begin{array}{l}\text { Cooling of shielding with series flow of outlet } \\
\text { helium is more reliable and preferred. }\end{array}$ \\
\hline Lower plenum shielding & $\begin{array}{l}\text { Th:s is a complex design but no problems are } \\
\text { anticipated. Seconcary core support may be provided } \\
\text { by shielding segments. }\end{array}$ & $\begin{array}{l}\text { At least one row of the removable radial shield } \\
\text { elements must be removed to provide access for } \\
\text { handling core shield assemblies. Handling and } \\
\text { cooling of the removable shield elements are major } \\
\text { problem areas and a disadvantage. }\end{array}$ \\
\hline Thermal barriers & $\begin{array}{l}\text { No major problems are expected. Requires about } \\
20 \% \text { less thermal barrier area than downflow. }\end{array}$ & $\begin{array}{l}\text { No major problems are expected. Larger lower } \\
\text { plenum height provides for dissipation of possible } \\
\text { hot streaks and thus offers better protection } \\
\text { against hot gas impingement. Some advantage. }\end{array}$ \\
\hline Control rod drive & $\begin{array}{l}\text { Sare as downflow. Only variation is length of the } \\
\text { driveline extansion member due to difference in } \\
\text { plenum height. Components exposed to reactor } \\
\text { savity must be designed for higher temperature } \\
\text { and fluence. }\end{array}$ & $\begin{array}{l}\text { The design is based on proven mechanism configura- } \\
\text { tions, available components and materials. Not } \\
\text { a deciding factor. }\end{array}$ \\
\hline $\begin{array}{l}\text { Instrumen }=\text { tree } \\
\text { with associated } \\
\text { components }\end{array}$ & $\begin{array}{l}\text { Design for rotating plug concept provides also con- } \\
\text { trcl rod drive guide structure. Thirty-seven } \\
\text { instrument trees are required to cover the core. } \\
\text { Eor alignment of control rod drive guide shrouds } \\
\text { and instrument trees with the top of the core, a } \\
\text { honeycomb type grid structure is provided. This is } \\
\text { a complex component; however, several alternate } \\
\text { design concepts are available. The replacement of } \\
\text { instrument tree and instrumentation is simple. } \\
\text { Prefferred concept. }\end{array}$ & $\begin{array}{l}\text { Sixty-seven core lock actuator assenblies are } \\
\text { required. Nineteen of them serve aiso as control } \\
\text { rod drive guides and supports and instrument trees. } \\
\text { Eighteen of the remaining act as instrument trees } \\
\text { for the blanket zone. Replacement of thermo- } \\
\text { couples is difficult due to longer and curved path } \\
\text { through entire core assembly. } \\
\text { - }\end{array}$ \\
\hline
\end{tabular}


TABLE 6-2 (continued)

\begin{tabular}{|c|c|c|}
\hline Design Element & Upflow Plant & Downflow Plant \\
\hline $\begin{array}{l}\text { Fuel assembly/ } \\
\text { blarket assembly }\end{array}$ & $\begin{array}{l}\text { Hexagonal stainless steel duct housing fuel rod } \\
\text { bundle, grid plate shielding, integral exit plenum } \\
\text { shielding, and a grid plate locking mechanism. } \\
\text { Fuel rod bundle is designed for top (hot end) } \\
\text { venting. Duct has two load pads for lateral } \\
\text { restraint. Grid plate lock is actuated from the top } \\
\text { of the assembly via a removable lock actuator rcd } \\
\text { but alternates are available. }\end{array}$ & $\begin{array}{l}\text { Hexagonal stainless steel duct housing fuel rod } \\
\text { bundle, grid plate shielding, and a grid plate } \\
\text { lock. Fuel rod is designed for top (cold end) } \\
\text { venting. Duct incorporates single load pad for } \\
\text { lateral restraint. Assembly does not contain } \\
\text { integral exit plenum shielding-separate exit } \\
\text { plenum shield segments are used; 3-row. Seismic } \\
\text { restraint feasibility uncertain. }\end{array}$ \\
\hline $\begin{array}{l}\text { Radial reflector/ } \\
\text { shield assembly }\end{array}$ & $\begin{array}{l}\text { Hexagonal stainless steel duct containing a wire- } \\
\text { wrapped bundle of reflector/shield rods. Uses } \\
\text { pneumatic balance-gravity holddown system. }\end{array}$ & $\begin{array}{l}\text { Hexagonal stainless steel duct containing a wire- } \\
\text { wrapped bundle of reflector/shield rods. Uses } \\
\text { mechanical lock. }\end{array}$ \\
\hline
\end{tabular}

Control assembly/ shutdown assembly

Except for downflow assemblies not having integral exit plenum shielding, the designs are identical consisting of a hexagonal stainless steel duct containing fuel rods, inlet and exit (upflow only) shielding, and a mechanical lock. The central 127 fuel rods are removed and replaced with r control rod and guide duct. Evaluation of dedicated assembly is desirable.

i 1 Pressure equalization system

,

Core disruptive accidents

(consequences)

Core disruptive: accidents (mitigation)
The hot-end, top-venting appears to be the most conservative design; however, it adds some design difficulties to fuel assembly. Additional

irradiation tests, costing several million dollars, may be required.

PLOF accident is predicted to generate more fuel vapor than other CDAs by an order of magnitude or more. Core vaporization of about $10 \%$ is calculated on the first recriticality. Subsequent recriticalities may lead to more core vaporization. PCRV and containment aerosol mitigating features are not assessed. PCRV internal response to $400 \mathrm{MW}-\mathrm{s}$ burst unknown. Consequences may increase for depressurized conditions.

External drains are not feasible because drainage would occur too late to prevent recriticality. Internal drains require removal of a large quantity of fuel rods. Poison requires timely addition of 2 metric tons of Europia. Seven assemblies may weld. together from a flow blockage accident; damage propagation is possible. In general, in-core mitigation appears difficult. Energetics/aerosol containment not yet resolved.
Reference design for many years with technical feasibility demonstrated in HELM 3 test.
Duct fallaway is considered technically feasible for recriticality prevention; however, it is uncertain. Unmitigated PLOF fuel vaporization/ energetics potential larger due to coherent fallaway. Flow blockage is not expected to cause

failure propagation if fallaway of blocked assembly occurs. Drains and poison are infeasible for same reasons mentioned in upflow. The duct melting and fallaway test (DMFT) program is on schedule. Fallaway may require enlarged interduct spacing affecting nuclear performance. 
TABLE 6-2 (continued)

\begin{tabular}{l|l|l}
\hline \multicolumn{1}{c|}{ Design Element } & \multicolumn{1}{c}{ Upflow Plant } & \multicolumn{1}{c}{ Downflow Plant } \\
\hline $\begin{array}{l}\text { Post-accident fuel } \\
\text { containment }\end{array}$ & $\begin{array}{l}\text { In-vessel crucijle increases PCRV height. } \\
\text { Requires upgraded active cooling. }\end{array}$ & $\begin{array}{l}\text { Because the refueling penetration plugs are } \\
\text { removed during refueling, PAFC is not functional } \\
\text { during this time. }\end{array}$ \\
For both upflow and downflowplants crucible design is not necessarily the best concept for in-vessel
\end{tabular}

For both upflow and downflow plants crucible design is not necessarily the best. concept for in-vessel containment of molten fuel. Alternate concepts are under irvestigation.

Licensing (CDA)

Consequences of beyond basis accidents $\left(\div 10^{-6} /\right.$ year) should be studied independent and apart from plant design requirements. Design for mechanical work and core melting/vaporization from conservative

analyses. Make realistic radiological consequences assessment using WASH-1400 as a guide. Twenty-fourhour containment integrity is required. Longer term containment requirements are uncertain. In general, licensing procedures for CDA are not well established.

Upflow natural circulation RHR to ultimate heat sink may reduce NRC concern about loss of coolable core geometry.

The location of the refueling equipment atop the PCRV imposes high seismic loads on it. Bottom location of main helium circulator and auxiliary circulator is best. Core support is seismically more desirable in location and configuration than in downflow as regards transmittal of seismic loads to the core. For commercial plant more tendons are required at PCRV support to resist gapping at that interface because of the overturning moment; however, design is manageable.

High operating radiation levels below rotating plug results in potentially more radiation streaming through annuli and penetrations and higher plug activation for removability. Refueling nozzle extensions require shielding during refueling operations. Radiation streaming through hot duct could activate steam generator, which is opposite duct mouth.
The high elevation of the main helium circulator and auxiliary circulator as weil as the core support structure imposes high seismic loading on them. Refueling equipment is in best possible location at bottom. PCRV support design is acceptable.

Lower operating radiation levels below core cavity plug and absence of annuli reduce radiation streaning problems on top deck. Steam generator activation minimal because it is not located. opposite duct mouth. Ex-core cavity shielding design is straightforward and conventional. 
TABLE 6-2 (continued)

\begin{tabular}{|c|c|c|}
\hline Design Element & Upflow Plant & Downflow Plant \\
\hline $\begin{array}{l}\text { Core distortion/ } \\
\text { seismic response } \\
\text { behavior }\end{array}$ & $\begin{array}{l}\text { Core distortion/seismic restraint is provided by } \\
\text { dual lateral restraint of the "limited free bow" } \\
\text { type. Dual load pads are at outlet end of core } \\
\text { assemblies. Operating and refueling loads are } \\
\text { acceptable. Seismic response acceptable. Some } \\
\text { development required but LMFBR precedent. }\end{array}$ & $\begin{array}{l}\text { Core distortion/seismic restraint is provided by } \\
\text { single lateral restraint at upper fuel/blanket } \\
\text { interface. Par-to-pad contact not achieved until } \\
\text { late in life; seismic response for non-contacting } \\
\text { case unknown. Restraint was selected to prevent } \\
\text { interference with duct fallaway option. Feasibil- } \\
\text { ity of single point restraint not established. }\end{array}$ \\
\hline
\end{tabular}

Fuel and blanket

assembly therma1-

hydraulic

$\frac{i}{0}$

In-vessel refueling equipment

Ex-vessel refueling
Acceptable forced circulation performance.

Natural circulation blanket cooling needs improve-

ment. Core design has to accommodate slightly higher core pressure drop or somewhat reduced nuclear performance.

Straight line refueling permits development of high axial forces. A minimal number of control rod drives need removal. Upper core cavity plenum height can be less than core element length. Interrelated movements of fuel handling machine support structure and rotating plug assembly entails complex logistic problems. Functions of actual machine are minimal, direct, and easily monitored. Coolant routing is direct. Seizure of parts does not prevent removal of machine. Dropped element is retained and can be regrappled. 14.6 days refueling time. Upflow is preferred.

Inclined transfer chute has precedent (Phoenix, LMFBR); it provides rapid transfer of spent core elements to storage. It thus provides minimal refueling and core element handling. Conveyor system needs development.
Fuel Assembly: During pressurized low flow operation, flow maldistribution reduces hot channel flow by about $50 \%$.

Blanket Assembly: Similar as in fuel assembly. Flow control devices have limited effect resulting in additional flow requirement or redesigning blanket with larger coolant volume fraction.

Offset feature limits magnitude of axial forces Requires removal of large plug to obtain access to plenum. Requires lower core cavity plenum height in excess of core element length. Several machine movements must be performed to remove any core

element. Engagement/re-engagement of grapples must be made in-vessel. Coolant routing is indirect. Seizure of deployment mechanism could make removal of machine very difficult. A core element dropped by accidental release of its lock could fall to a horizontal position making retrieval difficult. Fuel handling machine must be removed and components changed to handle exit plenum shield segments. Twenty-four days refueling time.

Requires additional transportable cask, transporter, and large air lock. Adequate space under PCRV is required. It has considerable impact on $B O P$ and refueling time. 


\section{TABLE 6-2 (continued)}

\begin{tabular}{|c|c|c|}
\hline Design Element & Upf low Plant & Downflow Plant \\
\hline Steam generator & $\begin{array}{l}\text { Has bottom-entry (feedwater) and top-exhaust } \\
\text { (steam). Appears to have best operational } \\
\text { characteristics sut bimetallic weld and } \\
\text { expansion loop design cause concerns. There } \\
\text { exist also scale-up problems. Prefer bottom- } \\
\text { exhaust. }\end{array}$ & $\begin{array}{l}\text { Bottom-entry and bottom-exhaust; similar to } \\
\text { HTGR-SC design; however, there are similar } \\
\text { bimetallic weld concerns as for top-exhaust } \\
\text { but to a lesser degree. Not a decider. }\end{array}$ \\
\hline $\begin{array}{l}\text { Core auxiliary heat } \\
\text { exchanger }\end{array}$ & $\begin{array}{l}\text { helical tube buntle seems to offer more flow } \\
\text { stability. Howeder, there are some in-service } \\
\text { inspection and szale-up concerns. Has capital } \\
\text { cost advantage. }\end{array}$ & $\begin{array}{l}\text { Bayonet tube bundle has seismic stop and hot gas } \\
\text { seal concerns; scale-up to larger units is } \\
\text { questicnable. Other design alternatives avail- } \\
\text { able. Not a decider. }\end{array}$ \\
\hline $\begin{array}{l}\text { Main helium circulator } \\
\text { with Loop isolation } \\
\text { valve }\end{array}$ & \multirow{2}{*}{\multicolumn{2}{|c|}{$\begin{array}{l}\text { Radial flow compzessor driven by synchronous electric motor with variable frequency speed control. } \\
\text { Both upflow and Jownflow plant circulators are vertically mounted and except for the much } \\
\text { larger thrust loads for bottom mounting, there is no difference between the upflow (bottom) and } \\
\text { downflow top) designs. Not a decider. } \\
\text { Radial flow compressor driven by induction electric motor with variable frequency speec control. } \\
\text { Both upflow and townflow plant circulators are vertically mounted and except for location, there is } \\
\text { no difference bezween the upflow (bottom) and downflow (top) cesigns. Not a decider. }\end{array}$}} \\
\hline $\begin{array}{l}\text { Auxiliary circulator } \\
\text { with aoop isolation } \\
\text { valve }\end{array}$ & & \\
\hline Natural circulation RHR & $\begin{array}{l}\text { Detailed transieat analysis has shown feasibility } \\
\text { of residual heat removal (RHR) from the core by } \\
\text { natural circulation at pressurized primary coolant } \\
\text { conditions. The primary coolant system and loop } \\
\text { isolation valves can be designed to enhance } \\
\text { natural circulation RHR in the CACS loops. Results } \\
\text { of tentative analysis indicate good potential of } \\
\text { natural circulation to ultimate heat sink } \\
\text { (atmosphere); however, design modifications to } \\
\text { equipment and BOP layout are necessary. Natural } \\
\text { circulation offers diverse and passive RHR. } \\
\text { Validation by anglysis and tests is required. }\end{array}$ & $\begin{array}{l}\text { Natural circulation RHR is not practical in a } \\
\text { downflow core. }\end{array}$ \\
\hline $\begin{array}{l}\text { RHR system design } \\
\text { (safezy class) }\end{array}$ & \multicolumn{2}{|c|}{$\begin{array}{l}\text { The safety class RHR system consists of two independent and diverse systems: core auxiliary cooling } \\
\text { system (CACS) anil shutdown cooling system (SCS), which are generically identical for both upflow } \\
\text { and downflow plants. During pressurized cooling helium flow rates must be carefully controlled to } \\
\text { prevent CAHE boilout. }\end{array}$} \\
\hline
\end{tabular}


TABLE 6-2 (continued)

\begin{tabular}{|c|c|c|}
\hline Design Element & Upflow Plant & Downflow Plant \\
\hline & $\begin{array}{l}\text { For the CACS, the different modes of operatior, } \\
\text { forced or natural circulation cooling, create } \\
\text { several design problems; e.g., CAHE sizing, CAHE } \\
\text { boiling, auxiliary circulator minimum speed range, } \\
\text { tubeside water flow stability, mixed mode } \\
\text { operation. }\end{array}$ & \\
\hline RHR system reliability & $\begin{array}{l}\text { Natural circulation improves RHR failure proba- } \\
\text { bility over revised downflow design (basis for } \\
\text { both plants) only by a factor of two or three } \\
\text { because: (1) RHR failures are dominated by running } \\
\text { failure during long downtime events, (2) long } \\
\text { downtime events are those which require depressuriza- } \\
\text { tion and for which natural circulation of helium } \\
\text { is not effective. Common cause analysis shows less } \\
\text { susceptibility for "design errors" in natural } \\
\text { circulation systems. Repressurization potential } \\
\text { would increase RHR reliability considerably but } \\
\text { at the expense of additional design requirements. } \\
\text { The true benefits of natural circulation RHR are } \\
\text { larger than calculated because: (1) dependence } \\
\text { on support system for natural circulation is } \\
\text { reduced, (2) early plant initiating event frequencies, } \\
\text { failure rates and repair times are less favorable, } \\
\text { (3) susceptibility to common mode failures in } \\
\text { early plants is larger. }\end{array}$ & $\begin{array}{l}\text { RHR reliability target can be met with the cur- } \\
\text { rent reference design which provides steam } \\
\text { generator flooding pumps (SCS) and separate } \\
\text { dedicated electric power supplies for SCS and } \\
\text { CACS. Lack of diversity in RHR systems could } \\
\text { result in common cause problems between systems. }\end{array}$ \\
\hline Licensing (RHR) & $\begin{array}{l}\text { With potential for using natural circulition } \\
\text { cooling for safe shutdown of the plant, provides } \\
\text { an alternate system diverse from two forced } \\
\text { circulation cooling systems. This higher degree } \\
\text { of diversity, assuming that natural circulation } \\
\text { cooling is verified to the satisfaction of the } \\
\text { NRC, promises to make the GCFR plant design easier } \\
\text { to license. }\end{array}$ & $\begin{array}{l}\text { Forced circulation cooling is required for both } \\
\text { the SCS and CACS. Since both these systems } \\
\text { employ turbomachinery with electric drives to } \\
\text { circulate helium through the core and heat } \\
\text { exchangers, a degree of diversity acceptable to } \\
\text { the NRC may not be achieved between the SCS and } \\
\text { CACS. }\end{array}$ \\
\hline
\end{tabular}


TABLE 6-2 (continued)

\begin{tabular}{|c|c|c|}
\hline Design Element & Upflow Plant & Downflow Plant \\
\hline $\begin{array}{l}\text { Containment/ } \\
\text { confinement building }\end{array}$ & $\begin{array}{l}\text { Somewhat larger in size than downflow. Concern } \\
\text { exists as regards separation of electrical } \\
\text { cables and water piping. Nót a decider. }\end{array}$ & $\begin{array}{l}\text { Electrical cables (top) and water/steam pipes } \\
\text { (bottom) have preferred separation layout. } \\
\text { However, there is concern about congestinn and } \\
\text { non-safety/safety piping separation. }\end{array}$ \\
\hline Reactor service building & $\begin{array}{l}\text { Is preferred because of less complicated layout } \\
\text { and less equipment associated with fuel handling } \\
\text { and storage. }\end{array}$ & $\begin{array}{l}\text { Little difference with upflow, however, un- } \\
\text { favorable building arrangement because of fuel } \\
\text { handling. }\end{array}$ \\
\hline $\begin{array}{l}\text { Maintenance and in- } \\
\text { service inspection }\end{array}$ & $\begin{array}{l}\text { For maintenance, access constraints with bottom } \\
\text { head mounted circulator motors and additional. } \\
\text { requirements due to rotating plug components are } \\
\text { undesirable features, e.g., seal replacement. For } \\
\text { ISI, access restrictions necessitate lengthy } \\
\text { inspection routines. Although less time required } \\
\text { than for downflow, rotating plug requirements } \\
\text { extend downtime. }\end{array}$ & $\begin{array}{l}\text { Component types and locations require timely. } \\
\text { performance of maintenance routines. Bottom } \\
\text { head penetrations, piping system types and } \\
\text { quantities and service facilities constraints } \\
\text { translate to longer ISI time periods. }\end{array}$ \\
\hline Major internal,s repair & $\begin{array}{l}\text { Major repair of internals is a generic task applicable } \\
\text { accomplished either by removal of component or in situ } \\
\text { difficult, and extended downtime is expected. Flooding } \\
\text { design (large core cavity closure) to reduce radiation } \\
\text { program is required to develop acceptable internal/ext }\end{array}$ & $\begin{array}{l}\text { to both upflow and downflow. Repair to be } \\
\text { It appears feasible but is very complicated, } \\
\text { of core cavity is required with present } \\
\text { to acceptable levels. A major engineering } \\
\text { ernal components and procedures. }\end{array}$ \\
\hline Availability & $\begin{array}{l}\text { Many of the major plant components (BOP and NSSS) are } \\
\text { flow designs. Within an assumed error band the expected } \\
\text { flow direction. It is in the refueling area (planned } \\
\text { apparent. } \\
\text { Refueling concept using the rotating plug and } \\
\text { straight-line refueling machine gives the upflow } \\
\text { design a significant advantage. Considerable cost } \\
\text { savings, especially in large plants, are anticipated. }\end{array}$ & $\begin{array}{l}\text { similar or identical for the upflow and down- } \\
\text { forced outages are thus about equal for either } \\
\text { outage) that major differences will become }\end{array}$ \\
\hline Operability & $\begin{array}{l}\text { The bottom-entry, top-exhaust steam generator is } \\
\text { slightly more stable in the low flow regimes, i.e., } \\
\text { during the startup and shutdown modes. Addition- } \\
\text { ally it is vented more readily, enhances flood- } \\
\text { ability. }\end{array}$ & $\begin{array}{l}\text { Steam generator was identified as only component } \\
\text { impacted by concept differences. Downflow unit } \\
\text { is slightly less stable in low flow regimes, i.e., } \\
\text { startup/shutdown. Venting of steam generator } \\
\text { less convenient. Not considered very significant. }\end{array}$ \\
\hline
\end{tabular}




\section{COST AND SCHEDULE COMPARISON}

As part of the study, the trends in capital cost differentials were evaluated, as was the impact a change to an upflow core might have on the development cost and schedule.

\subsection{CAPITAL COST}

Cost trends were developed to evaluate the differences between the upflow and downflow concepts. Plant capital costs are almost equivalent for the concepts evaluated. The overall cost additions for the upflow reference plant (NEU-D) compared with the updated downflow reference plant amount to $\$ 3.2$ million; see Table 7-1. To incorporate the equipment and change building sizes to provide RHR by natural circulation to the ultimate heat sink would add another $\$ 6$ million. However, it appears that the upflow core design also has the potential of technical and capital cost improvements, such as a horizontal main helium circulator, a fixed-core cavity plug, and revised reactor cavity internals.

In addition, the total cost of an upflow core is about $\$ 2.4$ million mure than for a downflow core; most of it is recovered by a reduction in the area of core ravity shielding.

\subsection{DEVELOPMENT COST AND SCHEDULE}

An assessment was made of the anticipated impact a changc in core flow direction would have on development cost and schedule. The differentials in development cost, including both $R \& D$ and design, are summarized in Table 7-2. The total development cost penalty for changing to an upflow core is between $\$ 34$ and 46 million. For the conceptual phase only an additional $\$ 2.5$ million are required. A front end schedule delay of approximarely 3 to 6 months 
TABLE 7-1

GCFR UPFLOW/DOWNFLOW EVALUATION SUMMARY OF CAPITAL COST DIFFERENTIALS

UPFLOW VERSUS DOWNFLOW TREND COST

(EFFECTIVE JANUARY 1979)

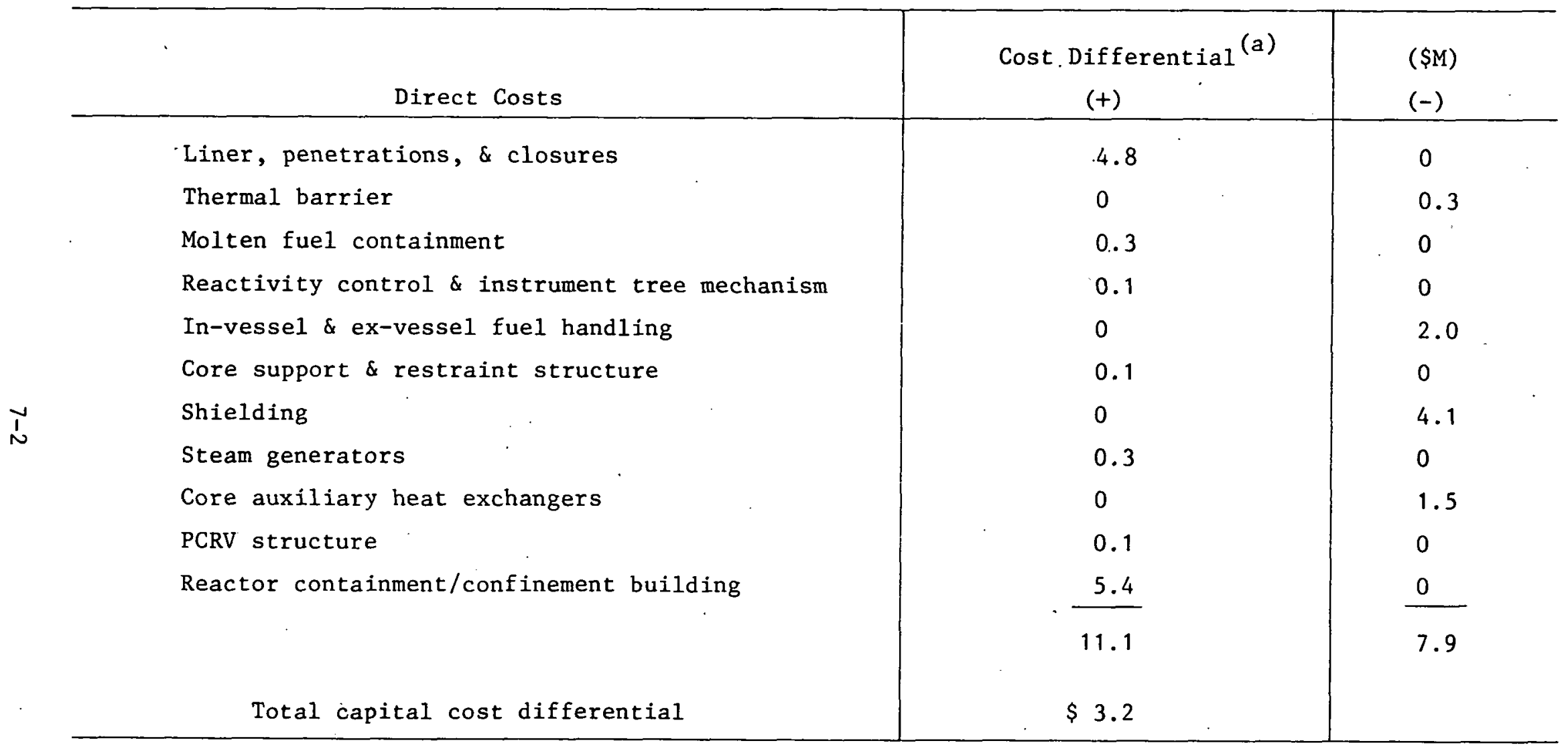

(a) Costs listed do not include GA indirects, G\&A, or profit. 
TABLE 7-2

GCFR UPFLOW/DOWNFLOW EVALUATION ASSESSMENT OF ENGINEERING PROGRAM COST IMPACT BY CHANGING TO UPFLOW CORE PLANT DESIGN

(TOTAL PROGRAM)

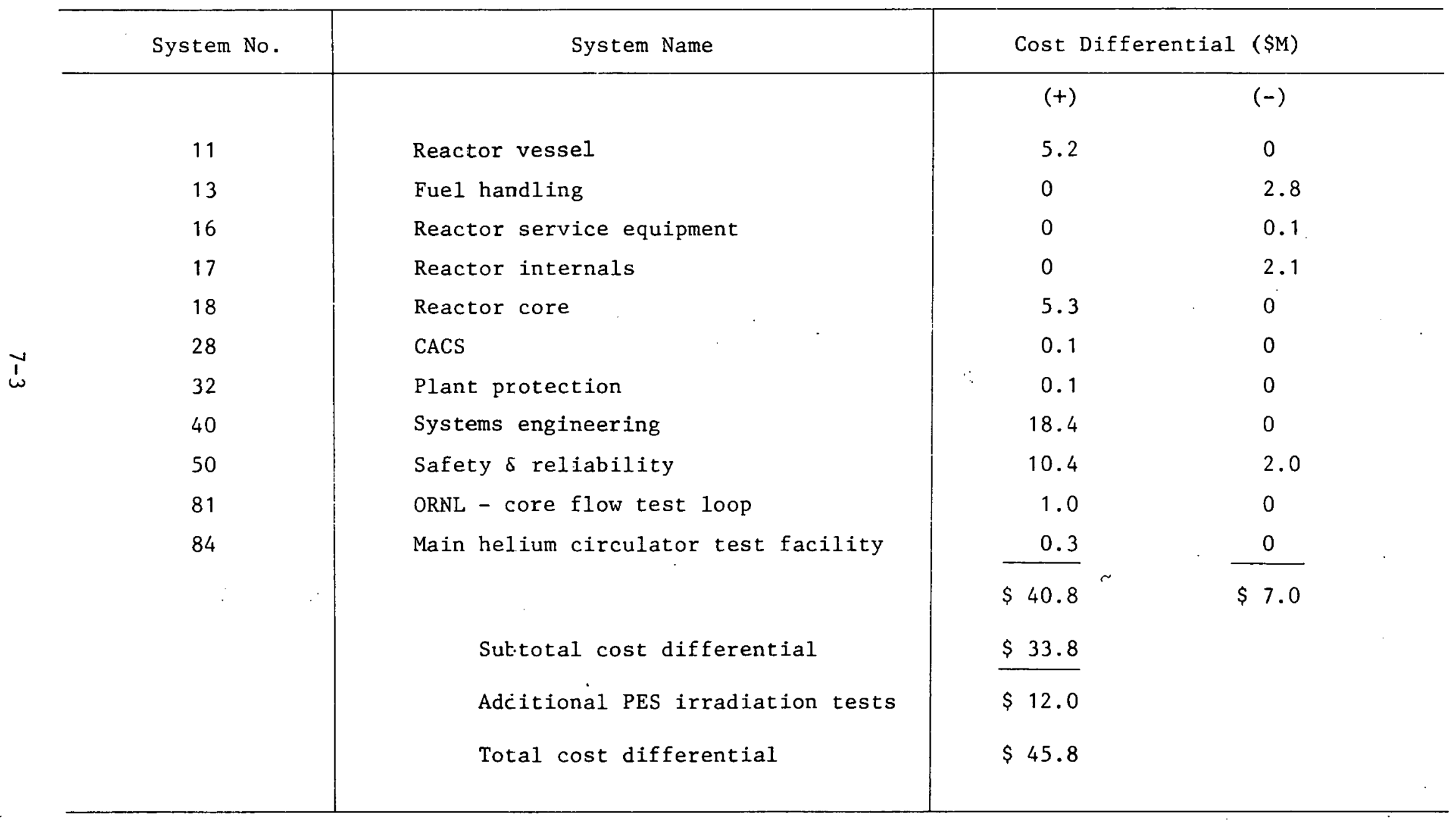


in establishing the demonstration plant conceptual design is anticipated because of limited available funding for necessary additional work.

The major cost items are the rotating core cavity plug, natural circulation tests, and a redirection of the safety program; additional PES irradiation tests may also be required. 


\section{CONCLUSIONS AND RECOMMENDATIONS}

\section{1 CONCLUSIONS}

Based on a comprehensive assessment of upflow and updated downflow designs against a set of pre-established evaluation criteria, a recommendation in favor of adopting an upflow core design was made. The basis for the upflow versus downflow plant evaluation and the final GA recommendation was two concepts:

1. NEU-D upflow plant specified in November 1978 as a result of a 6-week joint design convergence effort by GA and KWU.

2. Updated downflow plant to a set of ground rules and basic information common with the upflow design.

It is the judgment of GA that the GCFR with an upflow core is feasible, licensable, competitive in capital and operating costs with a downflow core GCFR, and that it has major advantages associated with the upflow core that justify the additional development entailed.

In general, both upflow and downflow plants received favorable overall evaluations. The principal factors that led to the recommendation favoring the upflow plant are the following:

1. The potential of the upflow core to provide pressurized residual heat removal by natural circulation has clear licensing advantages because of added diversity and reliability.

2. Natural circulation cooling capability can be verified with suitable development programs and startup testing to give owners and licensing authorities confidence in cooling reliability, particularly 
while the plant is being shaken down and while forced circulation cooling reliability is improving through plant maturation.

3. Refueling appears substantially better with upflow.

4. Plant capital costs are about equivalent for the upflow and downflow designs evaluated. However, upflow is believed to have more potential for capital cost improvements.

Studies of concepts for in-core termination of postulated core disruptive accidents (CDAs) were inconclusive (or negative) indicating major difficulties in assuring early termination with either upflow or downflow. In changing core flow direction from downflow to upflow, the option of single duct fallaway as a means of accident determination is eliminated. However, in balance the advantages in core cooling with an upflow core were considered to outweigh the possible but tenunus advantages of downflow with duct fallaway, especially when considering the probable need for better core lateral restraint for a downflow core which forecloses individual duct fallaway. It is recommended that work on in-core termination of CDAs for upflow cores continue and that evaluation of consequent mitigation schemes for the containment be investigated.

\subsection{CONFIGURATION RECOMMENDATIONS}

It should be recognized that the prime objectives of the upflow/ downflow study was to recommend the core flow direction, not to establish the plant conceptual design. It became apparent during the study that some of the selected NEU-D design features may carry an unduly high technical risk or may prove impractical; the best example is probably the rotating plug assembly for the core cavity closure. Some limited design effort on alternatives was thus pursued within the context of the study; it is briefly described in Appendix D. Based upon evaluations made during the study, a few design changes that modified the original upflow NEU-D 
concept are recommended. Further efforts should be focused on confirming the choice of the following features of the modified upflow plant concept:

1. Fixed (removable) core cavity closure plug.

2. Seven-element region refueling.

3. Natural circulation residual heat removal all the way to atmosphere.

4. Horizontal installation of main helium circulator.

5. Capability for flooding core cavity for major maintenance.

\subsection{RECOMMENDATIONS FOR FUTURE ACTIVITIES}

The following recommendations for on-going activities to define the plant conceptual design are based upon the evaluation and recommendation 'process experience. The list is not intended to include all needed activities.

1. Develop tradeoffs for possible improvements in blanket cooling under natural circulation conditions and the design basis depressurization accident.

2. Evaluate design options for the core auxiliary heat exchanger, particularly concerning accommodation of both forced and natural circulation operating modes and scale-up requirements.

3. Develop design tradeoffs for improved cooling reliability for depressurized primary system conditions.

4. Investigate effect on steam generator design and integration of the horizontal circulator and possible use of alternative materials.

5. Continue development of licensing guidelines consistent with GCFR plant characteristics. 
6. Perform a comprehensive'investigation of the means for containing and mitigating postulated core disruptive accidents in accordance with licensing guidelines.

7. Perform an extended evaluation of the functional requirements for postaccident fuel containment and the means for providing the capability.

8. Investigate the interactions between control rod guide tubes and control assemblies.

9. Further investigate the following aspects of fuel handling: the compatibility of the envelope of end-of-life fuel elements versus the handling machine capacity; reliable cooling throughout the fuel handling process; consequences of loss of cooling.

10. Perform design and performance studies to establish the cooling design for all portions of internal shielding. 
APPENDIX A

CORE SEISMIC ANALYSIS

Scoping seismic analyses of GCFR fuel assemblies were performed for both the upflow and the downflow cores. These analyses were performed using the finite element computer code MODSAP (Ref. 10), which is a GA version of the code SAP-IV (Ref. 11). The fuel assemblies were modeled as assemblages of beam elements having appropriate mass, stiffness, and damping properties. Ideal support conditions were assumed. Nonlinear effects such as gaps, friction, and impacts between assemblies were neglected, as was any coupling between the fuel assemblies and the grid plate.* The input motion was an envelope grid plate response spectrum, shown in Fig. A-1, encompassing all soil types, and obtained from the updated downflow core GCFR plant seismic model. The response spectrum was scaled to an operating basis earthquake (OBE) ground acceleration of $1.275 \mathrm{~m} / \mathrm{s}^{2}(0.13 \mathrm{~g})$, the value specified in Ref. 4.

Three downflow cases and one upflow case were considered. The downflow cases were: (1) an unrestrained core, (2) a core with a single point lateral restraint, and (3) a core with a dual point lateral restrain. The upflow core analysis considered only the dual lateral restraint concept.

The results of the analysis are summarized in Table $A-\dot{1}$. It was found that the downflow core without a core lateral restraint had an unacceptably large $O B E$ response. The response of the downflow core with either a single point or a dual point lateral restraint was found to be acceptable. The single point restraint was selected as the basis for the design comparison

$*$ It is recognized that gap and friction effects could be significant. However, their inclusion into the seismic analysis is at or beyond the state of the art and was considered beyond the scope of the current study. 


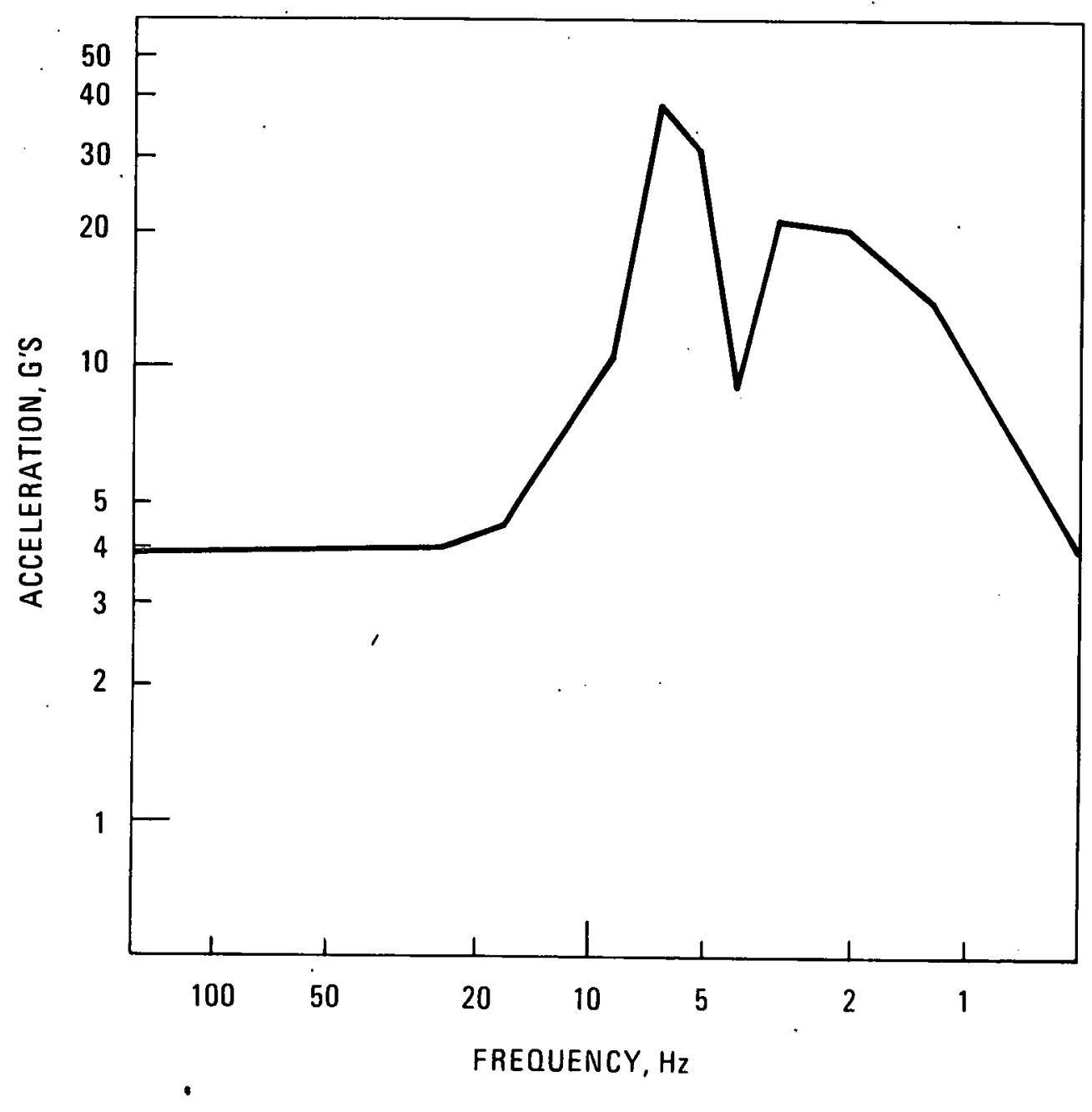

Fig. A-1. Grid plate horizontal envelope response spectrum scaled to $1.0 \mathrm{~g} \mathrm{OBE}$ 
TABLE A-1

UPFLOW/DOWNFLOW CORE DESIGN: CORE ASSEMBLY SEISMIC RESPONSE

\begin{tabular}{l|c|c|c}
\hline & $\begin{array}{c}\text { Lateral Restraint } \\
\text { Concept }\end{array}$ & $\begin{array}{c}\text { Fund. Frequency } \\
(\mathrm{Hz})\end{array}$ & $\begin{array}{c}\text { OBE } \\
\text { Response } \\
(\mathrm{mm})\end{array}$ \\
\hline Downflow & None & 6.5 & 48.0 \\
& Single point & 16.3 & 0.9 \\
Dual point & 48.6 & $<0.1$ \\
& Dual point & 68.0 & $<0.1$ \\
\hline
\end{tabular}


in order to keep open the possibility of duct fallaway as a CDA mitigation feature for the downflow core. The drawback with this restraint concept is that the assembly fundamental vibration frequency must be kept above approximately $15 \mathrm{~Hz}$ to keep the response within reasonable limits. This places a limit on the mass and length of the assemblies that may be used with this restraint concept, and in fact was the reason why integral exit plenum shielding was not incorporated into the core assemblies of the downflow core. A further consequence of this restraint concept is that it may severely restrict the design of core assemblies for commercial plants.

As anticipated, the OBE response of the upflow core with its dual point lateral restraint was very small and is considered to be acceptable. One area of concern with the upflow core which was not explicitly evaluated was the interface between the control rod drives and the control assemblies. However, it is felt that the design approach taken with the control assemblies, where the control assemblies are designed to fully contain the withdrawn control rods, provides additional security and flexibility in the interface design. Confidence exists that the interface can be designed with adequate margin for seismic loading. 


\section{APPENDIX B \\ CORE DISTORTION ANALYSIS}

Core distortion analyses were performed using the NUBOW-2D code (Ref. 12), developed at Argonne National Laboratory. A $60^{\circ}$ segment of the core was modeled as a two-dimensional single row of idealized elements. NUBOW considers thermal bow and bulging of the assembly duct, irradiation creep and swelling effects, and contact and gaps at load pads. The code computes assembly deflections, full power loads at the load pads, and refueling loads at the load pads.

Several desired goals of the core restraint design were established at the outset of the study: (1) to limit the distortions of the assemblies to a $10 \mathrm{~mm}$ envelope; (2) to keep refueling loads as low as possible; and (3) to maintain contact at one or both load pads throughout life. This latter consideration was aimed at reducing the potential for flow-induced vibrations of the assemblies, and maximizing the seismic restraint of the core.

The results of the study are given in Table $B-1$. The single lateral restraint of the downflow core requires small clearances between load pads, which results in relatively high refueling loads. Even with the small load pad clearances, pad-to-pad contact was not achieved until late in life.

In the upflow core, with its dual lateral restraint, a much more attractive design evolved. The clearances between load pads and at the restraint ring was larger than in downflow, and the refueling loads were low. The distorted shape of the assemblies stayed within the $10 \mathrm{~mm}$ allowable envelope, and contact was maintained at one or both load pads throughout the life of the core. 
TABLE B-1

UPFLOW/DOWNFLOW CORE DESIGN: CORE DISTORTION ANALYSIS

\begin{tabular}{lcccc}
\hline & $\begin{array}{c}\text { Load Pad } \\
\text { Clearance } \\
(\mathrm{mm})(\mathrm{cold})\end{array}$ & $\begin{array}{c}\text { Restr. Ring } \\
\text { Clearance } \\
(\mathrm{mm})(\mathrm{cold})\end{array}$ & $\begin{array}{l}\text { Full Power } \\
\text { Load (N) (a) }\end{array}$ & $\begin{array}{l}\text { Refueling } \\
\text { Load (N) }\end{array}$ \\
\hline Downflow & 0.26 & 0.26 & $3020^{(\mathrm{b})}$ & 5000 \\
Upflow. & 0.8 & 5.1 & 9100 & 1700 \\
\hline
\end{tabular}

(a) $1 \mathrm{~N}=0.225 \mathrm{lbf}$

(b) No contact until 700 days 
An area of considerable concern with core restraint systems of the type employed for the upflow core is the potential for reactivity insertions during startup. This was evaluated as part of the core restraint. study. The results of that evaluation are presented in Fig. B-1, which shows bowing reactivity insertion as a function of power-to-flow ratio for a normal startup from hot standby. For comparison purposes, analogous results for CRBR are also presented. As can be seen from the figure, the peak reactivity insertion for the upflow core GCFR is less than that for CRBR (12c vs 20c), and, when a power to flow of unity is reached, in the GCFR the net reactivity is a few cents negative, while in CRBR the net reactivity remains about $12 c$ positive. Furthermore, GCFR system design will allow a power-to-flow. ratio of unity to be reached as early as at 15\% power, as opposed to $40 \%$ power for CRBR, which should further minimize the effect of these small reactivity insertions. Since the reactivity insertions during startup are less than those for CRBR, and occur at lower power levels than in CRBR, it appears that they will not be a problem for the GCFR. 


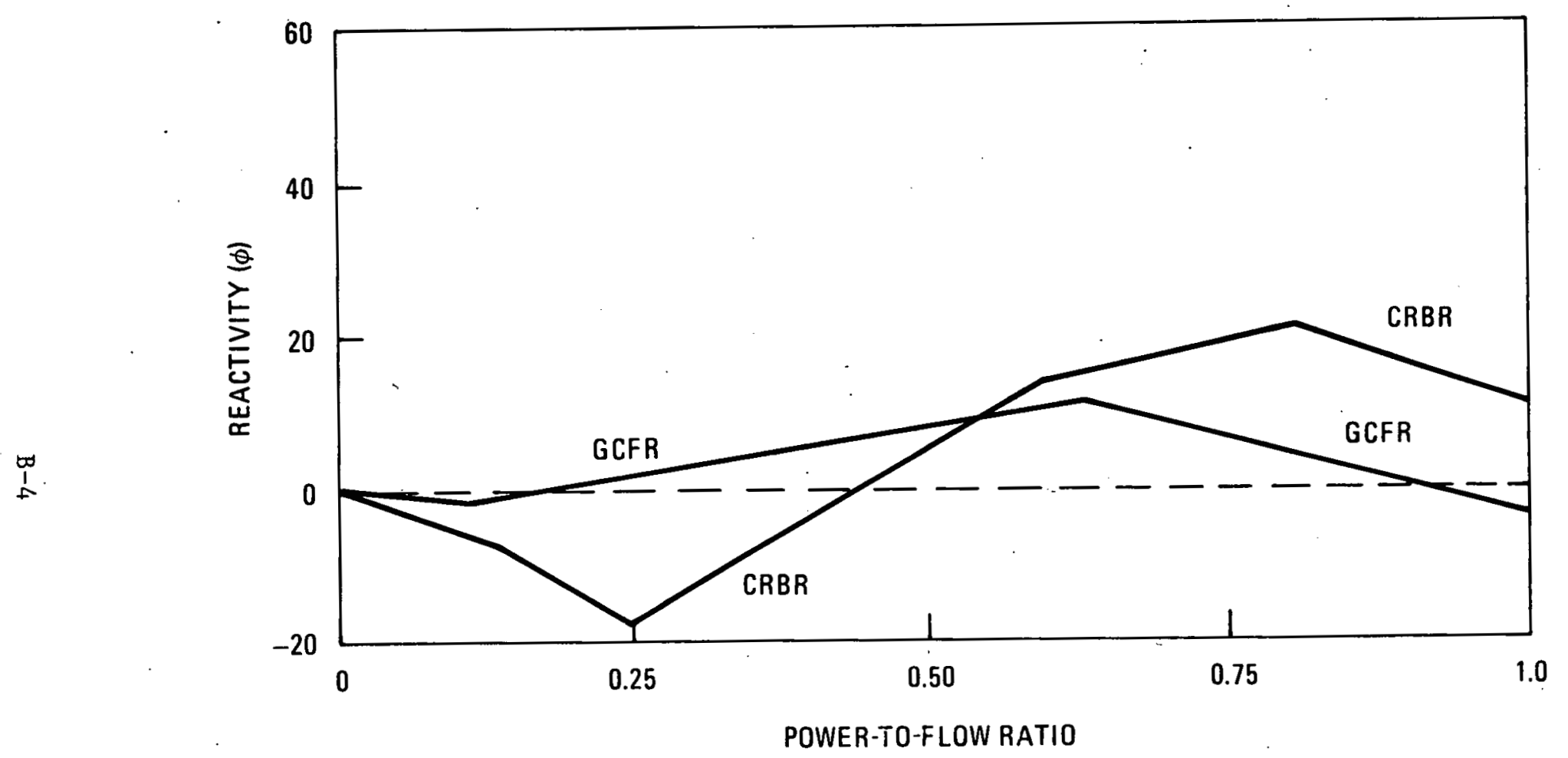

Fig. B-1. Bowing reactivity insertion during normal startup from hot standby (GCFR and CRBR) 


\section{APPENDIX C \\ KEY DESIGN CHARACTERISTICS ASSUMED IN AUXILIARY LOOP NATURAL CIRCULATION ANALYSES}

\section{1 INITIAL CONDITIONS}

Power
Pressure (circulator outlet)
Core pressure drop
System pressure drop
Core inlet temperature
Core outlet temperature
Elevation differences
(midpoint)
Active core to steam
$\quad$ generator
Active core to CAHE
Volumes
Total
Cold leg
Hot leg

System mass

\section{C.2 COMPONENT CHARACTERISTICS}

Main helium circulator

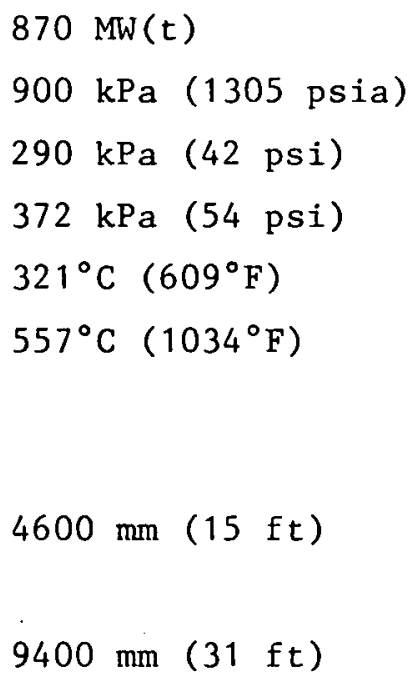

Electric drive, radial flow

Operating speed $=3450 \mathrm{rpm}$

Rotational inertia $=629 \mathrm{~N} \cdot \mathrm{m} / \mathrm{s}^{2}(464 \mathrm{ft}-$ $\left.1 b-s^{2}\right)$

Bearing losses $=628 \mathrm{~N} \cdot \mathrm{m}(463 \mathrm{ft}-1 \mathrm{~b})$

at $3450 \mathrm{rpm}$

Minịmum flow area $=0.316 \mathrm{~m}^{2}\left(3.4 \mathrm{ft}^{2}\right)$ 
Steam generator

Core assemblies

Blanket assemblies
Helical coil

Envelope: Bundle length $=8200 \mathrm{~mm}(27 \mathrm{ft})$

Shroud o.d. $=3700 \mathrm{~mm}(12 \mathrm{ft})$

Surface area $=3860 \mathrm{~m}^{2}\left(41,500 \mathrm{ft}^{2}\right)$

Core auxiliary heat exchanger Helical coil

Envelope: Bundle length $=1860 \mathrm{~mm}(6.1 \mathrm{ft})$

Shroud o.d. $=1980 \mathrm{~mm}(6.5 \mathrm{ft})$

Surface area: $223 \mathrm{~m}^{2}\left(2400 \mathrm{ft}^{2}\right)$

127 ( 30,068 rods)

Fuel $\operatorname{rod}$ o.d. $=7.275 \mathrm{~mm}$

Pitch $=10.4 \mathrm{~mm}$

Power $=91.8 \%$, flow $=89.6 \%$

90 ( 2 rows $=5400$ rods $)$

Blanket rod o.d. $=19.65 \mathrm{~mm}$

Pitch $=21.05 \mathrm{~mm}$

Power $=8.2 \%$, flow $=10.4 \%$

\section{3 ADDITIONAL ASSUMPTIONS}

Some additional assumptions that were used in the auxiliary loop natural circulation analyses are summarized below.

Cases 1 and 2 :

- Feedwater flow stops at main steam turbine trip $(t=0 \mathrm{~s})$; it is restored at $t=60 \mathrm{~s}$ with $15 \%$ of normal flow and $204^{\circ} \mathrm{C}\left(400^{\circ} \mathrm{F}\right)$ inlet temperature.

- Main loop isolation valves shut $(t=90.5 \mathrm{~s})$.

- Auxiliary loop isolation valves open $(t=91.0 \mathrm{~s})$. 
Case 1:

- Nominal decay heat

- Initial CACS standby conditions

Helium flow $=0.17 \%$ leakage through each loop isolation valve Water flow $=2.4 \mathrm{~kg} / \mathrm{s}(5.3 \mathrm{lb} / \mathrm{s})$ per loop Controlled flow to Air flow $=6.3 \mathrm{~kg} / \mathrm{s}(13.9 \mathrm{lb} / \mathrm{s})$ per loop $\}$ limit heat losses

- Water and air flows increase from standby to design value at $\mathrm{t}=40 \mathrm{~s}$.

Water flow $=76 \mathrm{~kg} / \mathrm{s}(1671 \mathrm{~b} / \mathrm{s})$ per $100 \mathrm{p}$

Air flow $=345 \mathrm{~kg} / \mathrm{s}(761 \mathrm{lb} / \mathrm{s})$ per loop

Case 2:

- Nominal decay heat plus $20 \%$.

- Helium flow $=0.17 \%$ leakage through each loop isolation valve.

- The water and air loops are already on natural circulation, driven by the heat load of the helium leakage flow; initial conditions: Water flow $=11 \mathrm{~kg} / \mathrm{s}(25 \mathrm{lb} / \mathrm{s})$ per loop Air flow $=75 \mathrm{~kg} / \mathrm{s}(165 \mathrm{~kg} / \mathrm{s})$ per loop 
APPENDIX D

ALTERNATIVE DESIGN STUDIES

\section{1 FIXED CORE CAVITY CLOSURE}

It became apparent during the upflow design study that the dual rotating plug assembly for the core cavity closure may pose a major problem with regard to technical feasibility and practicality. Design and evaluation studies were thus conducted on an alternative fixed, but removable, core cavity in conjunction with a seven-assembly refueling concept requiring a fuel handling machine with short-reach capability. Because the design of the actual plug was considered not to be a problem area (it is similar to the downflow design and shown in Fig. D-1), major emphasis was placed on the instrument tree design and the seven-assembly refueling concept.

\section{D.1.1 Instrument Tree}

For the fixed plug refueling concept, a support and guide structure above the core cannot be conveniently employed because of interference with refueling access to most of the core elements. The instrument tree concept is, therefore, based on the control assembly providing the guidance and alignment, as shown in Fig. D-2.

For the fixed plug, 67 penetrations are required for refueling access. Thirty-seven of the penetrations are occupied by instrumentation trees. Refueling access requires removal of all instrument trees and control rod drives. The instrument trees are laterally aligned by engaging the central control assembly of a fuel region or the central blanket assembly of a blanket region. The instrument tree is free to move axially with core axial growth. The telescoping feature of the instrument trees provides the potential for a simple backup holddown mechanism for the core. By employing 


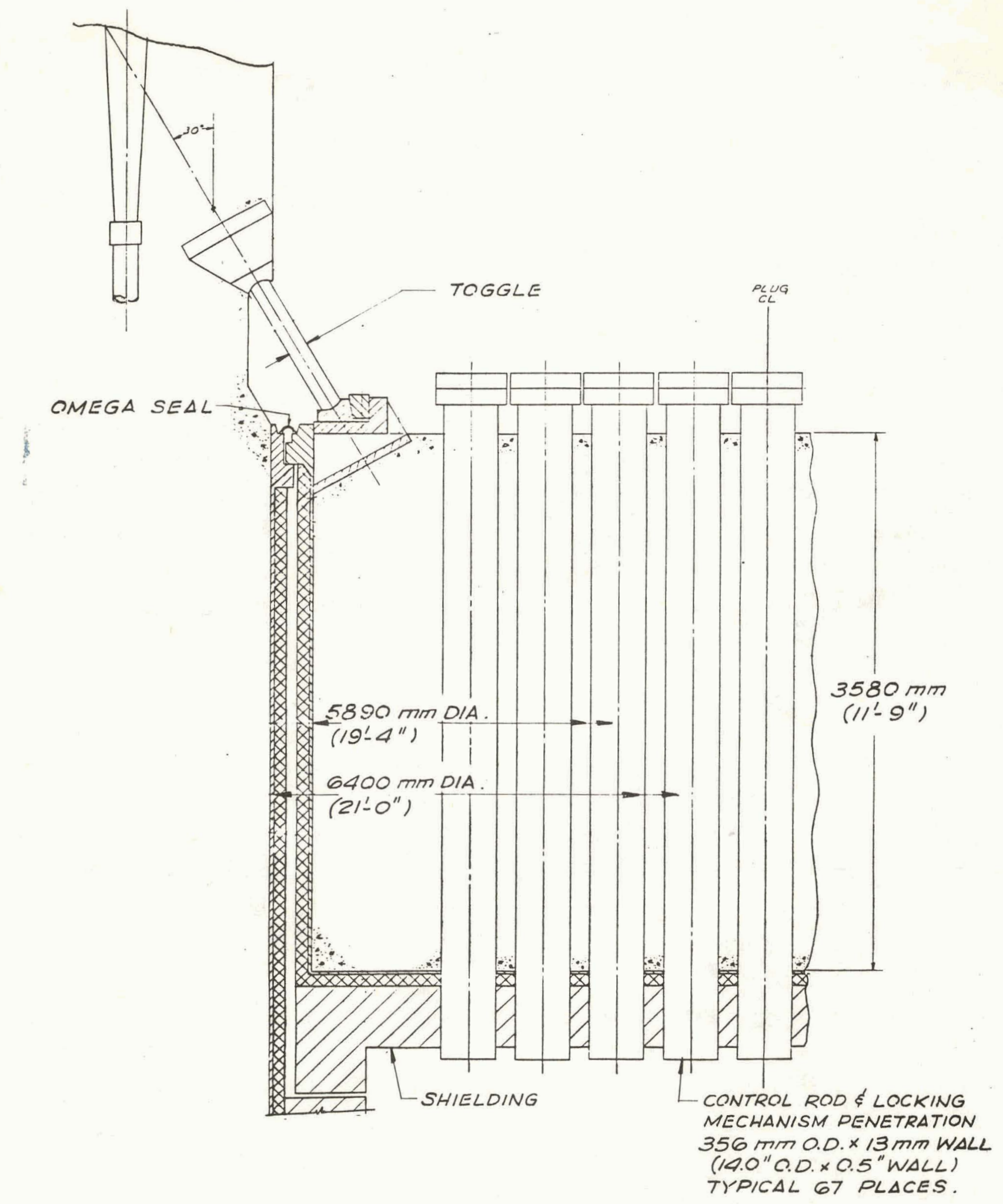

Fig. D-1. Upflow fixed core cavity plug 


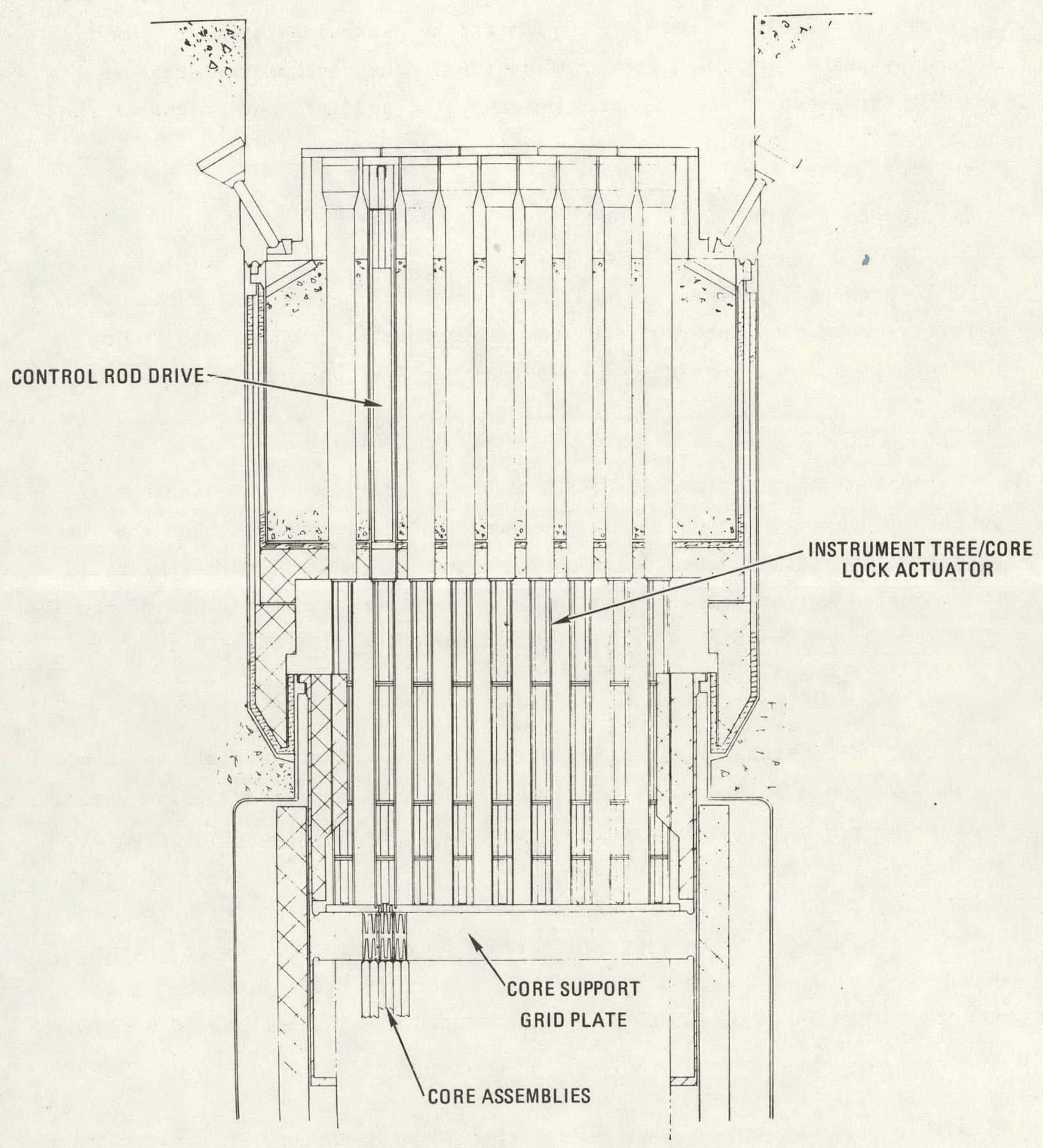

Fig. D-2. Upflow core - fixed plug concept. Control rod drive and instrument tree arrangement 
engaging stops between the central control assembly and the six surrounding fuel assemblies, an entire core region can be restrained against upward forces by the weight of the instrument tree. The control rod drive is axially supported in the top plug penetration, and only the weight of the instrument tree is borne by the region's central assembly.

\section{D.1.2 Seven-Assemb1y Refueling}

This refueling concept requires a top head penetration located directly above the center of each seven-assembly refueling region. The demonstration plant requires 67 refueling penetrations and the commercial plant 145 .

The fuel handling machine (FHM) is installed within the length of a penetration by means of a leak-tight, heavily shielded cask. The fue1 transfer cask (FTC), supported by a polar bridge and rail arrangement, is then coupled to the isolation valve, which encloses the upper end of the FHM. This arrangement enables a helium atmosphere to be maintained both in the FTC and in the penetration.

The FHM consists of two telescoping sleeves. The lower sleeve is open on one side, and incorporates a ball-screw-driven carrier and guide rails. A detachable grapple is carried on a supporting structure suitably pivoted on the carrier to provide the offset necessary to cover an array of seven assemblies. The lower sleeve extends downward into contact with the top of the core and serves to restrain assemblies adjacent to the one being withdrawn, a feature necessitated by the laterally restrained core and possible friction forces that may be developed when attempting to withdraw an assembly.

An element withdrawn from one of the offset locations is first rotated back to a position in alignment with the axis of the penetration. At this point, the grapple incorporated in the FTC is lowered into engagement with the detachable grapple holding the withdrawn assemb1y. When the two grapples have been properly secured to one another, the lower, detachable

$$
\mathrm{D}-4
$$


grapple is unlatched from its ball-screw-driven carrier, and the carrier rotated clear of the grapple and the assembly. The assembly is then drawn upward by the FTC hoist into the FTC passing through the body of the FHM in transit. A general arrangement of the seven-assembly refueling concept is shown in Fig. D-3.

During the foregoing operations, forced coolant flow for the spent fuel assembly is conducted downward from a self-contained blower and cooling system in the FTC by appropriate channels in the FHM and routed through the carrier to the lower grapple. From here the coolant flows downward into the fuel assembly and exits into the core cavity.

The FTC may contain one fuel assembly only, in which case it must deposit the spent assembly and pick up a replacement. Alternatively, the FTC may incorporate a magazine arrangement in which one or more assemblies can be exchanged without removing the FTC from the penetration. This concept would be particularly applicable to a commercial plant where refueling time must be minimal.

Once outside the penetration, the transfer to the spent fuel pool and the pickup of new fuel assemblies is similar to the original concept for the rotating plug refueling scheme.

Ongoing development of the concept described above is expected to result in considerable design improvements, specifically in the area of the FHM. In particular, better enclosure, retention, and handling of a withdrawn assembly are anticipated together with improved structural stiffness and more direct routing of coolant f1ow.

The alternative designs were found successful in avoiding serious concerns such as sealability and manufacturing tolerances encountered in the rotating plug evaluation. 

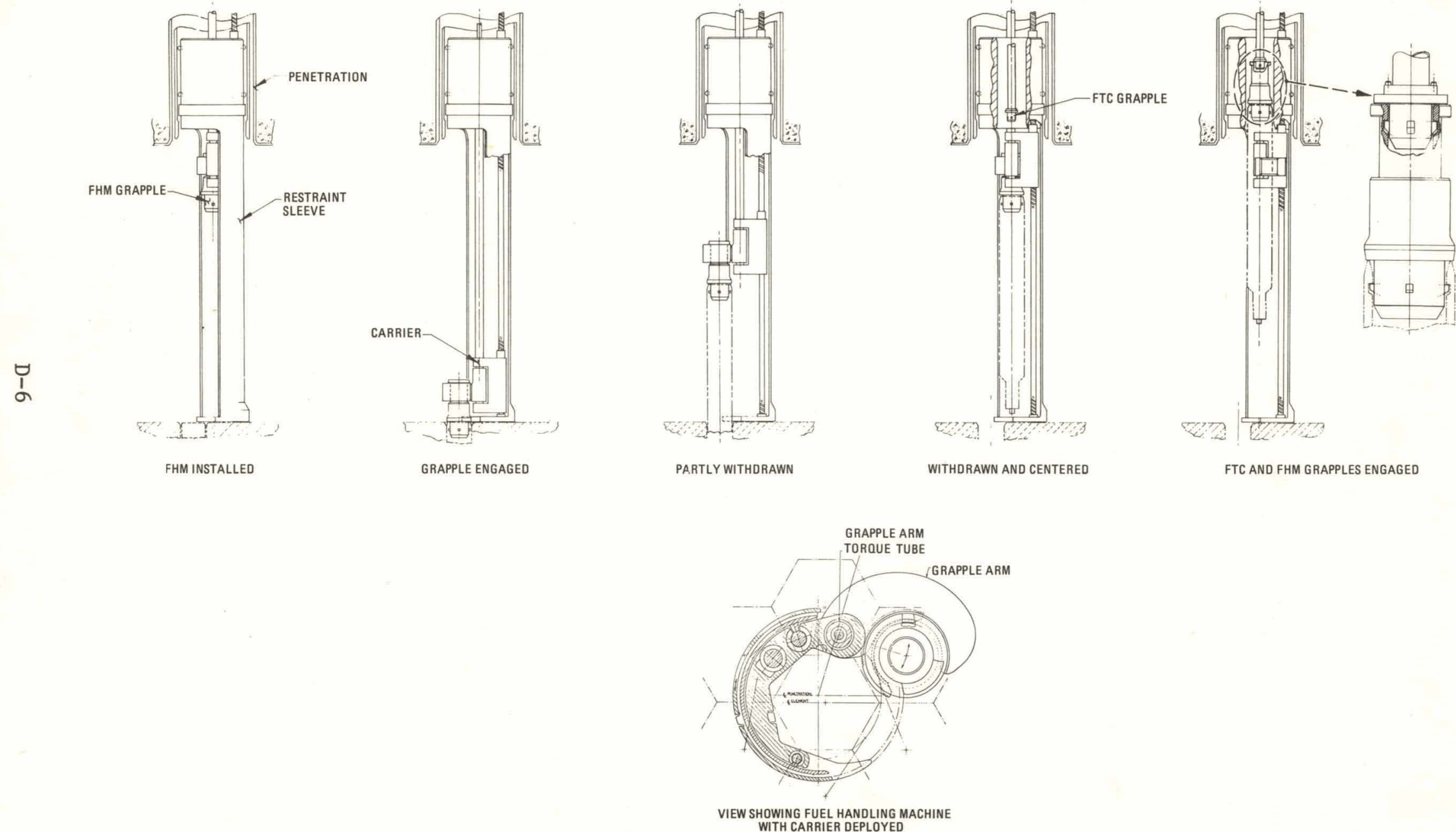

Fig. D-3. General arrangement of seven-assembly concept 


\section{D.2 HORIZONTAL MAIN HELIUM CIRCULATOR}

Limited design and evaluation work was also performed on critical elements of an alternative horizontal installation of the main helium circulator and its electric motor drive. The structural feasibility of the * PCRV was the critical aspect upon which most of the effort was concentrated.

\section{D.2.1 PCRV}

Three schemes for accommodating the main helium circulator within the PCRV were investigated. Because a commercial-size PCRV layout was considered more limiting, a $1200 \mathrm{MW}(\mathrm{e}), 6$-loop plant was chosen for the design study. The stress distribution in a 3-D model, based on pressure loading only, looks acceptable although additional work is required to resolve some outstanding concerns and interface problems.

The preferred concept (Fig. D-4) has the circulator penetrations within the actual PCRV structure. The entire PCRV rests on the containment mat. Cutouts are provided for tendon galleries, feedwater piping, and CAHE cavity access. The limited layout studies indicate that the PCRV pedestal height can be reduced as compared to the upflow layout with bottom mounted circulator. Containment and nuclear island aspects remain to be evaluated.

\section{D.2.2 Main Helium Circulator}

Some design effort was applied to a horizontal mounted main helium circulator (Fig. D-5). For comparison purposes, a 24,000 hp electric motor with water bearings for the compressor was assumed. To minimize the size of the PCRV side penetration, the diffuser design was changed from a vaneless diffuser (reference) to a "pipe" diffuser. With a reduction in the diffuser diameter by $0.76 \mathrm{~m}(2-1 / 2 \mathrm{ft})$, the main helium circulator side penetration measures $3.45 \mathrm{~m}$ (11 $\mathrm{ft} 4 \mathrm{in}$.) in diameter. The overall efficiency with a "pipe" diffuser is at least equal to but probably better than the reference design. 


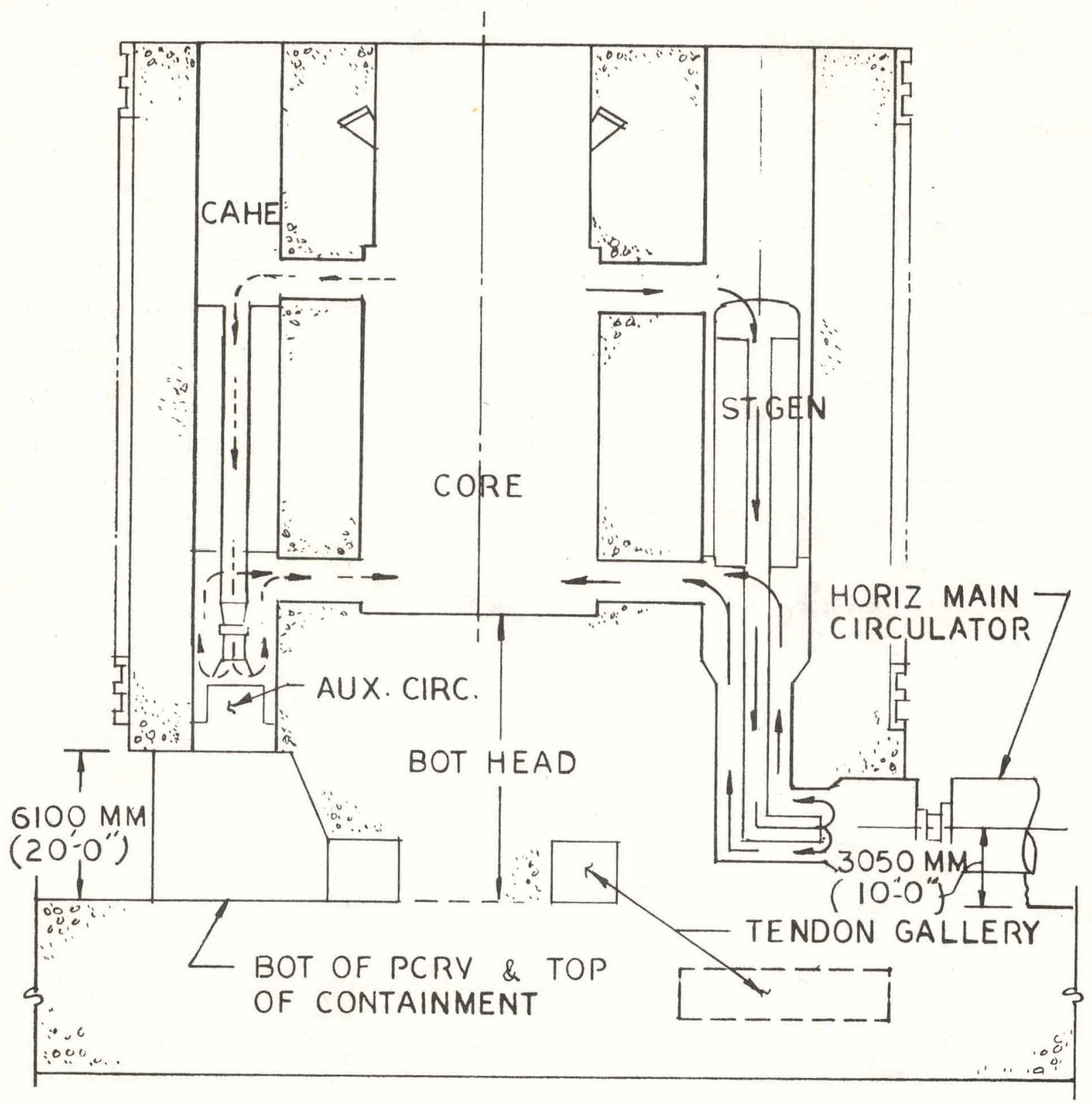

Fig. D-4. PCRV bottom head arrangement with horizontal main helium circulator installation 


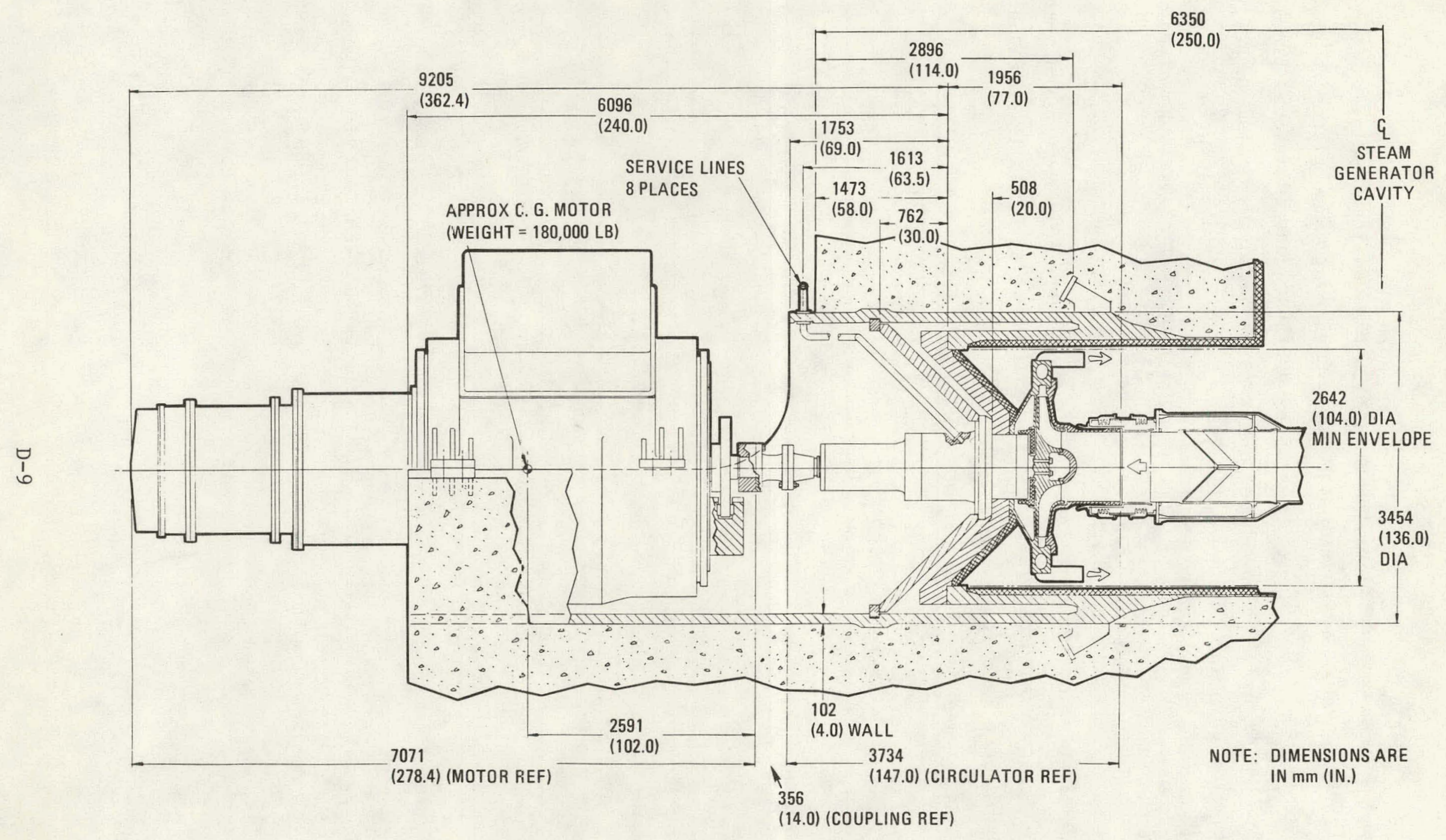

Fig. D-5. Horizontal main helium circulator installation 
In a horizontal position, the gravity-activated loop isolation valves probably need counter weights in the upper and lower valve plates to assure proper operation. This is not considered a significant additional problem. High pressure helium (from bottles) can power a backup mechanism to activate the valve for checking its operation (ISI) or valve plate location as well as to override a stuck valve plate. Main cooling loop isolation valves fail in the closed position.

A horizontal helium circulator position is apparently preferred because it permits a conventional electric motor design; it also has lower thrust loads and a better drain system. 


\section{REFERENCES}

1. European Association for Gas Breeder Reactor, "GBR-4 Safety Working Document and Supplement," July 1974/April 1975.

2. Plant and Fuel Engineering Staff, "GCFR Alternative Design Study,". DOE Report GA-A14856, General Atomic Company, February 1978 and Addendum to GA-A14856, April 1978.

3. Technical Staff; H. Menzel, Editor, "GCFR Upflow Core Study - Interim Report," unpublished data, January 1979.

4. "GCFR Baseline Data Book," Issue 1, General Atomic Company, unpublished data, June 12, 1978.

5. Deremer, R. K., and T. Shih, "RATSAM: A Compucer Program to Analyze the Transient Behavior of the HTGR Primary Coolant System During Accidents," General Atomic Report GA-A13705, May 1977.

6. Medwid, W. A., and L. L. Parme, "Natural Circulation in the Upflow GCFR," General Atomic Company, to be published.

7. Perkins, R. G., "AUXTRN: A Fortran V Program for Simulating the Dynamic Performance of the GCFR Core Auxiliary Cooling System," General Atomic Company, unpublished data, January 1975.

8. Taniguchi, T., and P. H. Raabe, "Rellability Update for the GCFR Residual Heat Removal System," General Atomic Company, to be published.

9. Frank, M. V., C. Kang, J. T. Reilly, and P. A. Wheeler, "GCFR Upflow Versus Downflow Core Disruptive Accident Safety Assessment and Post Accldent Fue $\perp$ Containment Evaluation," General Atomic Company, unpublished dața. 
10. Johnson, J. J., "MODSAP: A Modified Version of the Structural Analysis Program SAPIV for the Static and Dynamic Response of Linear and Localized Non-Linear Structures," ERDA Report GA-A14006, Genera1 Atomic Company, June 1976, Revised June 1978.

11. Bathe, K. J., E. L. Wilson, and F. E. Peterson, "SAPIV: A Structural Analysis Program for Static and Dynamic Response of Linear Systems," College of Engineering, University of California, Berkeley, California, Report No. EERC 73-11, June 1973.

12. Cha, B. K., G. A. McLennan, and P. J. Fulford, "NUBOW-2D Inelastic: A Fortran Program for Static Two-Dimensional Structural Analysis of Bowed Reactor Cores, Including Effects of. Irradiation Creep and Swelling," Argonne National Laboratory, Argonne, Illinois, Report No. ANL-CT-77-34, June 1977. 